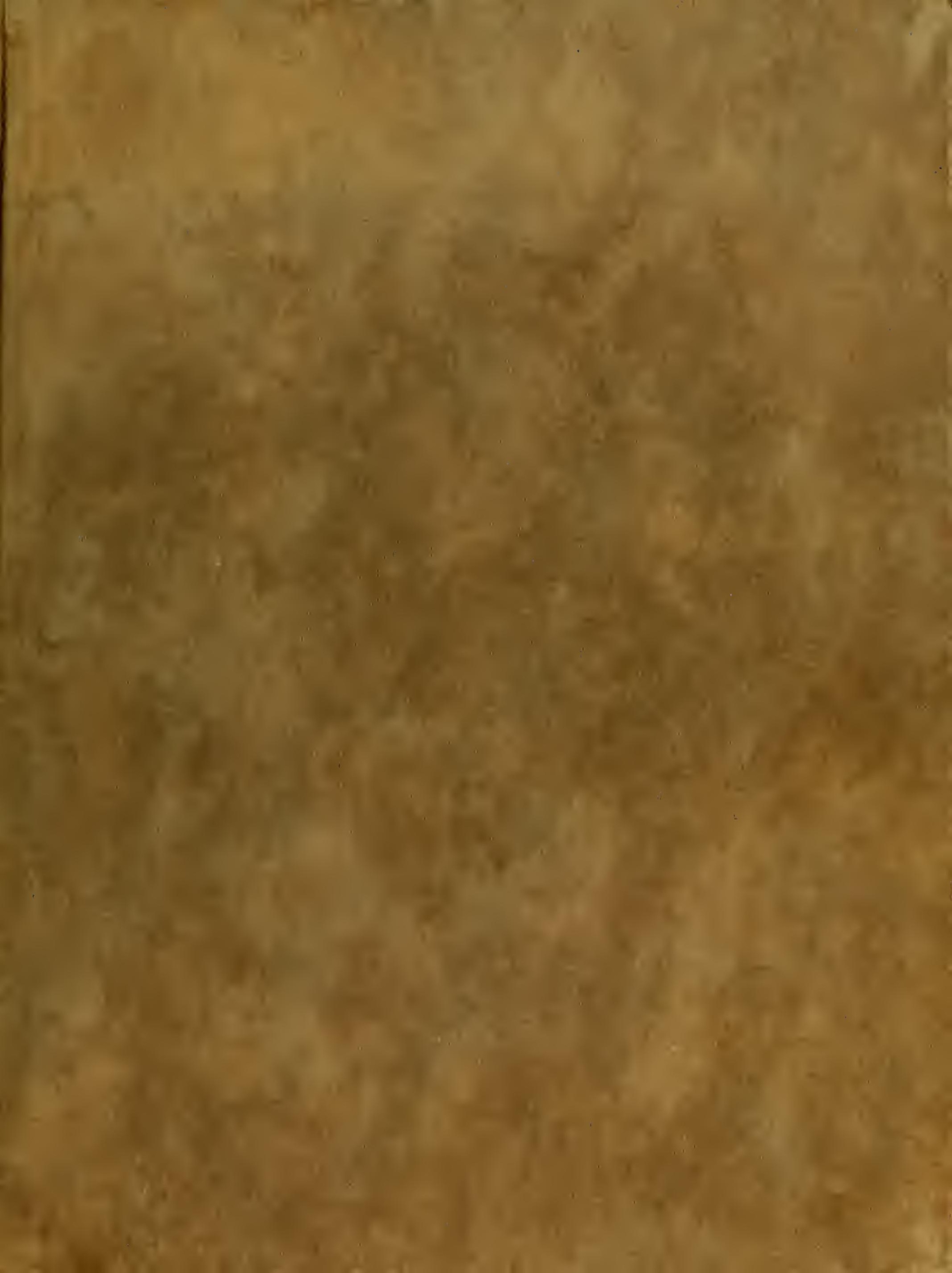






\title{
Neue Beiträge
}

X:II

\author{
anatomischen Kenntniss
}

der

\section{Hautdecke und Hautsinnesorgane der Fische}

. 1). Franz Leydig,

Profesior an der Universität zu Bonn.

Mit vier Tafeln.

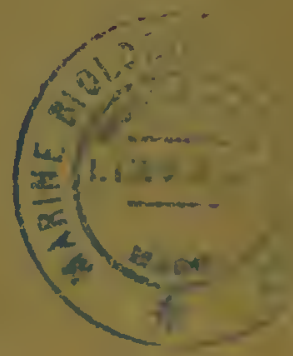

H : 11 e.

Max Niemeyer.

$\cdot 1879$. 


\title{
Neue B e iträge
}

\author{
anatomischen Kenntniss
}

der

Hautdecke und Hautsinnesorgane der Fische

Dr. Franz Leydig,

Professor an der Universität zu Bonn.

Mit Tafel VII bis $\mathrm{X}$.

Halle.

Max Niemeyer.

1879. 
. 
Die Arbeit, welche ich hiermit vorzulegen mir gestatte, steht in Verbindung mit den seit Längerem von mir iiber die Hantdecke der Wirbelthiere gegebenen Mittheihungen. Sie entstand aus dem W'msche einerseits anf frithere eigene Untersuchungen nachpriifend zuriickzukommen, andrerseits um mir ein selbstständiges Urtheil iiber manche Angaben anderer Beobachter zu erwerben.

1)ie Darlegungen beziehen sich eimmal anf Epithelien und Bindegewebe, zwei im Gefigge des thierischen Körpers uns fortwährend begegnende Lagen, denen wegen ihrer grossen Bedentung wohl jeder Histologe melr oder weniger Aufmerksamkeit zuzurvenden sich schon veranlasst gesehen hat. Vielleicht dass ich durch Gegenwärtiges uiber das morphologisehe Verhalten einige weitere Aufschliisse zu bieten inl stande bin.

Sodann habe ich iiber die Hantsinnesorgane einiger Fische zu berichten, ein Gegenstand, weleher noch viele migelöste Fragen in sich selliesst. Anch bezitglich dieser schwrierig zu durchschanenlen Organisation meine ich in einigen Punkten etwas vorwïrts gekommen zu sein.

L'nd so wïnsche ich, dass bei den Kemnern uns I'ffiegern der vergleichenden Anatomie mud Gewebslehre es nicht nugerechtfertigt erscheinen möge, wemu nachstehende Untersnchungen ans Licht treten; zumal mir mit diesen Bliittern die Gelegenheit werden soll, der "Naturforschenden Gevellschaft zu Halle" bei der Feier ilres hundertjïllirigen Stiftungsfestes meine Verehruıg bezeigen zu könneu. 


\section{Epidermis.}

\section{Zellen mit farigem Inhalt.}

In der Oberhant von Larven des Pelobates fuscus, *) welche bereits die hinteren Gliedmassen besassen und Fude Juni nutersucht wurden, bot der Inhalt der Ejpilemiszellen in den tieferen Lagen einen merkwiirdig'n Anblick insofern dar, als eine fadige Bildnug das Imnere erfïllte, nicht etwa bloss der einen oder anderen Zelle, sonderu iiber ganze Strecken der Oberhant hin.**)

Die Fäden sind in der allermanchfaltigsten Weise geschlungen und gewunden, dabei von verschiedener Dieke; oftmals theilen sie sich gegen den Fuss der Zelle zu nud lösen sich in Bïsehel feinster Fäserchen anf. Die Substanz ans welcher sic bestehen, ist zwar blass, brieht aber doch das Licht zienlich stark. In den meisten Fällen iiberschreiten die Fäden den Saum der Zelle nicht; doch lassen sich anch Zellen ins Ange fassen, wo der Faden eine Strecke weit hervorsteht. Haben die Fäden eine gewisse Dicke, so erweisen sie sich bei näherem Znsehen als eine Tereinig'ung feimerel Fäscrchen.

Richtet man die Aufmerksamkeit auf solche Zellen, in denen der Faden erst anfïngt sichtbar zu werden, so hat es den Anschein, dass derselbe in einem besondern hellen Rawn der Zelle, in einem Secretblïsehen, entstehe. ${ }^{* *}$ ) Die Begrenzung* des letzteren wird mach und nach soweit nath aussen geriickt, dass sie mit der Zellenmembran selber verschmilzt. Der Kern bleibt immer dentlich; ausserdem kimmen noch (지)pen kleiner gelber Fettkinmehen zugregen rein.

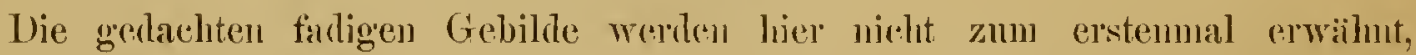
sondern sind aus den Larven einer andern Batraehierart, des Bombinator igneus, bo-

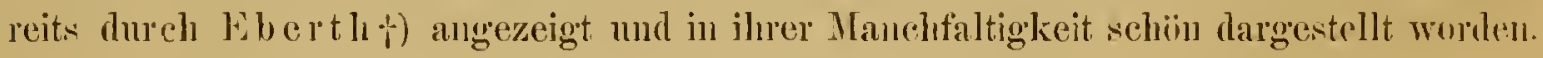

Wie weit Ephiderniszellen mit soldhou Inhalt miter den Larven der anuren

*) Im Ilinblick auf meine Mittheilungen über das Vorkommen des Thieres (Anure Batraehier der dentsehen Fauna, Bonn 1877) mag bemerkt sein, dass im Frihjahr 1878 die Larven in einem Graben bei Bonn, diesmal linksrheinisch, in ungemeiner Menge sieh gezeigt haben. Alle Larven dieser Brutstätte und Jahreszeit waren viel grösser als jene, welche im Herbst und reehtsrheiniseh zur Beobaehtung gekommen waren und es entwickelten sich anch darans um Vieles grössere und kräftigere Thiere.

**) Vergl. Figur 32.

${ }^{* * *}$ ) Figur 32 , b.

†) Zur Entwieklung der Gewebe in Schwanze der Frosehlarven, Arehiv f. mikrosk. Anat. 2. Band (1866). 
Batrarhier verbreitet sind, bleibt noch zu mutersuchen. Answer von Pilubates fuscus gewahre ich sice recht klar an den Larven von Hyla arborca, ebenfalls ans dar Zeit,

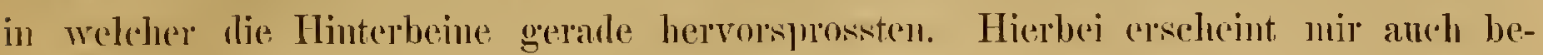
merkenswerth. dass in manchen Larven, anstatt der Fäden, mu eine kïmig-brörkelige Masse zugregen ist, die wieder ein andermal sich als gleidhfirmign, homogen mol das Licht stark brechend darstellt. Für gewöhnlich waren die Fiaden sehr dentlich und

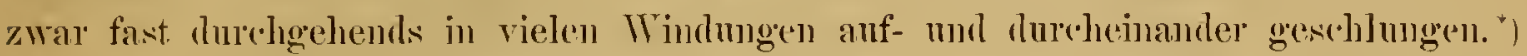

An den noch fusslosen larven von Rema csculcuta vermisse ich jerloch gedarhte Ciebilke, sowohl in der Hant des frischen Thieres als auch nach liehandlnug' mit Reagentien.

Bereits ans den Angaben Eberth's, sowie ans neinen Wahrnehmungen ergiebt sidh, dass nu in eine gewissen Zuit des Lartenlebens die Fascrbildnug zngegen ist: vidleicht dass hin mol wieder soldhe Zellen ,bei ganz kleinen Fröischen" sich noch findent.

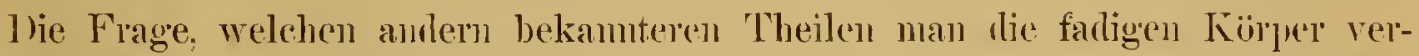
glejchen soll, lisst sich einstweilen kamm mit Sicherheit beantworten. Meiner Meimug nach kïmen folgende kilemente in Betracht kommen.

Fs liesse sich denken, dass die „Klïmpchen ron unregehmäissiger Gestalt nud mattgliunzenden Answehen", welehe ich als Zelleninhalt aus der Ejpidermis der hejtilien beschrieben habe*), Etwas verwandtes seien. Auch fiihle ich mich erinnert an die Zellen, welche im Ejithel der "Schleimcanäle“ z. 13. des Kanlbarsches durch den bröckligen, kriimlichen Inhalt von stark lichtbrechendem Wesen ans den gewïhnlichlen Epithelzellen sich abheben. Ferner darf sich die Vermuthung einstellen, dass jene von Audern ans der Ejudermis des Fisches My thinc erwïhnten Zellen ..welche sich in einen feinen Farlen abwiekehn lassen", nut gegenwärtig besprochenen Zellen der Batrachier etwas Gemeinsannes laben.

Ls lassen sich aber auch Ankniipungen nach den (x)uplen wirbelloser Thiere lim finden. Die sogenamnten Schleimdrïsen in der Haut der Gastroporlen sind Umbildungen von Epithelzellen und ihr Inhalt von versebiedener Art: mitunter entwickelt das Protoplasma eigenartige, spindelfïmige Kïrper. so bei trion, Limax, Helix; oder die Zellsubstanz wandelt sich mo in eine glinzende, hald rein homogene

*) Fig. 33.

**) Organe e. sechsten Simnes, Act. acad. Leop. Carol. Vol. XXXIV, Tab. III, Fig. 23 (von (oronella laevis).

***) Archiv f. Anat. u. Pliys. 1861, S. 302. 


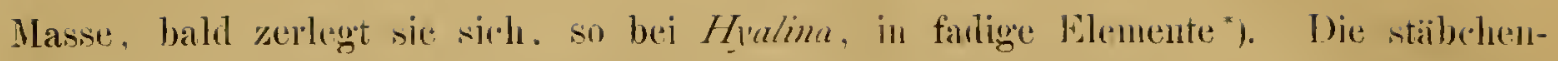
artigen Körper in den Hantdriisen zahlireicher Anneliden mögen ebenfalls verwantte

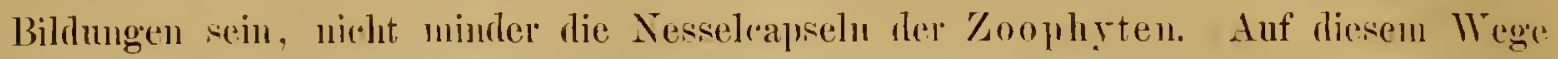
der Betrachtung sehen wir nus somit dahin gefilıtr, die fadigen Bildnugen in der Hant der Batrachierlarven den Brssusfiden nul Nesselfäden an die Seite zu setzen.

Schon melumals habe ich die Ansicht geänswert. dass die scharfrandigen kïrperchen in Hantsecret der Batrachier die ätzende griftige Wirkung dieses Stoffes vermitteln mögen. :ïhnlich wie ein Zusannnenhang zwisthen den Nesseløapsehn der Zoophyten und der bremenden Beschaffenheit des Hantschleines wohl ansser Zweifel steht. Hier bo'j den Batraehiern - kann man sirh vorstellen - iibernimmt zur Zeit

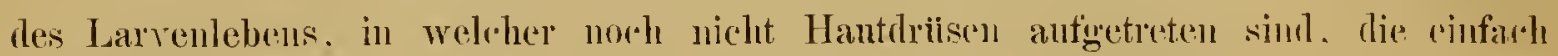

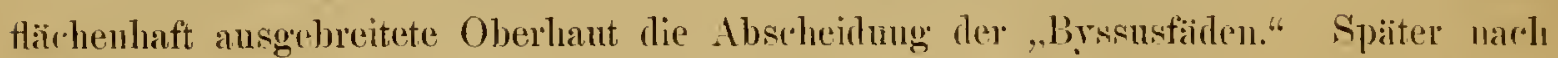

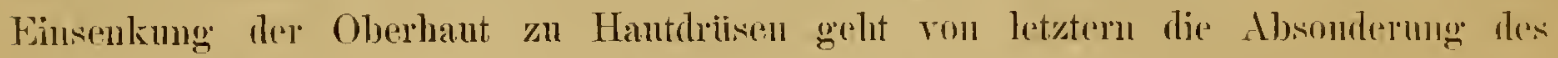
klebrigen Saftes ans, ohne aber selbst norh farlige Therile zu entwirkeht.

Der Kiirze der Bezeichnmgg halber kam ch sich vielleicht empfehlen. den besagten in der Haut der Batrachierlarven rorkommenden filementen den Ámmen Byssuszellen cinstweilen beizulegen.

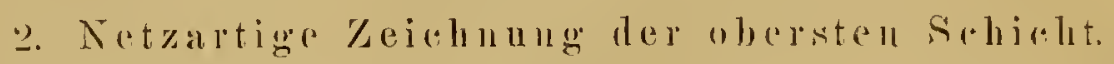

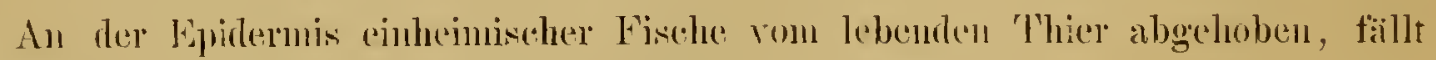

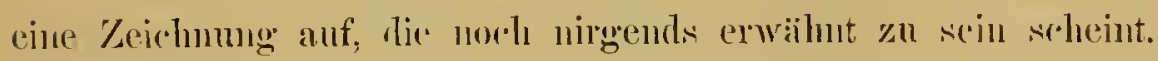

Die änsserste Lage der Zellen stellt bekamntliele ein I'lattenepithel dar ron scher zartem. hellen Wesen mul in allen zellen bleibt der liem deutlich bestehen.

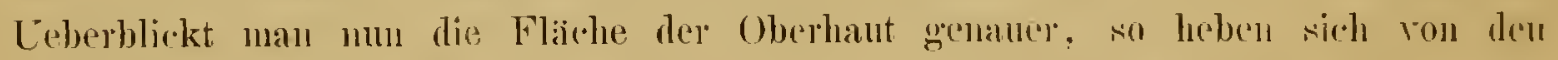

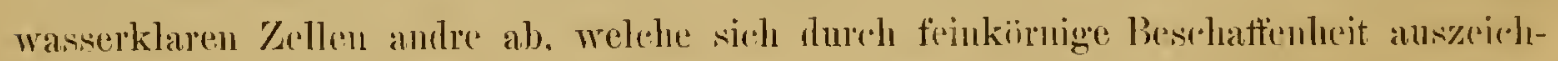
nen und die Zellen dieser Art reihen sich dergestalt in Ziigen zolsammene, dass als Ganzes ein netzfirmiges Streifensystenn zu Wege kommt, welehes gewissemassen die Obertläche der Hant iiberspinut.

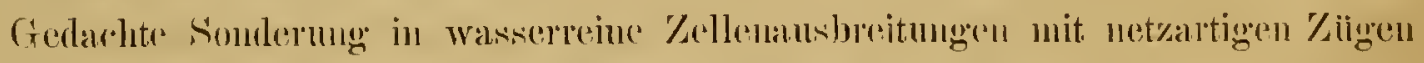
ron kïniger 'Tribung dazwisehen, selheint sieh iiber die ganze Hant wey zu er-

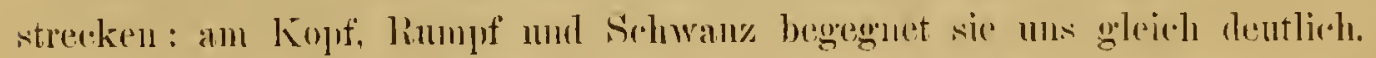

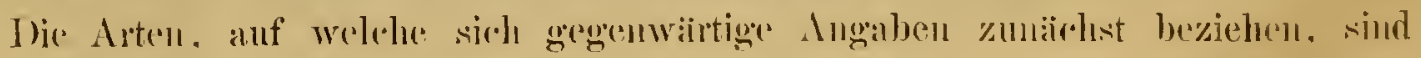
Cyprimus carassius und Perca Muzintilis.

*) Haudecke der (áastropoden, Archiv f. Naturgesch. 187t, S. 15 ir. 


\section{Porensanm.}

Vor kimen habe iols in eine Arbeit iiber die Ripluenstaeheln des Plewrodeles IVultli") die feineren Formenverlältmisse dargethan, wie sie bei Futstehung des .. P'mensammes" zusanmenwirken. Las gleiche lässt sich anch an der Epilermis der Fische wahlnehmen.

Die obersten \%ellen von Ciprimus carassins kömen muter. Tauchlinsen durch dicht stelıende feine Fortsätze des Protoplasma wie bewimpert anssehen**). Kommen aber, wie solches z. B. bei Pitromzon geschieht, Cuticularabsehejumgen hinzu, so entsteht der"..Porensamm".

Nach aussen hat man es eigentlich mit leistenartigen Erhebungen des Protoplasma zu thuı. Die C'ntieula, indem sie den Erhöhungen mu Tertiefungen folgt, erzengt Kerblinien des Randes mud über die Fläche weg eine Art Querstreifung, das ist. eine Sculptur. An der entgegengesetzten Seite der Zelle, nach muten, bilden die luotoplasmatischen Ansläufer nur faseraihnliche Fortsaitze.

An Hantstïcken ron Petromyson marmus welche frisch in eine Lüsung von loppelchromsanrem Kali eingelegt wurden, latte es den Auschein, als ob die dureh die Poren der Cuticula tretenden Protoplasmafortsätze aus den Oeffumngen hervorquellen und sich in eine iiber der Cuticula befindliche feinkiinige Masse umwandeln kömsen. Man wird hierbei an das erimnert, was sich an der Cuticularschicht des Lippemandes der Nacktsc-lmeken beobachten liess ${ }^{* * *}$ ).

An einem Pitromyon fluriatilis, deu ich, nachdem ex mur einige Stmulen in sehr verdiumtem Wreingeist geleg'en, zu untersuchen Gelegenheit hatte, zeigte sich abermals in klarer Weise, mu zwar in den unteren Schichten, dass zwischen den Zellen ein wasserheller Raum sich hinzieht. Durch diese Intercellularanume gingen rom Protoplasma der einen Zelle zu jenem der Nachbarzellen, in unumterbrochener Verbindung, fasrige Fortsätze der Zellensubstanz. Es bestehen sonach auch hiex in ler Epidermis Intercellularräume, welche von Protoplasmafiaden oder Balken durchspannt sind und wodureh die Zellenleiber nutereinander zusammenhängen $\dagger)$. Aelnliches hat auch Flemm ing maculosa beschriebent).

*) Archiv f Natnrgesch. 1879.

**) Fig. 31, a.

***) Hautdecke und Schale d. Gastropoden, Archiv f. Naturgesch. 1876, (Separatausgabe S. 5).

t) Fig. 2, a.

†f) Beiträge z. Kenntniss d. Zelle und ihrer Lebenserscheinungen. Archivf.mikrosk. Anat.XVI,1878. 
Langerhans sah boi Petrombon Pluncri Biischel ron Flimmerhaaren wie Inseln da und dort auf eigenartigen Zellen der Oberhaut stehen. Ohne die lichtigkeit dieser Angaben bemängeln zu wollen, denn sie beziehen sich auf die Haut der Larve (Ammorlytes), mörhte ich immerhin erkliiren, dass ich an den erwachsenen Exemplaren von $P$. marimus und $P$. Aluriatilis von solehen Cilien nirlits walnrgenommen labe. Auch Fïttinger ${ }^{*}$ ) spricht aus, dass er trotz der manniclifaltigsten Untersuchungemethoden keine Spur dieser Flimmerhare zu entecken vermorlit habe. Uebrigens ist im hohen Grade wahrscheinliell, dass des Letzteren "eellules gustatives" eins und dasselbe sind mit den "hlaartragenden Simneszellen" des Frsteren.

\section{Drisenzellen der gewöhnliehen Art.}

Yor vielen Jahren habe ieh zuerst auf das Torhandensein eigenartiger Zellen in der Haut unserer Flussfische aufmerksam gemacht und sie unter dem Namen .. Schleimzellen" in die Wissenschaft eingeführt **).

Der kurzen Besrhreibung sind zwar keine Mbbildungen beigegeben worden, aber die Angahen siml deutlich genug, wenn aneh nicht ganz fehlerfrei, und iberdies bieten die Messungen bestimmte Anhaltspunkte dan:

Nachlem jeh unterlessen diese "Becherzcllen" anf dis feinere Verhalten ans der Schleimhant der Reptilien ins Auge gefasst mul dariber IIanches veröffentlicht labe, besah ieh sie mir jetzt von Nenem ans der Haut von -Inguilla vulgaris, Perca Hurintilis, Lota vulgaris, Cyprimus carassins, (iastcrostcus aculcatus, mehreren Arten von Petromyzon und der Brut eines Salmo. Ton den gemarditen Wahrnehmungen mïide ich folgende herauslieben.

Lm eine Uebersielnt iiber die Vertheilung in der Haut zu erhalten, mag wohl allgemein Fischbrut ein sehr giustiges Object sein. wenigstens gewiilhten mir junge Fischelien eines Salmo mit noch grossem Dottersack und ehe das Hautprigment anfgetreten ist, hievon ein sehiines Bild. Das Thierchen, durch Eintanchen in eine Mischung von Osminmsiiure und Essigsiunce getioltet, liisst sehen, lass die "Schlemu-

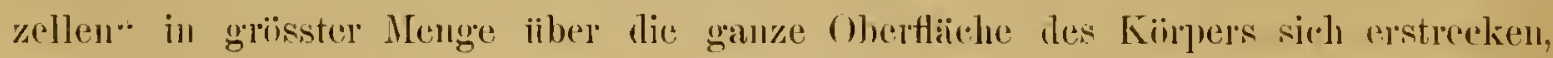

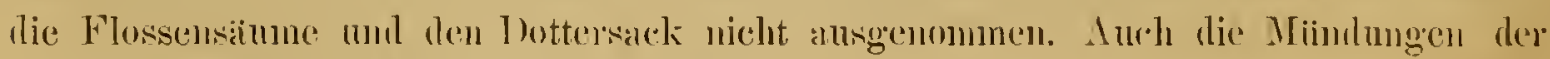
einzehıen zellen zeigren sich ganz deutlieh.

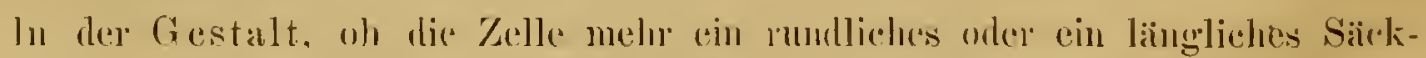

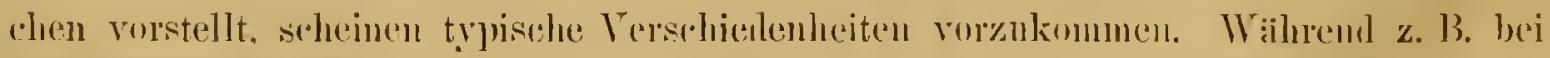

* l Rech. s. l. struct. de l'epiderme des cyclostomes. Bäll. d. l'acal. de Belgique, 1876 .

**) Leber die Hant einiger siisswassertiselıe, Ztsclurft. f. wiss. Zoul. Bul. III, (1850). 


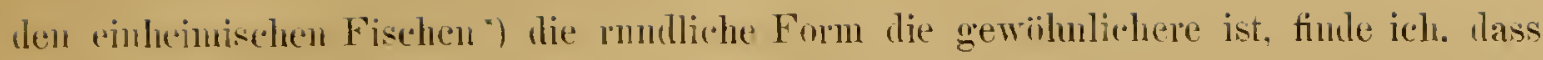

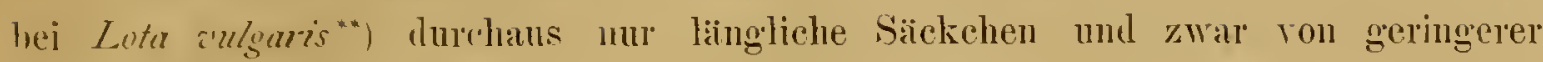
Groisse zugegen sind. Die Eprilernis der ainsseren Hant und das Epithel der Rachenschleimliaut verhalten sich hierin gleich.

Wir unterseheiden an den Zellen den Körper oder banthigen oberen Theil und dlen unteren oder den Fuss. Der erstere umschliesst das "Secretbläschen“. relches eine gewisse Punctirung an sich haben kamn als Ausdruck der Ansatzpuncte cincs feinen Maschenwerkes, wie ith solches beziiglich der Becherzellen der Reptilien angezeigt habe ${ }^{* * *}$. Der Fuss als eigentlich noch iibrig bleibender protoplasmatischer Theil der Zelle erscheint entweder von ähnlich plattem Wesen. wie ich es von den ghleichen Elementen der Blindschleiche, Anguis fragilis, dargestellt habe t), oder er zeigt sich. indem er die Kante dem Beschaner zukehrt, als cin fadiger Fortsatz. Joch ist anselriieklich zu bemerken, dass es auch Fialle giebt, wo der Fortsatz eine wirklich fallige Gestalt hat. - Der Kern der Becherzelle hat scine Lage im Anfangstheile des Fusses oder Fortsatzes; nur bei Ansicht von der Fläche erseheint er noch ron rundlicher Form; in der Seitenansicht hingegen oder im optischen Durchschmitt zeigt er sich wie cin halbmondförmiger Strich, von einem gewissen glänzenden Iresen.

Die Yïndungsöffnung der Schleimzellen bei Knochenfischen liegt zwischen deut Zellen iler obersten Lage der Epidermis. Eigenthiimlich ist das Terhalten bei Neunaugen: Pitromyzon marimus und $P$. fluviatilis. Zerstrent und einzeln uiber die Haut rorkommend, stehen die Schleimzellen in grösster Menge beisammen $\dagger \dagger$ ) an den Papillen und Blättchen des IIundsaumes. Fine unmittelbar an die andere geschlossen, setzen sic die obern Lagen der Epiilermis allein zusammen; sic sind aber ron dem streifigen Cuticularsanme iiberdeckt. Und so zeigt auch die isolirte Zelle iiber dem

*) Fig. 4.

**) Fig. 18

***) Zur Kenntniss der Sinnesorgane d. Schlangen, Archir f. mikrosk. Anat. Bd. 8, S. 340 .

†) a. a. 0 .

†) Die Papillen des Mundsanmes bei Petromyzon marinus, welehe in den Beschreibungen kurzweg als ein Kranz dichtstehender und zerfaserter Cirhen bezeichnet werden, scheiden sich nach ihrer Gestalt in zwei deutlich getrennte Formen. Zn äusserst steht nämlich eine einzige Reihe walzig kegelförmigeı Papillen, welche von vorn nach linten an Grösse zunehmen, ohne aber einen geschlossencn Ring zu bilden. Dann erst folgt nach einwäts eine Sorte flacher und vielfach eingcschnittener Papillen, oder vielmehr nach ihrer Gestalt "Zotten* zu nennende Erhebnugen, welche mehrere Reihen erzengen und ebenfalls von vorn nach hinten an Grösse wachsen: die grössten finden sich am hiuteren Po] des Kreismundes. 
Secretbläschen, dort wo man die freie rundlirhe Oeffinumg erwartet, gewissermassen einen von feinen Caniblehen durehzogenen Deckel*). Man darf sich wohl rorstellen. lass die Porencanälchen zusammen die Stelle einer einzigen Mündung vertreten nö̈gen. Am Petromyzon Planeri hat schom Langerhans die gleiche Beobachtung gemacht und hervorgehoben. Immerhin finde ich doch an anderen Kïr]erstellen - und stimme hierin mit Fïtting.er iiberein -- dass es anch bej Nemnangen frei sich ïftnente Schleimzellen gicht.

Die Menge der Schleimzellen an den Papillen des Mundsanmes bei Pitronnzon hat wohı den Zweck, das Anhüngen zu unterstiitzen, iihnlich wie das Hantsecret hei Batrachiern nach dieser Riehtung lin wirkt**).

Ton Anfang an habe ich die Schleimzellen als alngeanderte Epithel-wler Oberhantzellen angeschen und was ich jetzt bei obengenamten Fischarten ron nencu wahrgenommen. ordnet sich ungezwungen unter dieselbe Betrachtungsweise. Man sieht da und dort, wie in der Tiefe der Epidermis kleine gesehlossene Schleimzellen liegen, die sich nur durch das Torhandensein eines Secretraumes von den andern umgebenden zelligen Elementen unterscheiden. Die grossen und grössten befinden sich höher und öffnen sich deutlich nach aussen derart, dass die Miindung als rundliche Lüicke zwischen den gewöhnlichen Epidermiszellen liegt.

Erfahrungen an den gleichen Gebilden bei Reptilien latten es mir schon friiher wahrscheinlich gemacht, dass gewöhnliche orler geschlossene Ejpithelzellen zu Srhleim-

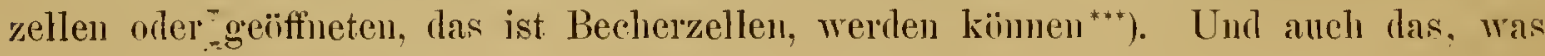
sich an den Becherzellen der Weichthiere beobachten liess, sprach fiir diese Auffassungt).

Ich labe bei melneren andern Gelegenheiten aufmerksam gemacht th) dass velwandte Driisenzellen der (Oberhant mit Nerven zusammenhü̈ngen. Auch hier bei den Schleimzellen wird man öfters Terhialtnissen begegnen, welche geneigt machen lï̈nen, eine Verbindung mit feinsten Ausläufern der Hautnes'ven fiil' wahtscheinlich zu halten. Man sieht, wie :unserst fein und zugespitzt der Fortsatz da und dort in die Tiefe

*) Fig. 2, b.

**) Vergl. meine Mittheilungen. Allgemeine Bedeckungen der Amplibien, Arehiv f. mikrosk. Anat. 1876, Separatursgabe S. 97.

***) Zur Kenntniss d. Sinnesorgane der Schlangen, Arehiv f. mikrosk. Anat. Bd. 8 , S. 340 .

†) Hautdecke d. Gastropoden, Areh. f. Naturgeseh. 1876.

t) Vergl. a. a. O. S. 328 (IInweis auf Verhältuisse bei Wirbellosen). 
sich verliert: ja ron einem wic breit abgeschnittenen Fuss zieht sich hiu und wieder rin migemein zartes Fäserchen weg. das schliesslich doeh noch ahermals wie abgerissen anssieht. Aber trotz alledem bleibt einzugestehen, dass es mir bisher nicht gegliickt ist, die Verbindung mit Ausläuferu von Nervenfasern in Wirklichkeit zu erblicken und gan\% unwahrscheinlich wirl die Sache, wemn man eine Querscheibe von einer der konischen Papillen des Mundrandes des Petromyzon marinus vor sieh hat. Hier setzen sich nach iem bereits schon oben bemerkten die oberen Lagen der Epidermis nhuc Unterbrechung nur aus Schleimzellen zusammen *).

\section{Driisenzellen besonderer Art.}

In der Haut ier Nemangen - ich hatte Petromyson marinus vor mir kommt, ansser den bereits in Torhergehenden erwähnten Schleinzellen, noch eine anlere Form ror, welche sich in ihren Eigenschaften mehr den Iriisenzellen ans der Epidermis der Amphibien :mmähert ${ }^{* *}$ ).

Die Irïndung dieser Elemente findet sich in der Einbucht einer gewöhnlichen Epidermiszelle und erscheint nicht selten, ja eigentlich in der Regel wie verstopft durch einen rundlichen. homogenen, etwas gliunzenden Körper, mit gezacktrandigem Hohllaum im Imnern. Letzteres Gebilde halte ich trotz seiner Zellenähnlichkeit fiul eine Art Secretpfropf ${ }^{* * *}$ ). Der Gang, gerade gestreckt oder häufiger noch gekriimmut, hebt sich scharf von dem rundlichen, gern concentrisch streifigen Zellenkörper ab, welcher selbst wieler einen Fortsatz gegen die Tiefe noeh anfweisen kann. Die elwïlunten glinzenden Secretpfröpfe erscheinen auch abgelöst, wie selbständlige Kï̈rper, welche sich in der Grenze der Epidermis hinziehen, wovon jeder inmer wieder mit (einem Hohllaum versehen ist $\dagger$ ).

Dicse Art „einzelliger Driisen", sonst nur zerstrent vorkomment, häuft sich stellenweise an und giebt den Fantpartien ein Anssehen, welches an die Perlbildung' anderer Fische und der Amphibientt) erimert und wie jene sthon dem freien Ange zug:inglich ist ttt). Die Epidermis erhebt sich in Hiigel oder Ḧ̈.ker von verschicdener Grösse, die man zuniichst auf Wucherungen der Ejpilemiszellen beziehen

*) In der Epidermis der Papillen des Kreismundes felılen, was hier angesehlossen sein mar, sowohl Kolben als atuch Körnchenzellen.

$\left.{ }^{* *}\right)$ Fig. 3.

***) Fig. 3, a.

b) Vergl. Fiv. 1, a.

汸) Vergl. Leydig, Die anuren Batrachier d. deutschen Fanua, S. I23.

计方 Fig. 13, c. 
moivhte; doch fïllt schon bei flichtiger Betrachtung auf, dass der anscheinende Kern der die Hiigel erzengenten Zellen einen gewissen Glanz an sich hat. Töheres Untersnchen deckt damn auf, dass keineswegs gewihmliche Epidemiszellen rorliegen. snndern vielmeh" Ansanmlungen der gedarhten ,einzelligen Drisen". Ther gänzende Secretpifropf latt den Kem vorgespiegelt mol die den Pfropf nmzinhende Mindung der Drise liegt in einem Ausschnitt, richtiger Bucht einer Zelle, ron welcher sich ein Weg zn den Intercellulargaingen himzieht. Ich hahe die Ternnthmog. dass dice gedachten Pfröpfe dasselbe sind, was Langerhans als "Rnulzellen" besehrieben mul abgebildet lat. Den Chromatophoren sie zu vergleichen, wie unser Autor will. ist. gewiss mstatthaft: diese haben ihr Homologon in den mavhlier zn erwähnenden Strahlenzelleu.

\section{Kolben.}

l)ie gegenwärtig ziemlich allgemein mit den Namen, Kolben* bezeichneten Gobilde sind ebenfalls von mir zmerst* ans der Ephdermis gewisen Knowenfische angezeigt, aber mit den Schleinzellen fiir eins nud dasselbr gemommen worden; ein Verfahren, was, wen anch nicht ganz zutreffend, doch amaihend rivhtig war. Haben doeh spiatere Untersulher die .. Kolben" ebenfalls in diesem Simne anfgefasst. Inh beschrieh sic als "hïhst entwickelte Schlemzellen", als "grosce mit vollkommen hellem Inlalt versehene Blasen".

Wie damals habe ich anch jetzt wieder die Aalnutte, Lofu zulgaris, motersurlit. allwo dic gerlachten Kiirper in jerlem Hantstiickehen durch Menge mul Anscelien sich sehy benerklich machen. Tom oben mo in natiulicher Lage, erscheinen sie unter

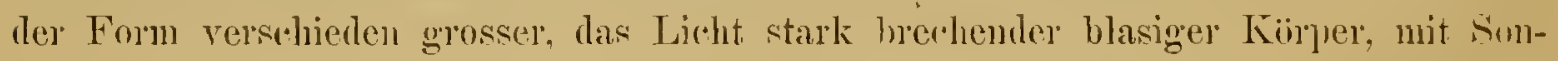
dermog in Rinde und Iniensulıstanz. Fine Oeftnmog ist nicht vorhanden. Von der Seite betrachtet, zeigen sie sich binfömig: iler Stiel, wellher auch wohl stark in die Lainge gezogen sem kamm. ist nach nuten gegen die Loderhant gewendet “").

Nach linwirkung verschiedener Reagention habe irh bezighlich des Bancs elmittelt, dass sic bestehen:

1) ans eincr feinen Hiille. liv sich unter Umstinden ziemlirh weit ahheben lisst. Sie kommt vom Stiel oder Fnss des Kiolbens, weleher den noch protoplasma-

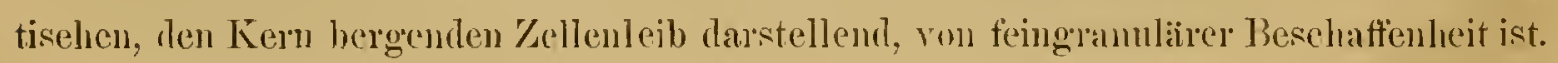

*) Haut der Suisswasserfische, Zeitschrift f. wiss. Zool. 1850. IDic z.u diesem Anfsat\% gehörigen Zeiehnungen besitze ich noch und sie bezengen mir klar, dass ich \%. B. von Lola rulgaris und . Inguilln vulgaris in den "Schleimzellen" die "Kolben" vor mir latte.

**) Vergl. Figur 16, Fig. 17, Fig. 19. 
2) Iren Hanptheil des kolbens macht die Innensubstanz aus, welehe weich ist, sehr anfyncllbar mul als Ganzes einen Körper von eiformigen Umriss bildet. Friselh ron waserklarem Anssehen, nimmt sie unter dem Finfluss von Reagentien :ine glcichmaissige, iinsserst feinkïrnge Triibung an.

i) Tentlich ist noch zn muterseheiden eine andere Substanz, welche als Sohale uder Kaiplechen dem Gipfel des Innenkibrpers antsitzt. Dieselbe brieht das Lieht viel stälker als der Innenkïrper, ist anch liairter und es treten in ihm leirlht zallheiche rersheren grosse Taruolen anf. Man danf wohi annehnen, dass dieses Käpuchen dureht Somterung und Lmbildung rom dem Innenkin'per sich abgeselieden hat.

Intem die ., Kolben " lie ganze Ejuilermis unseres Fisches anfs reiehlichste dur hsetz"n und iln im abgezngenen Zustande ein wie dieht durehstochenes Anssehen geben, rerleilien sie durch ihre gallertige, lejcht anfouellende Natur der Epirdermis die bekannte yuapprige, schleimige beschaffenheit. Der Stoff welcher ans den kleinen ... Schleinzellen" stammt, wirl wohl ebenfalls in diesem Simue beitragen; dass aber die ..Kolben" am meisten bei dem gallertartigen Wesen der Haut betheiligt sind, lehrt doeh die Untersuchung der frischen Hant aufs unzweidentigste.

Die Nennangen hatte ich in friiherer Zeit noch nicht anf den Ban der Epilermis mersucht. Dies geschah später vom Max Schultze*), H. Müller**), F. E. Schulze $\left.{ }^{* * *}\right)$. Langerhans f), zuletzt von Fittingerti) in mehr oder weniger eingehenter Weise.

Anch hier bei Petromyson furintilis mul Petromyzon marinus, die Arten welche ich prifte. fallen die .Kolben", ebenfalls hier den ron M. Schultze gebrauchten Xamen bcizubehalten, bei iluem glänzenden Wesen, wodurch sie sehr von der Umgebung abstechen, leicht in die Augen; sowohl in Fläehenansichten als auf Durchschnitten der Hant. Doch ist zu bemerken, dass im frischen Zustande die Lichtbrechumg noch nicht entfernt so stark ist, als sie nach Weingeist und anderen erhärtenden Fiisssigkeiten sich erhiiht.

Ifan darf an ihnen im Allyemeinen ein rundlich banchiges onler oberes Ende und einen rerengerten fussartigen Abschnitt unterscheiden. Wie sehr aber im Einzelnen die Gestalt wieder Abänderungen merworfen sein kamn, lehrt ein Blick auf

*) Arelir f. Anat. und Phys. 1861.

**) Wiirzburger Katurwiss. Zeitschrift, 1860 .

***) Archiv f. mikrosk. Anat. Bd. III.

†) Berichte d. naturí. Ges. in Freiburg i. B. 1873.

$\div \frac{1}{\circ}$ Bulletins de lacademie de Belgique 1876 . 


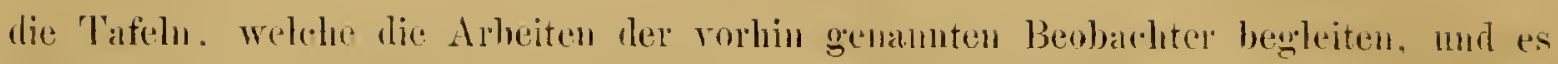

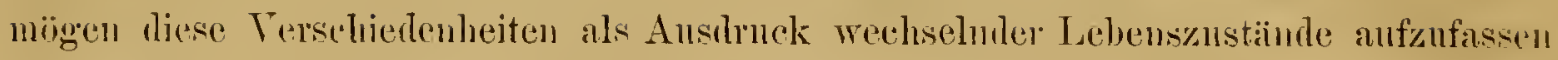
sein. Anch zeigen sich die Kïrper in frischen Zustande so weich, dass sie leicht die gewöhuliche Gestalt einbiissen.

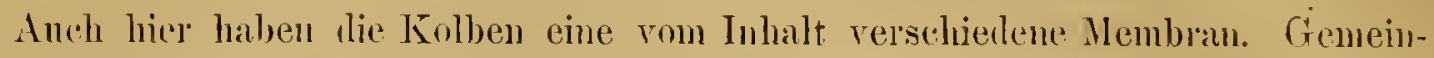
hin lisst sich dieselbe zwa nirht erkennen mul sie wird laher anch z. B. von F. F. Srohnze gelengnet, während Fättinger fïr ihr Torhandensein eintritt. An einem lange Zeit in Weingeist aufbewahrt gewesenen Petromyzon fluriatilis sehe ieh dentlich an vielen Kolben eine feine Iiille, welche zum 'Theil ziemlich weit ron der Sulsstan\% sich abletett*).

Der eigentliche Stoff oder die Hanptmasse thes Kolbens ist es, welcher sich durch starkes Lichtbrechnngsvermögen auszeichnet; er besitzt Schichtungsinien, bald mehr wie schalig sich umgreifend, so im verdiekten Theil, bald wie in Fuss lingesstreifig wertend. Bei Petromyzon marimus stiess ich anch auf Kolben. deren Sehichltungslinien gewissermassen in Unordnung gerathen waren, wodureh ein bihl dorrh(2induder gewortener Fïden entsteht, wie solches andh Fïttinger"*) schon reranschaulieht hat.

Inı baureligen Theile, gegen dessen freier knde zu, liegen Kerme, schr allgemein zwei, in seltenem thall sah ich anch hrei; sie sind mugeben von cinem lichten,

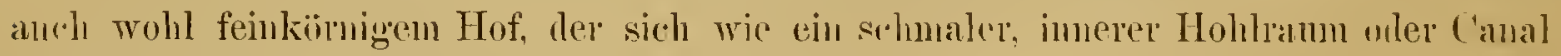
bis ans Finde des Fusses urstreckt.

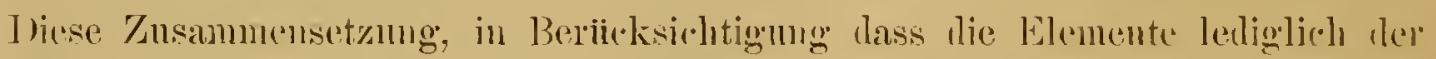

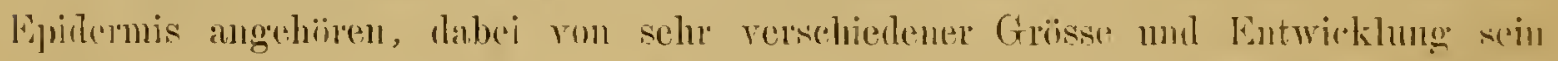
können, lehnt nus, dass wir es wietler mit umgelildeten bidermiszollen zu thun hahen. Thie Kerne sind gehliehen, vom urspringlichen P'rotoplasma ein 'Theil: die

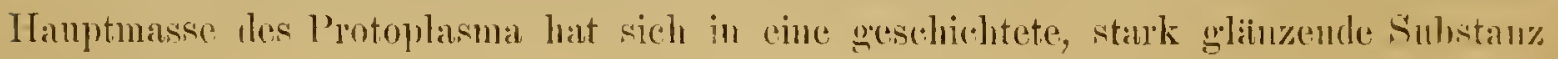
mugewandelt.

II. Sehultze manlite zuerst anf' eine Querstreifung der Kolben anfunerksinn.

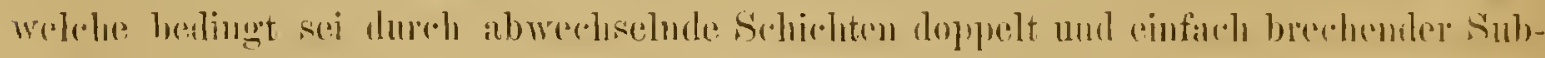

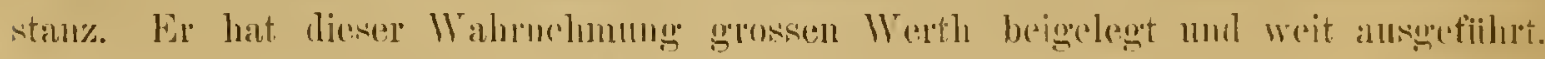

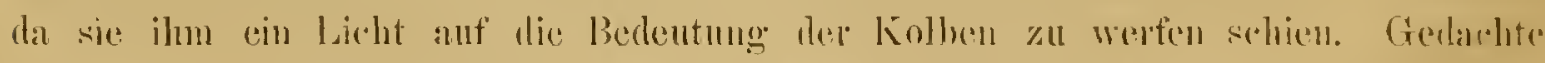

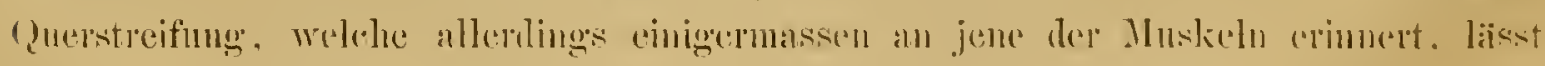

\footnotetext{
*) Fig. 7.

${ }^{* * *}$ ) a. :t. U. Pl. 11, Fig. 1.
} 
sinh unshwer sehen und sie ist wohl versehieden vom den vorhin rwähten Schichtungsinien. Allein ich relmag nicht dieser Erseheinung ein somlerliches Gewicht beizulcgen. da ich mich durch genaue Betrachtung des lanes iiberzengt zu haben galabe. dass mu die Hiille oder Zellemmembran es ist, welche durch feinste Faltenhilitung die Querstreitung bewirkt*). Und iiberdies stellt sich bei vergleichemlem Betrathten anderer Elemente der Epidermis heraus, dass fragliche Querstreifung nicht crwas den Kolben eigenartiges ist. Tenn anch gewöhnliche, lang ansgezogene Ejidermiszollen, mit Tanchlinsen untersucht. bieten eine unverkennbare, feine Querstreifung. dar; und die ebenfalls durch die sich faltende Hülle hervorgerufen erscheint.

Ifit den iibrigen zelligen Elementen der Epidermis haben die Kolben anch „2emein, dass sie in Anpassmug an die Nachbargebilde nicht immer glattrandig sind, sondern in mannichfacher Weise buchtig eingedriickt und in Kanten vorspringend.

Bei einem und demselben Thiere zeigen die Kolben grosse Versehiedenheiten in der Form: bald kurz und lick, sind sie wieder lang und schlank; mit immerem ('anal oder ganz solid anssehent. Insbesondere bietet aneh das untere Ende oder' der Fuss grossen Wechsel und, wie schon angegeben, bezeichnen wohl diese Formen Znstände, in denen der lebendige Kolben sich nach und nach voriibergehend befinden mag, die jetzt aber durch Härtung erhalten geblieben sind.

Ein gewöhnliches Bild ist jenes, wo der Fuss, unter Verbreiterung, seharf mol quer abgeschnitten erscheint, dabei aber in Ecken anfgebogen, indem sich die Endfliehe auf und zwischen die Hiigul, in welche die Oberflïche der Lederhaut ansgeht, hineinzuschicken hat ${ }^{* *}$ ). Ein andermal sehen wir das Ende des Fusses dicht zackig oder eingeschmitten, in Anpassung an die feinzackige Beschaffenheit der Lederhaut. Im Gegensatz hiezu trefien wir anch wohl das untere Ende banchig vorgequollen umd einfach abgernulet.

Endlieh fand ich anch, dass auf ganze Streeken hin sämmtliøhe Kolben nach unten in einen Farlen anshiefen ${ }^{* * *}$ ). Dies Verhalten zeigte sieh sowohl an einem Petromyzon marinus, dessen Haut friseh in doppelehromsaures Kali eingelegt worlen war, als anch an einem frisehen Petromyzon fluviatilis, anf den kurze Zeit sehr schwacher Weingeist eingewirkt hatte. Dic Ejpidermis mit der Nadel abgehoben und von unten betrachtet, gewiilnt hier einen ganz eigenen Anbliek, indem man gewissermassen

*) Siehe die eben angefülurte Figur.

**) Vergl. Fig. 1, b.

***) Fig. 5, b. 


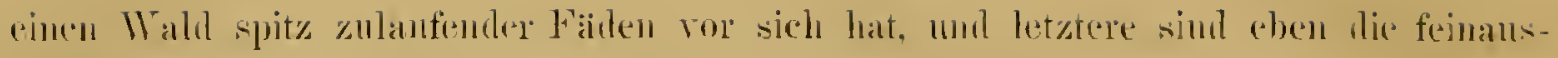

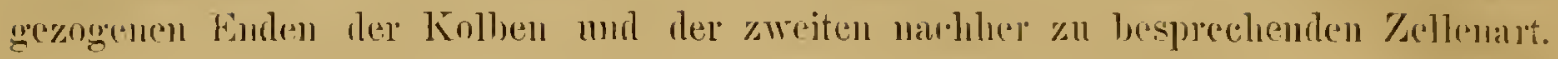

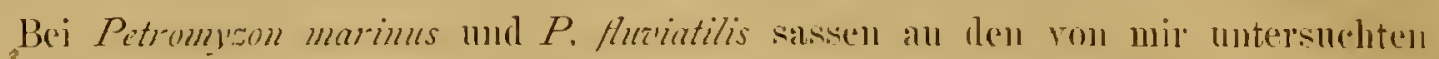
Hautseluniten die Kolben in Allgemeinen mit dem Fuss dicht der Lederhant an:

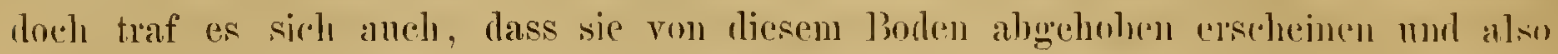
höher in der Epidennis standen. Hiebei mallte sich noch genn die Liicke bemerklich, in der sie friiher auf dem Corinm gesessen waren. Mrïgen sir alher andh alle

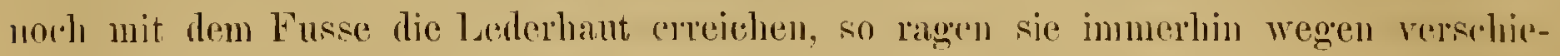

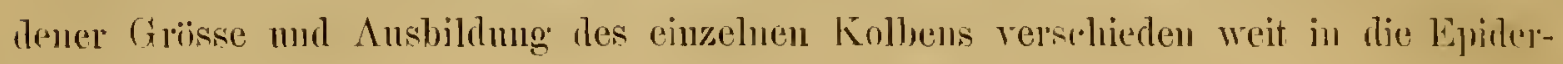
mis selber heranf.

Nicht zu verkemen ist ferner, dass der Charakter her Speries linfluss auf Crrösse und Form der Konben hat: jene ron Petromlron marimus sind länger als diejenigen ron Pctromyon fluriatilis; die ron Petromeron Planeri sind nach den diuriber rorhamlenen Angaben zu schliessen, noch kiir\%es.

Am wberen alogermuleten Finde ist in len weitans meisten Fiallen keine Spur einer Oeffum zu bemerken: sind jedoch die Kolben duroh Zusatz ron Kalilange sehr gequollen, so kamm sich au gedachtem Orte cine Durchbrechung orler Oeffinugg zeigen und die zwei Kerme sammt protoplasmatiseher Umhiillumg treten heror *

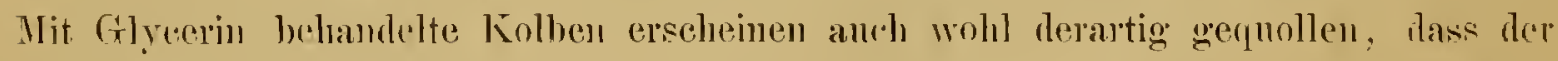

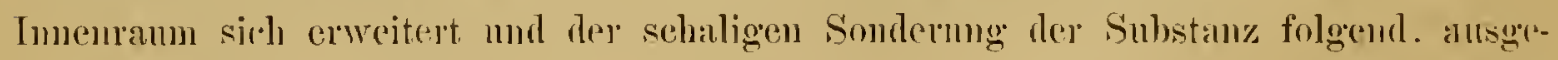
sprochene Zickzacklinien amnimmt. anch nach unten zol gleirhsam in rinzehe Splalträıme siølı zerleg't.

Irem wir jetzt die Frage zu beantworten stuchen, als was dite Kolben anzu-

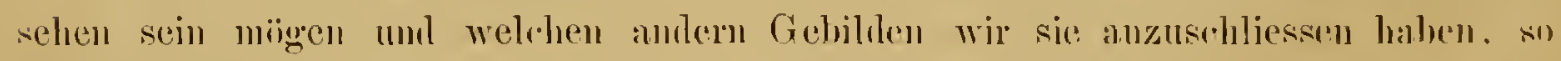
wird wohl gegenwairtig in Hinblick anf Petronlzon, Niemand meln jenem 'Theil dere Anffassung. M. Schultze's bejpflichten wollen, wontuh die Kolben musenliiser Natur waiben. Die feine Querstreifung ist, wie oben dargethan, als laltmug der Hiille vou mutergeorduetem Werthe mol nieht einmal etwas eigemartiges fiir die Kolben. dal sie anch an anderen zelligen kilementen der Ejhidermis anftreten kimm.

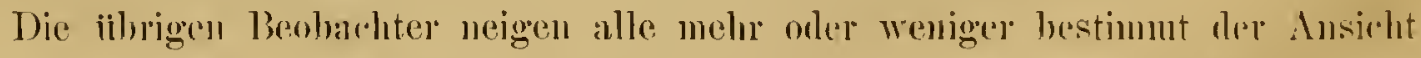

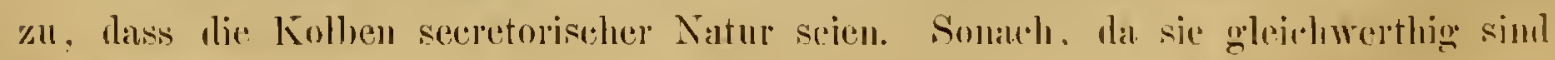


einer cinzelnen nugcbildeten Epidermiszelle, diirfen sie für eine den einzelligen Drisen rerwandte Bildumg erklärt werden.

Zu dieser ron mir beziiglich der Kolben der Ḱnochentische ron Anfang an geltenl gemachten Auffassung fiihren mich die gregenwärtigen Untersuchungen zuriick. Sic lehren, dass wir es mit Zellen der Oberhant zu thm haben, deren Protoplasma sich grossentheils in eine stark lichtbrechende, geschichtete mol selbst den Fadigen sich näliermle Substanz umgesetzt hat. Fiottinger will sogar beobachtet haben. dass diese Substanz auf die freic Fliiche der Ejpidermis nach und nach heranstritt. Narch meincon Beobarehtungen an Petromyzon fluriatilis bleibt aber ein solches sich Oeffincu der Kolben immer nur ein kinnstliches, mehr einen Platzen rerogleichbar, das durel starke Quellung verursacht ist.

Trollen wir mis mit der Anffinsung, dass die Kolben den einzelligen Iritisen morphologisch vergleichbar seien, nicht begnigen. sondern wïnschen wir ihr W'sen noch im Fingeren bestimmt zn sehen, so halte ich eine Andentung liberth's fiur zontreftend. Narhdem nämlich der Letztere jene mit eigenthïmlichem Inhalt ans.grostatteten Epidermiszellen bei Bombinator ignitus anfgefunden latte nul sich beminhtit. deren Bedentung zu erforschen, bemerkt er: ., Irh bin schliesslich dabei stehen gुeblieben, dass es sichl wohl um verwandte Bildungen handelt, wie sic in der Haut von Petromyzonten vorkommen." Gedachte Verwandtschaft — wollen wir beisetzen beschü̈nkt sich natiolich darauf, lass Beides Zellen sind mol der vom Protoplasma gelieferte, stark lichtbrechende Stofi in den beiden Thiergruplpen etwas Zusammengrehïriges sein möge.

Viclleicht kïnnte man noch jeneu Theil der Ansicht II. Srhultze's, dass die Kolben bei Petromyon zugleich Endorgane der Nerven seien, beitreten. Mir selber ist es zwar, so wenig wie an den echten Schleinzellon, gehungen cine wirkliohe Verbindung zwischen den Nervenauslänfern der Lederhant und deu Kolben zu sehen; anch nicht in den Fïllen, wo die letzteren mit feinfädig anslanfendem Fude, im isolirten Zustande, zahlreich ror Angen lagen. Am ehesten lassen noch nitunter Schuitte durch die ganze Hant die Termuthung, dass ein derantiger Zusammenhang bestehen nügge, aufkommen. 1)em es tritt da und dort ein blasser, nervöser Streifen hart bis an die Grenze der Lederhant, gerade merhalb des Kolbens; und man mïclite gylanben. dass der nervöse Faden anf den Achsenfaden oder den imeren Hohlraum des Kolbens trifft, wonach dam das P'rotoplasma in banchigen Absehnitt sammt den dort befindlichen zwei Kernen die Geltung als Ende der Nerven erhalten wiirle.

Wollten wir nun anch eine solche Ammalnne für zulässigg halten. so steht uns 
doch wieder der Unustand entgegen, dass die blassen. feinkïnigen Nerrenstreifen des Coriums, welche da und dort die Richtung gegen den Fuss des Kolbens nehmen, wegen geringer Zahl niclit entfent in Stande wiiren, alle Kolben anf solche Weise zur versorgen, anch wem sie sich noch in die allerfeinsten Fäserchen zertheilten. Die Zahl jener Kolben, welehe den Nerven anfsiässen, wïrde alsilamn sehr klein bleiben gegreniiluer von den vielen andern, welche der Nerventerbindung ermangehn miissten. Innnerhin wäre dies kein durdschlagenter Finwurf; dem inh darf anfiilıren, dass in den verschiedenen Fällen, wo ich bei Wiirmern, Arthropoden und Weichthieren auf Terbindungen einzelliger Hautdrisen mit Nerven hinznweisen hatte, es ebenfalls nur einzehe Zellen waren, welche in gedarhter Art ansgezeichnet erscheine11 ").

An den Kolben der Kuochenfische kann das anscheinend Sperifische, welches jene des Petromyzon an sich haben, mehr zuriicktreten. Die Kolhen in der Haut der Aalrutte, Lota a'ulgaris, weisen durch den Besitz eines protoplasmatischen, den Kern enthaltenden Fusses, deutlicher anf Schlcimzellen hin; wobei dan die gallertige Innensubstanz des banchigen Theils dem Secretraum sammt Inhalt der Becherzelle zu entsprechen liatte. Der Mangel einer Oefinung und das stark g]inzende, liairtere Käppuhen entfernt sie aber wieder von den eigentiirhen Sehleimzellen, so dass wir es eben wohl mit Bildungen zu thun haben, welche im allgemeineren Sim als verwandte zusammengehören mögen, im Besonderen aber doch durch starke Verschiedenheiten getremut bleiben.

\section{Körnchenzellen.}

In der Ejidermis der Cyclostomen finden sich ansser den Köben noch merkwiirdige, muter dem Namen Körnchenzellen znerst durch Kölliker bekanmt grewordene Körper. Auch diese Elemente sind in grosser Menge zugegen, dabei vou wechselndem Unfang und was das Anssehen im Gamzen betrifft, so haben sie gregeniiber von den Kulhen etwas Weiches in Umriss. Von Gestalt sind es mugefïhr kuglige Gebilde, versehen mit einem oder nehreren langen Fortsätzen, welche in die Ticfe, zur Oberflairhe der Lederhant streben. Der Zellenkörper liegt weit oben in der kpidermis, mumittelbar nuter der Horns(hicht**). Gleich den andern Elementen der Epidermis behalten sie im grehärteten, isolirten Zustande mancherlei Einbuehtungen mol kantige Znschärfmngen als Folge der Anpassmg" an die Umgebung.

*) Vergl. auch meine Bemerkungen ïbcr die Nerven der Driisen bei Insecten, Archir fü mikrosk. Antt. 1876 .

**; Fig. 1, c. 
Ein weiteres anf Form und Bau geriehtetes Studium an Petromyon marinus brachte mir noch Folgendes zur Kenntniss*).

Den Zellenkïrper unsehliesst eine Memhran, die nach oben, gegen das abgermudete Ende zu, diimner ist als riickmiirts, wesshalb die dunkle Umrisslinie dort ins Zarte sich umsetzt. Dass es sich um eine wirkliche Hembran handelt, ergiebt sich auch darans dentlich, dass im Falle durch Reagentien das Protoplasma sich zuriickzicht, jetzt ein lichter Raum zwischen Memhran und Zellsubstauz sich aufthut, durch welchen am vorderen Umfang sich feine fadige Spitzen des Protoplasma hinspannen. Es kann anch die Membran einreissen und den Inhalt voryuellen lassen.

Die Zellsubstanz scheidet sieh in zwei Partien: in eine obere. welche nach aussen gewentlet and königg ist, und in eine hintere helle, nichtkïrnige. ron welcher die Fortsitze ausgehen. In letzterer liegt anch der mit Nucleolus rersehene Kern. Hat man freilich schon in mamichfacher Wreise veränderte. insbesondere stark gequnllene Körper vor sich, dam gewinnt es den Ansehein, als ob die Membrau einen einfach kïrnigen Ballen nmschliesse. Der körnerlose Theil des Protophasma. welcher den Kern birgt, kann sich in gewisser Lage und nach Reagentien anch so scharf als besonterer dicker Streifen oder als eine den Kern schalig umgebende Substanz al)heben, dass man an jene Form von Ganglienzellen erimnert wird, bei welchen rom Kern der Fortsatz abgeht**). Offenbar hat bereits F. E. Schulze ron diesem Sachverhalt etwas gesehen, ohne lariiber ins Klare zu kommen: demn das ..zirkelkopfähnliche Gebilde" in Inneru des Zellenkörpers, welehes mit den Fortsätzen in numittelbarer Terbindung steht, ist eben dieser den Kiern bergende Theil des Zellenleibes. Allerdings weiss ich nicht anzugeben, warum man doch nur verbailtnissmässig selten gedachte Sonderung zu Gesicht hekommt; noch am ehesten gelingt solches an Hautstiicken, welche man der Einwirkung von doppelchromsanrem Káali ansygesetzt hatte.

Der ans dem hellen Theil des Protoplasma abgehende Fortsatz, welcher sich gern näher oder entfernter rom Zellenkïrper gablig theilt, kamn dentlich auf Strecken hin fein quergestreift sein; was abermals kund gibt, dass die oben besprochene Querstreifung der Kolben nichts Specifisches ist.

Da die Fortsätze saimmtlich in die Tiefe, znr Oberflïche der Lerlerhant. sich wenden, so habe ich eifrig besonders darnach getrachtet, das eigentliche Ende der-

*) Vergl. Fig. 6, welche die Körnchenzelle in verschiedenen Zuständen darstelit.

**) Vergl. Fig. 6, die zwei \%ellen rechts. 
selben kemnen zu lernen. Da Schnitte duch die Haut heriber keinen Aufschlnss geben, indem sich hiebei die Fäden zwischen die Zellen rler Epinlermis nach unten wieder dem Blick entziehen, so hob ich an der, in doppelehromsanrem Kali grelegenen Haut von Pitromıon marimus, mit der Nadel kleinste Stiickchen der Ejpilermis ab und suchte dieselbe mehr durch Riitteln des Objectglases als durch Instrumente zu zerlegen.

Es kommt jetzt an den anf so sachte Weise frei geworilenen Zellen melureses Beachtenswerthe zum Torschein: zunachst dass die Gabchiste des Fortsatzes sich wieder theilen kïnucu; sodann ïberzengt man sich, dass die bereits sehn fein gewordenen Fortsitzo sich noeh nm vieles weiter erstrecken, als die bisherigen Zeichnungen versinulichen. Sie ziehen sich in geralezu unmessbare fuine Fädehen ans. Einigemal lat es mir dem anch gesehienen; als ob ein derartiges Fidehen mit ebenso feinen Bruchsticken ron Fäserchen zusammenhinge, welehe zwischen den untersten Lagen der Ejpidermiszellen hin und wieder bemerkbar waren: wäre das letztere Vephalten ran erwiesenes. so gïbe es einen Fingerzeig. nm lie Natur der Kiirnchenzellen morphologisel bestimmen zu kijnucu; aber ich bin trotz aller hielauf velwandten Miilıe iiber diesen Punkt unsicher gebliehen. In den weitaus meisten Fäillen rejsst selbst der Faden schon da ab, wo el anfiingt ganz fein zu werden. Es kommt anch vor, dass die nenen Gabeliste mit Terbueiterung aufhören; allein dies deute ieh auf Stellen, wo nach Abbrechen des Fortsatzes eine Quellumg stattgefunden hat: ilem die feinen Euden, von wel-hen eben die Rede war, niissten erst viel spiiter folgen. Sollte es in der That noch gelingen, Acu Zusammenhang dor feinsten Auslänfer unter sich darzuthum, und eine eben solche Terbindung mit Nervenfisserelien, welehe von der Lelerhaut in die Ejudermis eintreten, so wäre der Platz, wo die fraglichen Elemente eimzureihen seien, bestimut. Deun dic Kïmolunzellen wiirlen alsilann, trotz sonst abweichendem Tresen, mit jenen pigmenthaltigen oder pigmentfieien Strahlenzellen zusammenzustellen sciu, von welchen nachher Giuiges zu sagen sein wilerl.

Immerhin wiirden gegrenwibtige Elemente, ansser mehreren der angefilnten Figenschaften, noch durch andere bisher nirht bekannt gewesene ziige sich unterseleivlen.

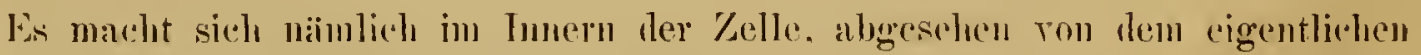
Kem, non ein anteres kugliges Gebilde hin mol wierler hemerklivh, welehes entweder von kiipugem Aussehen ist und alsdann wie eine Art zweiter Nurlens sjeh darstellt: oder es erscheint vollkommen wasserklar und hebt sich dadureh elice wie 
eine Varunle oder Secretblischen von der königen Umgebung ab. Ferner habe irh anch hie und la noch einen zapfenartigen Forcsatz wahrgenommens, welcher aus ier Zelle hervorstand; bald von demselben blassen Wesen, wie das Secrethläschen, halı zu einem anscheineml farligen Theil vou seharframligem Aussehen zusammengefillen. Beidemal erhalten wir den Eindruck, als ob der Fortsatz zu der Vacuole orler dem Serretblïschen in Bezielıng stänte ").

Das eben Mitgetheilte kann die Vermuthung erwecken, dass anch an den Kïrnchenzellen ein secretorischer Torgang mit im Spiel ist; was im Zusammenhang. mit der möglicherweise bestehenten Nervenverbindung an solche Simesepithelien erimnern danf, bei welchen empfindende mud abscheidende Thliatigkeit vereint sein mag.

Noch sej bemerkt, dass die Körnchenzellen dem Umriss nach und durch ihre langen Fortsiitze leblatt an Ganglienkugehn mit Auslänfern erinnern; aber das Ausselıen der K̈̈rnchen, welehe ziemlich grobbrïickig sind, deutet ein griosseres Lichtbrechungsvermögen an, als solkhes den Körnern echter Ganglienkugeln zukommt.

\section{s. Strahlenzellen mit und ohne Pigment.}

Der Abhandlung iiber die Hantdecke umd Schale der Gastropoden") habe ich eine Beilage angefiigt, in welcher nuter der Aufschrift: „Die verästigten Zellen im Ejithel und der Lederhaut", die hier gemeinten Elemente im Zusammenhang und naeh ihrer Besleutung besprochen werden.

Ans der lipidermis der Fische hatte ieh frijher mur die mit Pigment erfiillten verzweigten Zellen - also Chromatophoren - angezeigt. Deshalb jst jetzt zu elwähnen, dass lier die hellen, nicht pigmenthaltigen Strahlenzellen ebenfalls zugegen siml. Hieron habe ich mich \%. B. an Cyprinus carassius iiberzengt. Im frisehen Znstande der Haut wirl man ihrer jedoch schwer ansichtig: schwache Lösungen von doppelchromsaurem Kali siml anzuwenten, nm sie deutlich hervortreten zu lassen. Sie erscheinen jetzt als lıelle Zellen, deren zum Theil lange, verïstigte Auslänfer sehr fein sind nul ohne Spur von Pigment; der Kern kann im frischen Zustande ein gewisses glünzendes Anssehen haben.

Ganz besonders schön lassen sich die Strahlenzellen ans der lipitermis der Larven von Pelobates fuscus isoliren **). An einem Thier. das etwa iiber Nacht in sehlr schwach angesänertem Wasser liegt, zerfält die Epidermis von selber in die

*) Vergl. Fig. fi, die drei oberen Zellen.

Archiv to Naturgesch. 1876.

***) Fig. 22, e. 
gewöhnlichen Fpidermiszellen und in die gedachten Elemente. Letztere sind lang verzweigte Gebilde, der Kärper und die Auslïufer dir.ht erfiillt mit Pignnent, und noch jenseits des Pigmentes setzen sich die Ausläufer, schr zart und blass geworden, bis zu mumessbarer Feinheit fort.

Wie man in der Klasse der Amphibien iberhaupt die Contractilität der ästigen Chromatophoren verhältnissmässig leicht beobarlıten kann, so auch hier an unseren Larven. Das vom lebenden Thiere abgeselhittene Hautstick zeigt nus die lang Inin ausgezogenen verästigten, durch das l'ignent schwarzen Zellen. Setzen wir alstam die Lapren in sehwach angesäuertes Wasser, so sind aus den schwarzen Netzfiguren einfach längliche, spindelförmig angeschwollene Gebilde geworlen.

Man muss wohl diesen zelligen Elementen in der Epirlermis eine gröissere Bedeutung zugestehen, seitlem festgestellt ist, dass sie mit Nerven zusammonhängen. Ich beziehe mich hiebei auf die miter meiner Anleitung erschienene Arbrit von Ribbert iiber ric Anatrmic der Hantderke bei Saiugethieren *). Dort wird iler Nachweis geliefert, dass dic verzweigten Zellen mit Ansläufern von Nerven, welche von der Lerlerhatut her in die Schleimschicht der Oberhant eintreten, sich in V'erbindung setzen.

\section{Becherförmige Simnesorgane.}

1. Fisclie.

Die Zahl der Beobachter, welche sich bisher rlie Frforschung des Banes der berherfirmigen Organe der Fische lat angelegen scin lassen, ist nicht gross zu nennen und iiberdies weichen die. rorhandenen Angaben in nicht unwesentlichen Punkten ron einander ab.

I.h selher liess, als $j \cdot h_{1}$ in Jahre 1850 znerst auf rlie Anwesenheit dieser Körper als "merkwiirdiger Gebilıle" in der Oberhant der Fische hinwies **), clieselben aus Zellen von einerlei $\Lambda$ rt bestelsen. Dieselben seien verliingert, mit einem Kern versehen unt besiissen eine gewisse Aelnlickeit mit den musculizen Faserzellen.

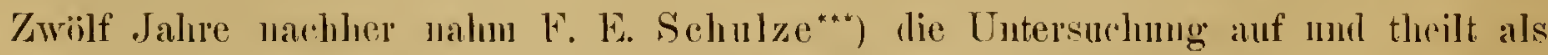
Ergebniss mit, dass die Organe aus zwei gainzlielı versehiedenen Arten von \%ellen zusammengesetzt seien. Die einen seien einfahe Cylinderepithelzellen ron allerdings

*) Archiv f. Nitturgesehichte, 1878.

**) Leber d. Hant einiger Siisswasserfisehe, Zeitselur. f. wiss. Zool. 1850.

***) Leber d. becherfürmigen Organe der Visehe, Zeitschr. 1. wiss. Zool. 1862. 
anssermolentlicher Länge, die andern diinne, stäbchen-oder tadenfümige Elemente oler Nervenendzullen.

Die Darstellnng des histologischen Banes welche F. F. Schulze gegeben hat, erfieut sich der allgemeinen Znstinumng der dentschen Morplonlogen, ohne dass freilich, wie mir scheint, anch mu ein Finziger die Untersuchung des Gegenstandes bei Fischen selbst vorgenommen lıatte.

Der nächste Beobachter, Jobert*t), meldet als nenen Fund, lass eine feinkörnige Substanz ansser den Zellen vorhanden sei, in welche siclı zunäelıt die Aclısencylinder dler Nervenfasern auflisten. Und was die zelligen Elemente iles Organs betrifft. so gelten sie dem franzisischen Anatomen einfach als falenfurmig verlängerte Epidermiszellen ohne sonstige Anszerchmung.

Die letzte mir bekannt geworlene Albeit iiber besagte Oryane lieferte Zin(cone*). Er muterscheiclet an Wulhs drei Zellenformen: selı lange Zellen, teren Fuss sich verästigt; dann feinere mit mittlerer Anschwellnng fiu den Kenı: endlich solche, "welche sich dureh cine grüssere Anhäufung von Protoplasma um den Kern lıervorheben. Dariiber jedoch, ob diese Zellen unter sich von wirklich versehiedener Art seien, bleibt der Autor zweifelhatt: er meint, die letzteren kinuten and Jugendzustiude der zweiten Form sein. Wine anscheinende Bestätigung von der Gegenwart rer "kürnigen Substanz" geben die Abbilduingen. Stifte oder Härrehen (.ceiglia o setole“) an Vorderrande des Organs seien nicht zu finden gewesen.

Man sieht ans dieser Zusanmenstellung, dass genaner ggenommen die Beobachter nur in wenigen Puncten iibereinstimmen: Die Organe bestehen ans Zellen und diese, aus der Epidermis herrorgegangen, tragen noch mehr odler weniger den Charakter verlaingerter Epiderniszellen.

Es lag laher nahe, nachlem ich mich mit den entsprechenden Bildungen bei Amplibien und Reptilien in der Zwischenzeit beschäftigt hatte, anch auf die Simnesbecher bei den Fischen zuriickzngreifen. Ich that dieses, intem ich den Hecht, Esox lucius, den Flussbarsch, Perca fuaratilis und Kanlbarsch, Acerina cormu, die Karausehe, Cyprimus carassins, endlich die Aalrutte, Loto anlguris, untersuchte und ich glaube in der morphologischen Kemntniss besagter Bildnngen einen S.luritt vorwärts gethan zu haben.

Wesentliche Unterschiede kamen bei den einzelnen Species kanm zum Tor-

*) Études d'auatomie compareé sur les orgaues du toucher, Aun. d. sc. nat. 1872.

:*) Osservazioni anatomiche su di alcune appendici tattili dei pesci. Rendiconto della Reale Accademia delle seienze fisiche e matematiche. Scttembre 1876. 
schein mul halte ich mich daher in der näheren beschreibung nur an cine Art, an den Hecht, weil sich gerate an ihm zuerst ein besserel Eimblick thun liess. Die Theile wurden sowohl dem eben getödeten 'Thiere entummnen mul sonar ganz frisch mutersucht. als auch nach Einwirkmg vou dhemischen Hilfsmittelı. Es empfehlen sich besonders die Simesbecher aus der Mund- mo Rachenhiohle, namentlich dic an Gaumen stehenden.

Jas ganz frische Organ erscheint ziemlich hlass mul fein gramulail; iloch so, dass gegen das freie Fude zn eine dentliche Zejehumng von zusammenneigenden Streifen orler Stähchen crkembar ist. In dem hinteren 'Theile liegen Kerne, deren umschliessende Zellenkïrper sich kamm nut dam nur durch zante, verschwommene Linien abgrenzen").

Richten wil den. Blick bei starker Vergröisserung, untel Anwemdung von Tanchlinsen mul selbstverständlich bei Vermeidung alles Druckes, anf die kreisiunde. von der Ejoidemnislïcke mmzogene freie Flächc oster den Gjpfel des Organs, şn wird uns klar, dass der... Simesbecher" sich in eine Mitte und cine Rinde suheidet. Mic Rinde wird gebildet von den erwïhnten Streifen oler stabähnlichen Iinien, welrhe von anssen her zusammenneigen; lie sich abhebende Mitte, man könnte anch sageu, das Mark, stellt sich zunïclıst als eine feinliönige Substanz dar**).

Gehen wil nun wierler zuriek zur Betrachtung der Seitentläche des Bechers, mul fassen einen Strich oder Stah, scharf ins Auge, so liist sich je ein soleher "Stab" in zwei Seitenlinien ron feinst gramulärer Natul anf, während slazwischen eine helle homogene Ache hinzieht. Ist das Orogan noch in lebenden Zustande, ganz unvarändert und dabei ctwas zuriickgezogen, so kömuch wir anch als Fortsetzum und

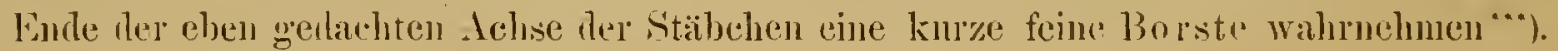

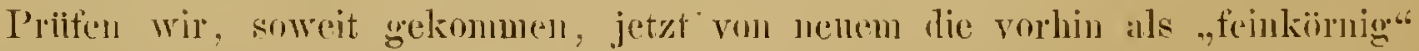
bezeichnete ()berflïche ller Marksulsstan\%, so löst sich bei anfuerksamsten Zusehen

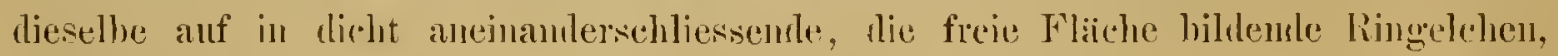
wovon jedes ein schärfer gezeichnetes Küjpfehen oder Häckerchen muschliesst

Durch Anwendmeg rhemischer Mittel, namentlich von Osmimnsäure und dop)-

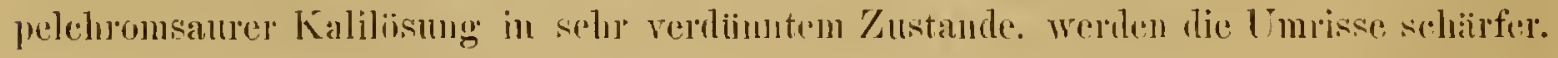

") Vererl. Figul 25.5.

-) Nigr. 25, dis Orgnn links.

‥) Fig. 27.

†) Fig. 26 . 
Hiedureh, und indem wir jetzt anch die Organe nit Nadeln zu zerlegen suchen, ergibt sich uns folgentes.

An den Zellen, welche die Rinde des Organs erzengen, lassen sich mnterscheiden: ein muterster feinkörniger Theil welcher den Kern birgt und an Ende fasrig sich anffranzt: lanm weiter naeh oben eine leichte banehige Anschwellnng: hieran schliesst der stabformig verengte Theil; zuletzt folgt eine kurze, feine Borste als Endstilck $\left.{ }^{*}\right)$. Eine Art innerer Hohlram der Zelle, vou dem banthigen Theile begimmend, durch den stabförmigen Abschnitt sieh fortsetzend, mo absehliessend mit der ..Borste" kam jetzt wegen härterer Linien noch mehr sinnenfïllig werden.

Die Zellen der Mitte sind kiirzer, dicklicher, granulärer, birnfinmig. Das obere Ende scheint nur wie dureh ein Deckelchen orler Cuticularkäpluchen gesehlossen, dessen Verdickung das erwähnte Küijfehen vorstellt.

Was die feinkörnige Substanz betrifft, welche nach Jobert vorhanden sein soll. so bin ich dariiber nicht ins Klare gekommen. Das nach unten gerichtete Ende der Zellen erscheint, wie schon bemerkt, anfgefranzt oder in feinste Fäserchen anfgelöst. Mir diinkt mun, dass die Masse dieser Fäserchen, in der Eintiefung der Lederhautpapillen liegend, eine anscheinend kirnig griimelige Substanz erzengen kamn; vielleicht unter Mitwirkung der aus der Papille getretenen Achseneylinder der Nervenfasern.

Was die Miindung anbetrifft, so sind besagte Organe für sich nicht mit einer Höhlung versehen, sondern sie stellen massige Bildungen vor. Die Oeffinnng iiher ihrem Gipfel gehört dem Epithel oder der Epidermis an. Im nptisehen Sehnitte lebender .,Simesberher" zeigt sich nicht selten die Epithelliicke oder Spalte dureh Zurickziehen des Zellenkïrpers vertieft, ja wie trirhterfümig eingesenkt**). Die Zellen des Organs bilden Boden mid Riickenwand der Mnlde oder des Trichters. Das Zustandekommen dieser Eintiefung, sowie die sehr wechsehnle Weite der Oeffnung ist schwer zn verstehen, wemn man nicht eine Contractilitït der zelligen Elemente gelten lässt. Fỉne zusagendere Erklärmng wäre freilich, wenn man im Gewebe der Papille musculïse Elemente nachweisen könnte, was bis jetzt nicht gelingen will.

Noch sei im Hinblick anf die anderen oben genannten Fischarten bemerkt, dass, wie ich schon längst angezeigt, die „Berher" bald einen geraden "vlindrischen, bald einen kegelförmigen, ein andermal einen nalıezu kugeligen Umriss darbieten küınen.

*) Fig. 27.

**) Fig. 28, Fig. 29. 
In ganz frischem oller lebenden Znstande stellen sich die das Organ zusammensetzenden Zcllen in der Beschaffenheit dar, wie sie oben erörtert wurle. Leicht aber - ich sah es z. B. an Cyprims corassins - ändert sich dies dahin um, dass die bezeichnete lichte Zone oller der Innenramm sich in eine lielle längliehe Vacuole umsetzt. welehe nach hinten bogig abschliesst, nach vorn aher wie geütuet ersiheint").

Hüchst selıwierig bleilut es immer, die Endborsten wahzunchuen, da sie sehr veroginglicher Natur zu sein scheinen. Man kann viele ler Organe ansschneiden, olne etwas von Borsten ansichtig zu werden. Und selbst wenn man sie an dem einen ..Becher" gewahrt, will wieder ilas Auffinden derselben an denen der nailısten Unngebung nicht grelingen. Am elesten kommen sie zum Vorschein, wenn dic Oeffmung des Organs sich mulden - oder trichterfümig eingezogen hat ${ }^{* *}$ ). Alsdann neigen die kuzen, blassen Bürstehen so gegen einander, wie es ctwa in der Puppenhiilse des Nachtpfanenauges, Saturnia carpini, jene Borsten thun. Welche dic bokannte „Fiselneuse" erzeugen. Ein eigentlirhes freies Hervorragen ler Borsten ans rier Oeffnumg der Epidermis heraus. habe ich niemals wahrgenommen.

Noch sei der Terinderungen gedacht, welche die zelligen Elemente der Organe

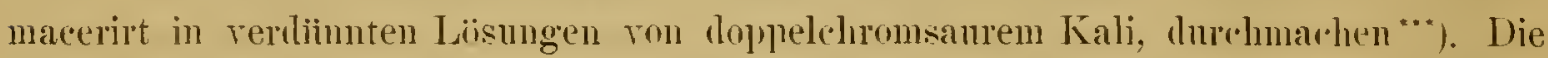
einen der Zellen sind wie zn schmächtigen Fasern geworden mit leichter Anftreibung mach rorm zu: andere zeigen sich in derselben Richtmug staiker verbreitert durch eine längliche Vracuole, welch letztere selbst wieller einfach künig gefiult sein kann, ein andermal wie ron eincr Art zarten Balkenwerks durchzogen. Anch die Partie jenseits der Tacuolc kann sich versehieden larstellen: häutig farlig verengt oder zusammengefallen, ist sie zuweilen ein streitig-körniges Kliimprenen; dann anch wieder ein wirkliches. scharfiandiges kurzes Fädchen mit zugespitztem Ende; aurl wohl ein glänzentes Endknïpfelen. Ticht sclten ist ler fein ansgezogene vordere Theil der Zelle plibtzlicll so verbreitert, wie wenu er zu einer voller freien, jetzt znsanmengezogenen Oetfinug geelient haitte.

In Oryanen, welche in noch selıwïrheren Lösungen lagen, ist die Zalıl jener welche den mehr oler weniger veränderten Innenram erkennen lassen, grösser als in solchen, welche stiilkeren Lösungen ansgresctzt waren. In letzteren sind jene Formen häufiger, welche cin stharfandiges, stahartigges 11 esen zeigen; wobei ein feines Endknöpfehen orler Fäilchon ahgelist von der Zelle, dentlich sein kann.

*) Fig. 15.

**) Fig. 28, Fig. 29.

***; Fig. 30 . 
Den Mittheilungen, welche ich schon frïher iiber die Papille, ihre Gefässe und Nerren rongelegt labe, funde ich nichts wesentliches hinzuzufiigen. Die Papillen der äısseren Haut sind gern mehr oder weniger pigmentirt: jene der Mund- und Rachenhöhle sind meist unpigmentirt. Bei mancher Art scheinen sie durehweg eine etwas kurze und dickliche Gestalt zu haben, z. B. beim Hecht. Am Gaumen trifft man gern sehr grosse Papillen, auf welchen daun erst mehr oder weniger zahlreich die kleinen mit den ..Bechern" gekrönten Erhebungen stehen *).

Fassen wir das Allgemeine wie es sich ans den vorangegangenen Lutersuchungen ableiten lässt. zusammen. so grelangen wir ungefïhr zu nachstehenden Sätzen:

Auch die zelligen Elemente der becherförmigen Organe der Fische zerlegen sich in eine Rinden- und in eine Achsenschicht. entsprechend dem, was ich bei Reptilien und Amphibien als Dantelzellen und als zelligen Innenkibrper untersehieden hahe.

Die Borsten mit welchen die Zellen der Rindenlage nach vorn abschliessen, gehören sonach ebenfalls nur dem Rande an und ich vermuthe, ohne dass ich im Angenblick den Gegenstand ron nenem vorgenommen hätte. dass die feinen Spitzen der die Wand des Organs bei msern Eiderhsen erzengenden Zellen, welche einen streifigen Saum hervorrufen ${ }^{* *}$ ) mit diesen Borsten der Beeher bei Fischen zusammenzustellen sind.

Die Zellen der Mitte oler Achse haben keine Borsten, wohl aber sitzt dem freien Fnde ein Knöptehen oder Spitzehen anf ron stärkerem Lichtbrechungstermögen. Den letzteren Gebilden fiir gleichwerthig halte ich die, je nach der Finstellung als Ringe oler als feine Spitzen, inmer aber ron gliuzentem Aussehen sich zeigenden Endtheile der Zelle, welche ich an den Orwanen der Larren von Triton gesehen habe $\left.{ }^{* *}\right)$. Ehenso möchte ich die von mir bei Anguis fragilis wahrogenommenen "Stiftchen und walzigen Fäden", welche aus der Miindungsstelle der Sinnesbecher hervorragten, iu die gleiche Reihe ron Bildungen bringen.

Yan darf daher ammehmen, dass es zweierlei harähnliche Gebilde an musern

*) Eine derartige , stammpapille, welche sich in fünf Ausläufer zerspaltet, an deren Ende die becherförmigen Organe sitzen" habe ich z. B. aus der Rachenschleimhant eines Leuciscus bereits in der Histologie S. 299, Fig. 160 veranschaulicht.

**) Die in Deutschland lebenden Arten der Saurier. S. 101, Taf. XII, Fig. 151.

***) Hautdecke n. Hautsinnesorgane der Urodelen, Morphol, Jahrbuch Bd. II, S. 301, Taf. XVIII, Fig. 1, Fig. 2, Fig. 3. 
Organen gibt: solche welche aus den Mantelzellen hervorgehen, blass und zart sind und von verginglieher Satur: und zweitens andre den Innenzellen anfsitzend, welehe einen scharfen, glänzenden Unriss haben und länger ansdanern.

Und so mïhte ich an dieser Stelle abermals die Termuthung iunssern, dass die ans anderen Simnesorganen der Wirbelthiere bis jetzt bekannt gewordenen unbeweglichen Borsten jenen Hairehen der Randzellen der Hautsimnesorgane der Fische an die Seite zn setzen sind. So beispielsweise die von mil erwaihnten langen, staren, leicht einschmelzbaren Haare im Tebengeruchsorgan der Reptilien. Auch schon manche Angaben bei Anderen leiten auf diesen Gedanken. Man betraehte \%. B. die Tafehn und die Worte der Beschreibung in MI. Srhultze's Schrift iiber den Bau der Nasenschleimhant. Dort wird beziiglich der ,kleinen, stabförmigen Aufsaitze" auf ilen .,Nervenzell'n' der Geruehsgrube des Hechtes bemerkt, es sei zweifelhaft, ob sje wïhrend des Lebens sehon existiven oiler erst durch die Chromsiiure cutstanden seien. Ja mit Riicksieht auf die Regio olfactoria des nengeborenen Kindes, in Chromsänre erlä̈rtet, heisst es: die fadenförmigen Fortsätze anf der freien Fläche des Epithels scheinen hervorgequollene Theile der peripherischen Rieclizellenfortsitze zu sein; an ganz frischen Präparaten war keine Spur iber die freie Flaiche des Epithels hinansragender Härchen zu erkemnen.

Hailt nan nun damit zusammen, was ich iibel die Somlerung der Substanz der Riudenzellen ermittelt habe. so hat eben rie von mir wiederholt vorgebrachte Auffassung eine gerrisso Begriindung: wourch ilie hinfälligen Borsten aus iler hellen homogenen Innensubstanz, wie eine Art Abscheidung entstehen oder deren frej herrorragenile Fortsetzung sind.

Die derberen Stifte der Innenzellen denke ich mir in goleicher Bezielıung zun Zellenleib, mit dem Unterschiede, dass sie noch mehr den Cuticularbildungen sich nähern. Bei Thieren, welche auf dem Lande leben und also immer beeinflusst sind von der anstrocknculen luft, kïmen dic Haare bestimmter den eben angerleuteten Charakter annehmen, wie ich solehes bereits bezighlich der Geckotiden hervorgehoben lablue ").

Endlich gestatte ich mir, anch noch iiber die von F. F. Schulze bei verschierlenen Fischen beobarhtete zarte, helle Röhre, welche die Borsten unschliesst,

*) Allgemeine Bedeckungen der Amphibien, Scparatausgabe, S. 57. - Im Tagblatt der Natur* forseherversammlung in Cassel, Herbst 1878, erklärt auch ein andrer Beobachter die stiftartigen Körper für Cuticularbildung. Die Blätter sind mir leider nicht melı zur Hand, um genaner citiren zu könnel. 
die Vermuthung an-zusprechen, dass sie dem von den hellen zarten Füilen der Rimdenzellen gebildeten Kranze entiprechen miige. Die eingeschlossenen Borsten sind nach genamutem Verfasser von starkem Glanze, was sieh an das oben Dargelegte anschliessen wïrle.

Alle bisherigen Beobarliter haben sich bemiiht, den unmittelbaren Zusammenhang zwischen den Zellen besagter Organe und den herrortretenden Nervenfasern

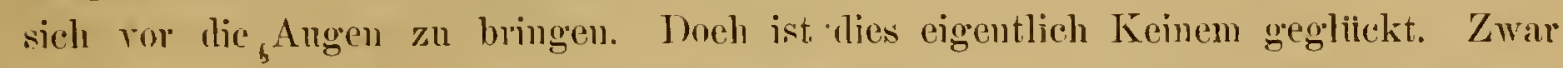
anch dicsmal gewalute ich z. B. an Cyprinus carassius wie ans den Papillen des Ifundrandes. nach abgehobenem Ejpithel en oder das andere feine Fïserchen heranssteht, welehe man wohl anf freie Aelsencyliuler zu denten einiges Recht hat. Es ist wahrscheinlich, dass solche feine nervöse Fäserchen in die anfgefranzten Eulen der Zellen iibertreten mögen; - aber eine etwelche Sicherheit war hieriber nieht zu erlangen und es blieb bei solehen bruchstiiekartigen Walnnebmungen.

Ueberbliekt man iibrigens die Mittheihungen, wie sie in Anbetraclit ler Nerrenenden an den Sinnesbechern bekamnt geworden sint, so darf man die Vermuthmug hegen, dass nach Gattungen mo Arten, wie anch in anderen Organisationen, typische Verschiedenheiten sieh ansprägen werden. Man betrachte von diesem Gesichtspuncte aus z. B. die bildlielien Darstellungen, welehe Jobert vom. Thullus barbatus gegeben hat*). Auch denke ich hiebei an dasjenige, was ieh iiber terninale Ganglienkngehn, norll innerhalb der bindegewebigen Grmndlage, bei Schlangen beobaclitet habe**).

Endlich sei noch erwïhnt, dass anch hier bei ten Fischen, :ihnlich wie ich es sehon an den gleichen Organen der Schlangen erkannt, das Simesorgan urspriinglich völlig in der Epidermis vergraben ist, die Deckzellen sonach in ununterbrochenem Znge dariber hingehen. Frst wem nach und nach die Thätigkeit der Zellen des Imnenkörpers zur Entwickhnng kommt, entstehen einzehne kleine Oeffinungen, richtiger Liicken zwisehen den Deckzellen, entsprechend in der Gröisse den einzelnen Zellen des Tnnenkürpers. Zuletzt Hiessen die kleinen Oeffumngen zu der griisseren zusammen, welelue den Gijfel des Organs mingiebt.

\section{Larven der anuren Batrachier.}

Wie sich mir der Bau der Hautsimmesorgane bei den Urodelen dargestellt hat. wurde anderwärts ausfïlurlich berichtet**). Die Organe aus der Mundhölıle ter

*) a. a. O. Pl. 6. Fig. 47 , Fig. 49.

**) Zur Kenntniss der Sinnesorgane der Schlangen, Auch. f. mikrosk. Anat. Bd. 8, 1872, S. 334.

***) Ueber die allgemeinen Bedeckungen d. Amplibien, Arebiv f. mikrosk. Anatomie 1876. 
Froschlarven, iiber welche wir F. E. Schulze die bekannte schüne Abhandlung verdanken, hatte ich friiher noeh nicht in den Kreis der Untersuchung gezogen. Dies ist jetzt geschehen und ich erhube mir anch dariiber einige Bemerkungen.

Es wurlen die Larven vou Pclobates fuscus ans versehiedenen Stadien gewiihlt; 'Thiere ohne Gliedmassen, dann andere mit zwei und endlich solche mit vier Beinen.

Die "Gesrhmacksknospen" stehen nicht bloss anf Papillen, welche selbst wieder sehı verschieden gross sein können, soulerı sind auch soust über die Schleimhant des Mundes, besonders des Gaumens verhreitet. Der Umfang der ."Knospen" ist ein reeht wechselnder, ja manche sind selı kleju. Die grösseren scheinen immer anf den Papillen zu sitzen; anch stehen sie gern gedoppelt beisammen. Niiher greprift, im frisehen Zustande, zeigen sie sich nur zusammengesetzt ans einer Gruppe von Zellen, die hinten banchig verbreitert, vorne fast stabartig verengt sind, demnahlı eine etwelche umgekelirt hiruformige Gestalt haben. An der Spitze kann ein glinzentes, rundliches Körperchen sich abheben. Feine Borsten als Randzone erblicke ich nicht "*). Die gewïhnlichen Epiderniszellen bilden eine Sehale nm das Zellenpacket, welches selber durch ein gewisses dnukelkïniges Wesen von der umgebenden Oberlant absticlit. Somit herrseht in Ganzen doch eine gronse Aelnlickeit mit den gleichen Gebilden bei den Larven der Urodelen.

Unf so sehe ieh anch wiederum von nenem, hass die "Sinnesbecher" urs]riinglich von der Ejpidermis vällig iibordeckt sind: Die Lage der Deekzellen geht ohne Unterbrechung iiber den Gipfel her Organe weg. In diesem Falle ist anch noch nichts von den seharfrandigen, ghänzenlen Spitzen oder Stiftehen der Zellen anfgetreten: letztere erschejuen erst. wenn dic Deckzellen tine ()effnung orler einen Durdlogang frei lassen.

Nachdem die "Kunspen" von der bindegewebigen Grumllage rein und schart abgefallen sind, so zeigt die Obertiache der Papillen eine sehwathe Mulde, welche zur Anfuahme der "Knospen" gerlient hat.

Die "hecherfirmigen Organe" habe ich anderwärts als verwandschaftlich zusammengestellt mit den eigenartigen, von mir zuerst angezeigten Epithelplatten,

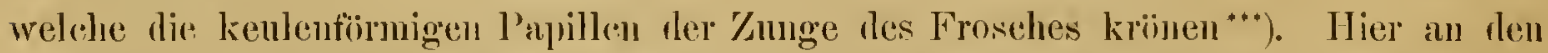
Larven von Pelobates scheint im Auftreten und Verschwinten der beiderlei Gebilte eine Wechselwirknug zo bestehen. Man gewahrt, dass an gröisseren Larven, die dem

*) Die Geschmacksorgaue der Froschlarven, Arehiv f. mikrosk. Anatomic Bd. 6.

**) Figuren 21, 22, 23.

***) Allgemeine Bedeckungen der Amplibien, Separatausgabe S. 54. 
Einle des Wassurlebens entgegengehen, zwar die Papillen, etwa des Gaumens, noch vorhanden, aber die Simnesbecher gesehwunden sind: ilı Platz zeigt sich von gewöhnlichen Epithelzellen eingenommen. In den Papillen selbor sind Grefisse und Nerven noch sichtbal, doch scheint mil ein gewisses feinkörniges Wesen der Nerven anzudenten, lass ein Torgang der Riickbildung begonnen hat.

Bei Larven dieser Zeit ist bereits die Zungre als thaches und weiches IV arrachen aufgetreten und mit ih" die eigenartigen bithelplatten (,., Solnmerkplatten “). Sie stellen sich dar als rom ibrigen Epithel abgegrenzte Partien, deren Zellen etwas dunkles an sich haben, hin und wicher anch Tacuolenbildung zeigen, sonst aber von zartem Aussehen sind ohne eigentlich specifischen Charakter. Zngleich mit ller Anlage der Zunge sind anch die sehlandefirmigren Hrisen dieses Oronans da.

Fs mag auch hier angeschlossen werlen, dass bei Hyla arborea, deren Larven ich gleichzeitig untersuchte, die Menge der Simnesbecher aussen am Kojf eine ganz ungemein grosse ist. Mir diunkt, nach der Erinnerumg, dass die Larven des Laubfrosehes hierin die anderen Batrachier iibertreffen. Die "Becher* bestehen abermals ans Packeten birnförmiger Zellen. - Von Stelle zu Stelle hoben sich an der Epidermis die Zellen mit den Biischeln langer Wimperhare ab.

A n merkung. Bereits vor laingerer Zeit*) labe ich angezeigt, tass bei gewissen H ir u diuccn Organe vorkommen, welche den "Bechern" oder" "Geschnacksknospen" der Fische verwandt seien. Bald nachler fand ich etwas Aehnliches bei Lumbricinen und sprach anch dic Vermuthung ans, dass gewisse von Keferstein und Elılers bei Simmculus beschriebenen Organe die gleiche Bedeutung haben mögen.

Der feinere Bau ist noch wenig erforscht. Was ich an den Organen der Egel sah, erscheint in meinen 'Tafeln zur vergleichenden Anatomie versinnlicht. Jene der Lumbricinen hat unterdessen ein sorgfältiger Beobachter, v. II ojsisovies, geprüft und einige vorlänfige Mittleilungen nebst Zeichnung darüber veröffentlicht. $\left.{ }^{* *}\right)$ Vor Kurzem hat Eisig***) an einer anderen Gruppe der Anneliden, bei Capitelliden, verwandte Organe entdeckt und cine ins Einzelne gehende Darstellung des Baues gegebell.

\section{S e i t e no r g a ne.}

1. Knochenfisehe.

Es wäre wiinschenswerth, alle die einheimischen Fische, Art für Art, anf das Seiteneanalsystem untersucht zu sehen; sowohl was den Verlanf der Canäle betrifft,

*) Arch. f. Anat. u. Phys. 1861 (Augen und ueue Sinnesorgane der Egel).

**) Kleine Beiträge zur Kenntniss der Anncliden, Sitzgsber. d. Akad. d. Wiss. in Wien, 1877.

***) Die Seitenorgane und becherförmigen Organe der Capitelliden. Mittheilungen aus d. zool. Station in Neapel, Bd. I. 
als anch die Weise der Miundungen, ferner das V'erhalten zur Lederlant, zı den Schuppen und Knorhen, sowie entlich im Hinblick anf len histologischen Bau. Wie wenig zusammenhängend hierin unsere Kenntnisse sind, lässt sich z. B. aus llem Werke von Herkel und Kner: Die Sisswasserfisehe der isterreichischen Monarchie, ersehen, obschon diese Iehthỵologen mehr als Andre bei jerler Art anf las Seiteneanalsystem geachtet haben. Nicht selten miissen sie sich anf allgemeinste l3emerkungen besrlı̈inken: z. B. die Kopfoanäle sind lier dentlich, dort mudeutlich. auch wohl kaum sichtbar. Die vorläufigen Mittheilungen, welehe Solger*) iiber die Seitenorgane der Fische veriffentlicht hat, erwecken die angenehme Hothinng, dass durch diesen Anatomen der Gegenstand wird gefordert werlen. Iuh habe einstweilen mul nur mit liticksicht anf gewisse Flagen, die folgenden wenigen Arten mutersucht: den Hecht, Esor lucius, dann den Stichling; Gusterosteus aculcatcus, den Kaulbarsch, Accrina cermua und die Aalintte, Lota z'ulsaris.

A. 1) allgemeinen Verhältnisse der "Seitenlinic des Herlites siml, woranf zuerst $v$. Siebold in bestimmter Weise hingewiesen luat ${ }^{* *}$ ), etwas eigenartig. Die Seitenlinie nämlich, insofern sie durch besomlers geartete Schmplen ansgenliickt wird, erscheint hier fortwaihrend unterbroehen: es finden sich zwischen den "analisirten" Schuppen zwei mul mehr Reihen gewöhnlicher, nicht ranalisirter Sehmpren. Wie zum Ersatz alyer sinul oberhalb und unterhalb der Seitenlinie zerstrent ebenfalls ranalisirte Schmplen rangegen, gewissermassen, ,accessorische oder rudimentäre Seitenlinien" wie Andre sie nemen.

Betrachten wir uine der ., eanalisirten" S.hnppen bei mässiger Vergrösserung, so crgiebt sich ball, dass der "Canal" eigentlich eine Furche ist, gebililet dureh einen Ansschnitt am Hinterande der Schuple, wobei die liänder etwas verdickt sinul

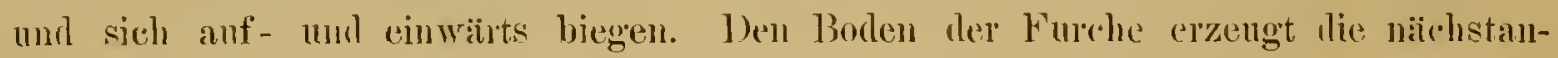
sehliessemde Schmples. Man bemerkt nm fermer ledeht. lass in der Furche eine An-

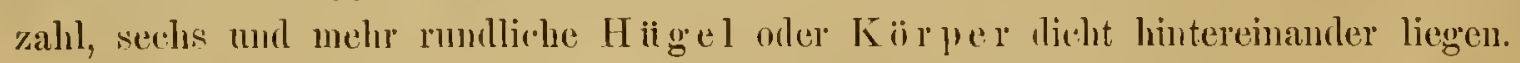

Wendet man sich dem näheren Studium der Hiigel zon, so stellt sich lierans, dass sie den Bau der "becherfïmigen Orenge" laben, wobei sie aber, obwohl nuter sich versehieden gross, dneh in Allgemeinen nmfänglicher sind als die "Recher". Fs zeigt siel wieder eine zellige Znsammensetzung und abermals eine moweifellafte Sondernng iler Flemente in eine Mittelpartic nnd in eine liandschicht. An den zellen

*) Ueber die Seitenorgane der Fische, Leopoldina XIV.

**) Die Süsswasserfische von Mitteleuropa, Leipzig 1863, S. 326 . 
der Randschicht - Mantelzellen - mterscheiden wir cin etwas banchiges hinteres Eule min einen rorderen, stabartig rerengten Theil. Mit diesem neigen sie alle bei Besichtigmng des Organs ron oben - sehiö strahlig zusammen. 1)as Eude der Mantelzellen ist eine zarte Borste mo diese erscheint als Abschlnss einer hellen Inmenzone des stabartigen Theils der Zelle.

Dir Zellen der Mittelpartie oder des inmern Ballens sind körniger, kiirzer mul breiter mul an ihrem Grjpel kamn sich ein glänzendes Körnchen abheben.

Es rerdient nun fermer alle Beachtnng, dass ..,Seitenorgane", wie sie eben nach ilnem lan beschieben wurden, nicht bloss in den ."'analisirten" Schuppen der Haupt- und den Nebenseitenlinien vorhanden simd. sondern anch sonst noeh sich verbreiten"). An Rumpfe stehen sie in Reihen, welche uner zur Längsarhse gerichtet sind. Die einzelne leihe kamm aus sechs bis zehn Hïgelı znsammengesetzt sein. An solehen Hautstellen nïhert sich das P'igment nur bis zu einer Art Grenzlinie und anch die zahlreichen Schleimzellen bleiben anch hier zuriick, so dass die Reilue der. Simneshiigel etras wie abgeschlossenes an sich trägt, obsehon sie nicht in einer Furche der Selnppen ihre Lage hat ${ }^{* *}$ ).

Näher anzugeben, in welcher Zahl etwa die querstehenden Reihen von Sinneshïgeln iiber die Seitenflaichen tles Leibes sich verbreiten, getrane ich mir nieht, da jeh bisher nicht im Stande bin, sie mit der Lupe anf der murerletzten Hant zu erkemnen. Es bedarf viehnelı immer erst der Fläehenschnitte mi der mikroskopischen Untersuchung, wodnreh es umständlicher wird, sich ein Bild iiber Menge und Vertheilung zu rerschaffen.

Au der Hant des Kónfes, z. B. der Wangengegend, trifft man neben Becherorganen der gewöhnlichen Grïsse auch andre, welche in ihrem Umfange den Simeshiigehn der Seitenlinien nicht nachstehen, so dass es goleichgiiltig wirl, welche Bezejehnung man denselben beilegen will.

Es bleibt beachtensmerth. dass bein Hecht die .,becherförmigen Organe“" und die Organe des Seitencanalșrstems an Rmmpf im Wesentlichen des Banes iibereinstimmen.

Zur Wiederanfnahme der Untersuchung der Kopfeanäle bin ich noch nieht

*) Die Schrift von F. Fée, Rech. sur le nerf pneumo-gastrique chez les poissons, Strasbourg 1869, in welcher das Seitencanalsystem des Hechtes eingehender bearbeitet zu sein scheint, kanu ich durch den Buchhandel nicht erhalten und vermag daher nicht zu sagen, ob dieser Autor die oben gcmeinten, nicht in Schuppenfurchen stehenden Organe schon gekannt hat.

**) Fig. 24. 
gekommen, aber wenn ich meine friiheren mir noch vorlicgenten Anfzeichnugen zı Rathe ziehen darf, so finden sich z. B. im Canal des Unterkiefers exhte ,Nervenkü̈pfe" das heisst, eine Auflüsmng unl Entfaltmig der Nerven zu einem Hachumullichen Hiigel, bedeckt von der Lage hoher Cylinderzellen, in welche herein die letzten Ausläufer ier Nervenfasern sich verlieren.

B. Auch die Gattung Gasterostens, merkwiirlig als Vertreterin der Makrelen in unserm Siisswasser, besitzt naclı der Entdeckung von Solger an G. pungitins freie Seitenorgane am hompf, und zwar so, dass entweder nur ein einziges ofler je zwei einen Metamer entsprechen. Ich habe bisher nur den dreistachlichen Stichling G. aculcatus untersuchen können. Von einem Seitenkanal ist weder fïrs freir Ange noch durch die Lupe etwas anfzufinden; und an senkrechten Schnitten zeigt sich, dass die Substanz der Lederhant, in gewöhnlicher Weise von Längshagen nut senkrecht aufsteigenden Ziigen gebildet, von einem Canal nicht durehbrochen ist. Hingeggen lassen Flächensehnitte wahruehmen, dass die Epidermis in ziemliehen Abstämden von Geffnungen durhsetzt wirk, welche mit jenen der Sinnesbeeher iibereinstimmen und bloss grösser sind. Die Seitenorgane selber, zu denen die rmullichen Spaltiiffunngen wohl fiihren, habe ich nielıt gepriift; es ist aber nach der Analogie mit lem llecht wahrscheinlich, lass sie im Ban mit den Sinnesherhern iibereinstimmen un nur unfänglicher als diese sein werlen. Ameh an Kopf ist werler von "Schleimmanilen“ noch von .,Schleimporen" etwas sichtbar. — Sinnesbecher stehen z. B. an Mnuclrand und in besondrer Menge an Gaumenwulst. Sit sind die kleinsten mir bekannt gewordenen, und die fiir sie bestimnte Geffinung im kither ist kamm griisser als dher Banch tler in allergrösster Menge am Gaumen herumstehenden Schleimzillen. 'T'rot\% der Kleinheit glanbe jeh doch soviel beziighich des banes gesehen zu hahen, dass sie die oben an andern Fisehen beschriebene /ansanmensetzung haben. Fs simt Gruppen rou Zellen. Welche mit ilurem stabartig vejengten Halstheil nach worn zulsammenneigen: selbst eine feinste strahlige Zeirhnung, anf Härohen beziehlar: moine

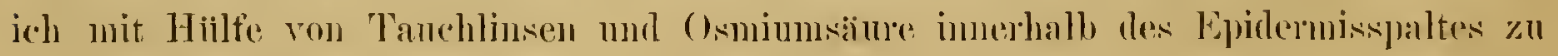
erblicke'sl.

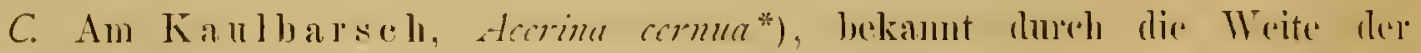

*) Der Kanlbarsch, in Main bei Wirzburg hänfig, wird dort gleich dem Flussbarseh aut den Markt gebracht: hier in IBonn, wo dies nicht gesehicht, schien er mir und Anderen ein im lihcin sel. tener Fisch zu sein; was aber nicht der Fall ist. limmal aufnerksam geworden, erhielt iel in diesem Frihjalı eine ganze Anzahl. Er geht dea Rhein hinanf bis Basel. Vergl. Lenthnel, die mittolrheinische Fisebfanna, Basel 1877. Im Neekar bei Tibingen felit der Kaubarsch. 
Kopteaniale, habe idh die ., Nervenknöpfe" nach langer Zwiwchenzeit wieder berselenell.

Ohne an disem Orte anf eine znsammenfassemlere Darstellumg des Banes cinzugehen, scien nur die Puncte nahmhaft gemacht, welche zu den friiheren Wahrnchmungen jetzt noch hinzukommen, odler sie verbessern.

Das Bindegerrebe des Hiigels. welches die Nervenentfaltung und die Blutgefiisse trïgt, ist von sehr weichem, fast gallertartigem Wesen: ein zartes streifiges 13allienwerk in feinste Fisserchen ansgehend. nimmt einen gallertartigen Stoff zwirchen sich anf. 1)ie zelligen Elemente im frischen Zustande sind älnserst zarte. blasse Protoplismazellen. Das Bindegewebe grenzt sich gegen nas Epithel hin hautartig ab nud gerade unterdalb, man kömte beinahe auch sagen, innerhalb dieser häntigen Grenzschicht liegt das zierliche und dichte Netz der Bluteapillaren. Durchschnitte

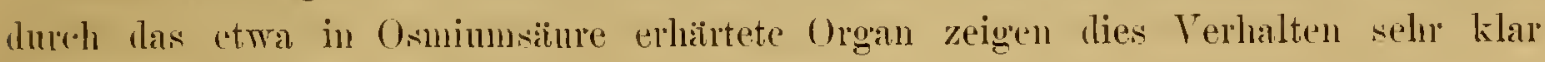
uml man fiillt side erinnert z. 13. an die Membrana choriocapillaris des Auges.

Ueber die bindegewebige Grmullage zieht sich cine eigenartige zellige oder epitheliale Lage hin*\%. Die Hauptmasse derselben besteht ans langen, blassen Cylinderzcllen, die leicht in eine ansheinend kïnige Substanz sich umsetzen; der Kern liegt im hinteren Abschnitt der Zelle und hat ein kleines randständiges Kernkörperchen. Fasst man an Prälaraten welche dureh Osminmsäure erhärtet sind, den Grenzsanu ciner solehen Zellenteihe mit starker Tergrösserung ins Auge, so meine ich grlinzende Poncte in Reihen wahnzunelment orler in andrer Ansicht eine :iusserst fuine Zackenbildung. Ich mörhte mir diese Puncte und Strichelchen als eine Art feinster Sculptur des Grenzames der Zellenkïpfe deuten

Wine zweite Zellenart sind rundlich birnförmige Elemente, welche in ile Lage der Stabzellen so eingestrent sind, dass sje der Obertiähe dieser Zone sich nähern. Indem sie dabei ziemlich ancinumershliessen. grenzen sie sich als Ganzes wic ein mittleres Feld des epithelialen Ueberzuges ab. Die zu imerst liegenden Zetlen sind die grösseren, nach dem liande hin werten sie kleiner. Die Einzelzelle von oben betraclitet, ist nicht immer von rein rondem Lmriss, sondern einigermassen rckig. Ancle diese Elemente wurlen zwar von mir friiher schon bemerkt; wälurend irh sie aber einfach zwischen die stabzellen eingestreut glaubte, hat erst Solger er-

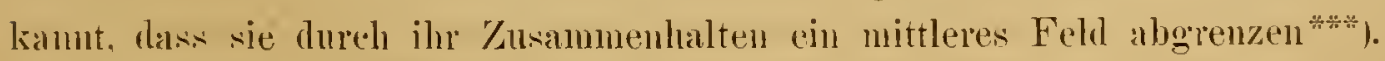

*) Fig. 43; Fig. 44 .

**) Fig. 4:2, b.

***) Pig. 41. 
Ferner zeichnen sich die binförmigen Zellen - und dies hat zuerst F. E. Srhulze wahroenommen - durch den Besitz eines. ., starren Haares" aus. Es lasien sich die Hiirchen dadurch am besten zur Anschanmeg bringen, dass man auf den aus dem eben getölteten Thier heransgenommenen „Nervenknopt" Osmimnsäure einige Minnten einwirk'n liisst. Alsdamn steht eine helle, blasse Borste von Stelle zu Stelle ans dem hande des Zellenlagers hervor; wialnend der Zellenleib selber bereits einen schwärzlirhen Ton angenommen hat* ${ }^{*}$. Die Länge der Borste ist eine werhsehnde.

Blickt man auf die Fläche des Mittelfelies, so erscheinen zwischen den Birnzellen Gruplen von Strichen und eimmal mit den frei vorstehenden Borsten vertraut geworden, erkenut man diese Striche als die jetzt niederliegenden Haare**). I abri ergab sich Gelegenheit, iiber die Form der Borsten noch weitere Beobachtungen zu marhen. Tiele derselben haben die Form einer wirklichen Borste, doch sohon häıfig. mit etwas verbreiterter Wurzel; andere aber sind dentlich dreiseitig zugeschnittene blattartige Erhebungen der Zellen $\left.{ }^{* * *}\right)$, etwa so, wie ich es zuerst an ähnliche'n Zellen aus dem Ohrlabyrinth der Vägel gefunden und versinnlicht habe $\dagger)$. Uebrigrens dart ich wohl an diesem Orte auch daran erinnern, daks vom mir längst in Jahre 1852 ans dem Seiteneanalsystem der Sclachier und aus den Gallertröhren Epithelzellen nit ,stachelartigen Fortsiit\%en" angezeigt worden sint.

Die sohwierigste Frage bleibt wie in allen simnesonganen jene nach der cigenttlichen Endigungsweise der Nerven.

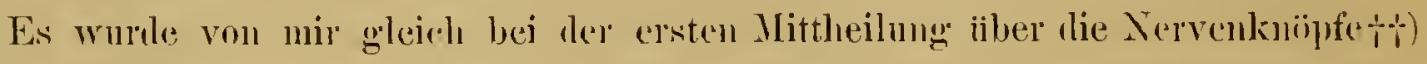
die wiehtige 'Thatsalche hervorgehoben, dass die Nervenfasen durch die Maschen des Bluteapillarnetzes nar.h auscen in das bipithel treten, un dort zu emien. Gegreniber

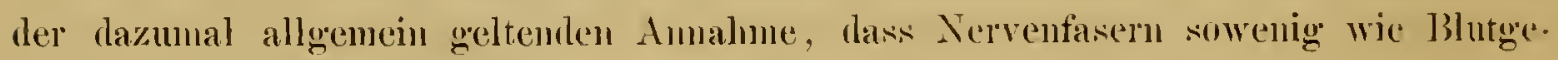
fässe den binlegewebigen Boden jemals verlassen, eroffuete dieser Narhweis des Uelbertretens der Nervenelenente in eine epitheliale Schicht eine Reihe von Beobarhtungern,

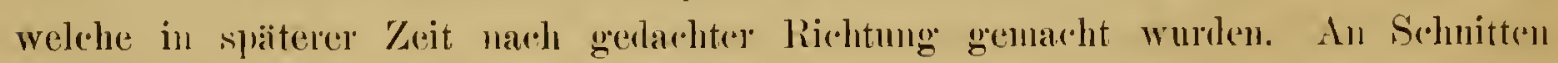
durch Nervenkü̈pfe welche in Osmiumsäure gehairtet wurden, lisst sirh gran aluf

*) Vergl. Fig. 43 .

**) Fig. 41, c.

***) Fig. 42, a.

t) Lehrbuch der Histologic, S. 270, Fig. 141 e. - Mit grosser Surgfale lat spaiter Panl Meyer in der selö̈nen Schrift: Citudes histologiques sur la Labyrinthe membraneux et plus spécialument sur le limaçon ehez les reptiles et les oiseanx, Strassbourg 1786, die feinere Beschaffenheit diess. Zellen dargethan.

†) Froriep's Notizen, April 1850. 
Strerken weit die epitheliale Lage ab und dam kömen die Nervenfasern frei herrorstehen: wihlend das abgerissene Ende in das abgehobene Epithel sich hineinzieht*).

Die in die Zone der Cylinkerzellen eingedrungenen Nervenprinitivfasent sind anfünglich noch mit Mark verwehen, sonach dunkelrandig, verschmälern sich im weiteren Verlauf, und werden leicht varicös; zuletzt verlieren sie dis Mtark und haben das Answehen freier Arhencylinder. Bis zu diesem Puncte ist die Beobarhtung sicher mul rerhïltnissmiassig leicht. Ueber das eigentliche Ende der frei gewrordenen Fasern aber bin ich schwankend geblieben. Zuerst schien es mir, als ob sie frei (enden $\%$ ) fortgesetzte Unterwuchungen lieswen wahrscheinlich werden. dass die letzten Endigungen, wie ich mich ausdrürkte ,unter dem Bilde diner Capillarverzweigung sich rerlieren, ako in Netzform authörten ${ }^{* * *}$ ). Endlich habe ich noch einer dritten ..anscheinenden" Endigungsweise gedacht und veranshaulicht: die blass gewordenen Nerrenfasern verbinden sich mit binfömigen Zellen, welche in der Peripherie der Stabzellen liegen $广$ ).

Durch die gerade anf obschwebende Frage gerichteten Untersuchungen F. E. Srhulze's, welche ïber die von mir mu obenhin erwähnten birnförmigen Zellen wichtige Aufschliisse gaben, war ich bis vor Kurzem mit diesem Forscher iiberzengt. dass die feinsten Nervenfasern sich nit dem unteren Ende der birufönnigen Lellen rerbinden ft), die anden Ansichten iiber die Endigungwweise sonach aufzngeben seien.

Jetzt aber nach wieder vorgenommener Priifung bin ich von nenem muscher geworden und muss gestehen, dass die von mir friiher gehegte Ansicht von einer netzförnigen Endigmag der Nervenfasern mir wieder fiir die an besten begrindete goilt. Termeidet man mämlich jeglichen Ihruck mo betrachtet das frische Object ohne Deckglas, so sind imerhalb der eprithelial-kiornigen Zone Theilungen und bogenförmige Verbindungen der feinsten Nerrenfasern doch mverkembar. Andrerseits aber streben einzehe Fäserchen auch wieder so entuchieden gegen manche der Birnzellen, dass ein Uebergehen in solche Elemente mir wie friiher doch aurh vorhanden zu sein scheint.

*) Vergl. Fig. 44.

**) A. a. O. S. 122 .

***) Archiv f. Anat. u. Physiol. 1850, S. 174.

†) Lehrbuch der Histologie, S. 57, Fig. 3̈1.

it) Man vergleiche gegenüber meinen mehr schematisch gehaltenen Figuren die streng nach der Natur durchgefiihrten Zeichnungen in der Abhandlung F. E. Schulze's: Sinuesorgane der Scitcur linien bei Fischen and Amphibien, Archiv f. mikrosk. Aunt. Bel. 6. 
Fasse irle daher die Einzelwahmehnmmgen zusammen. so liesse sich die Tor-

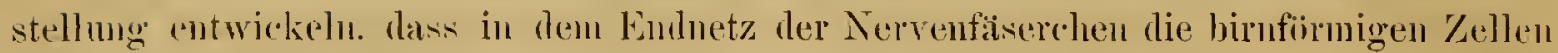
mit einem feinen Ansinufer wurelı.

I.l, habo seiner Zeit*) berichtet, dass bei Lota z'ulgar is von den Terven des Seitenranals welche in "Nervenknijpfe" ansehwellen, sir.h zuvor norh Stämmrehen ablïsen kïnnen,

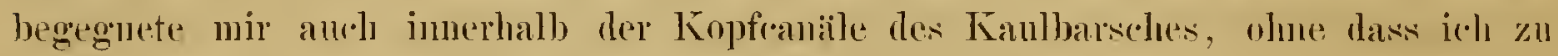
sagen wiisste, wo mul wic diese Nerven emden.

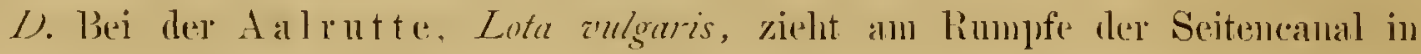
der Substanz der Lederhant numuterbrochen hin; ron Stelle zu Stelle, in ziemlichen Abständen, schieben sich die Knochentinnen ein, in deren șohutz der Nervenknopf liegt. 1)as Skeletgebilile zeight in der Form nach der Lainge des Canals leichte Abänlermugen, erscheint jedoch immer nerade nuter dem Nervenkuopf etwas ankgebancht. Knochenkörperchen fehlen in der Substanz ler Rinne so grut wie in den Sohnupen und man darf wohl die einzelne Knochenrime als eine umgewandelte Schuple amsehen **).

Ihe Nervenknöpfe in den weiten Räunen der Kopteanäle ersoheinen, was ich schon fribler angab, fiirs freje Ange und in lebenlen Znstande, wie wasserhelle Körperchen oder man möchte beinahe sagen Bläschen. An den mit Sorgfalt heraus-

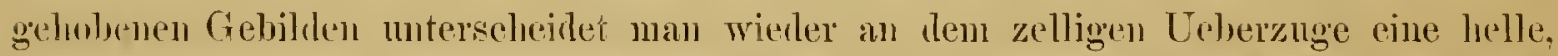
ans langen eylindrischen Zellen bestehenden Randzone nud eine Art Mittelfeld, dersen Elenente ron oben gesehen, sich als rumblohe, dicht zusammens.hliessemle grössere Zellen darstelhen, von leicht kirnigem, zartem und blassem Wesen. 1)as Heraustreten der noch dunkelrandigen Nervenfasern ans der bimlegowebigen, das 13lutgefässnetz tragenden Schicht in die epitheliale Lage ist su dentlich wie bei Acrina.

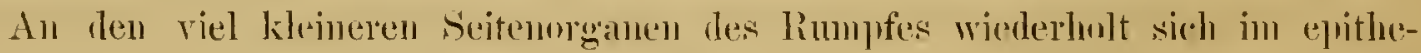
lialen 'Theile die Tremung in Mittelfeld und Randzone ***). Letztere nimmt lexhelt

*) Alchiv t. Anat. ul. P’ys. 1850, S. 175 .

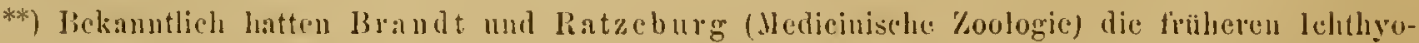
logen sebon bekannt gewesenen Schuppen dieses Nisches iberseluen. Iel miachte den neneren Beschreibungen beifitgen. dass die schuppen keineswegs trei in Gruben der llant liegen, sondern sie sind in der substanz de Lederhat geborgen. 1)er stock des Coriuns bildet je ein Griibcheu, das

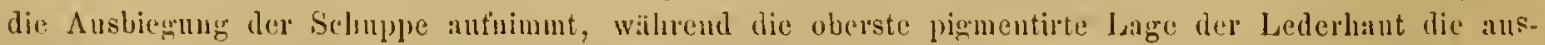

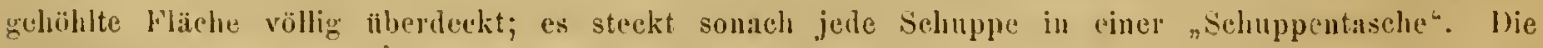
Einzelsohuppe hat die lorm cines zierlichen tiefen Schibschehens.

***) jig. 40 . 
den Anschein einer feinkïnigen Lage :u, aber das Zusehen bei starker Vergrösserung lehrt, ilass sie aus langen, feinen, granulären Zellen von Staljform besteht *). Blickt man anfmerksam mit Tanchlinsen auf die Oberfliche der noch zusammenhängenden St:abchen, so lisst sich eine charakteristische, aber änsserst feine Zeichnung rrkemnen, bestehent ans regehmässig und dicht sich krenzenden Linien, etwa vergleichbar der bekannten Terziermng des Deckels der Taschemuhren. Fasst man seitlirh abstehende Stïbehen scharf ins Ange, so will es scheinen, als ob die Zeichmung dureh eine Art Endkijppehen oder P'lättchen der Stäbe der Rimlenlage erzengt werde. Weitere Aufkliimg vermochte ich einstweilen dariber nicht zu erhalten.

Auf dem Xlittelfelde sind he. Besiehtigmng ron der Fläiche ähnliche Strichelchen zn crkemen, wie bei Acorina mul werden wohl ebenfalls anf Härchen onler Borsten der Zellen zu beziehen sein.

Auch bin ich im Augenblicke dariiber unsicher geblieben, wie es sich mit den Mündmngen des Seiteneanalsystems verhält. Man sieht am fristhen Thiere neben der Seitenlinie einen, hiäufig zwei weissliche oller gelbliche Puncte, auch wohl drei, letzteres namentlich nach hinten zu. Ihre Vertheilung von Stelle zu Stelle an der Seitenlinie kam sofort den Gedanken herrorrufen, dass es die .,Poren" der Seitenlinien sind, und unter dem Mikroskop weisst sich auch der Pnnct als eine Oeffumng in der Epidermis ans. Im Bereiche des Konfes fehlen die Poren rbenfalls nicht, sind aber zahlreieher und obsehon im Ganzen anf die Bahnen der Kopfeaniile beziehball, stehen sie inch anch wieder zerstreut an Stellen, welehe weit ah von einem ... A.hleimeanal" liegen. Dasselbe zeigt sich aneh am Rumpe. Sind mun alle diese P'uncte wirklich die Ansmiindnugsstellen des Seitencanalststems. su miissten dessen Haupthahmen zum Theil lange Rïhren in die Lederhant absenden, die sich alsdam als Poren iffinen. Wahrscheinlich ist aber, lass es sich um grosise becherorgane handelt.

Beziiglich der Frage, ob die Seitenorgane der Kunchenfisehe metamerisch am Rumpfe anftreten, mächte irh noch die Bemerkung anshliessen, dass mir die Lintersuchung ron Salmenbrut diese Ansicht zu bestätigen scheint. Winzige, noch mpigmentirte und mit grossem Dottersack rersehene Fischchen zeigen an ler Seitenlinie etwa 30 Simneshigel: sie sind so rertheilt, dass je eines nmmittelbar hinter je einem Septum intermuseulare zu stehen kommt, mithin imner ein sitiick rinem Wrirbel-

*) Fig. 41, c. 
abschnitte entsprirht. Fs sind alle diese Sinneshiigel noch freie Seitenorgane, bestehend

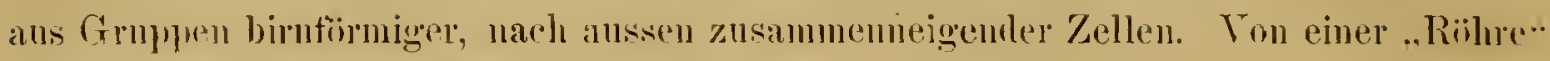
ist bei dieser Gattung nirhts rorhanden.

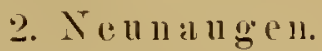

Die drei Alten: Petromyoon Plancri, Pitromyzon fuciatilis und Petrommzon marimu, scherinem, was bisher nirlit genaner beachtet wurde, in der Form und Ansbildung der Knofornuben luml Seitenorgane Verschiedenheiten an sich zu haben.

Au dem kleineu Neun auge, P. Planeri, hat Langerluas a nachgewiesen, dass hier ansser den Kopforuhen eine Hanptseitenlinie vorhanden ist nut norh melnee Sebenlinien, wovon die eine sich his zum Schwanze forterstreckt.

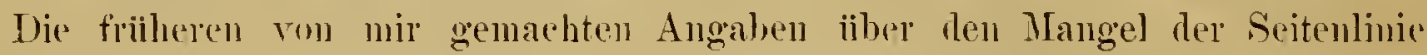
bezogen sich auf das Flussnenuange, P. Anzintilis. Indem ich jetzt ein frisolues grosies Exrmplar auf die "Poren" von nemem hesehe. vermag ich ansser jenen des Kopfes zwar den Anfang einer Seitenlinie zu erkennen, am oberen Rande des Kiencukorbes ler, bis zur Hïhe des rierten Kiemenloches, allwo der letzte Hiigel sichthar ist. Sind nm wirklich norh weitere ,Seitenorgane" vorhanden, so mörhten sie nicht mehr auf Hiigeln, somblern anf dem Haehen Corium stehen mud somit der Eyidermis allein angehiiren.

Schlägt man die Schriften der besten Irhtlıyologen nach. so erhält man den Findruck, dass sie aulh nielit gliicklicher iju Auffimden gerlarliter Grebilde gewesen sind. V. Siebold \%. B. bemerkt ganz allgemein fuir die Gattung: Die Hant der Lampreten ist olne Seitenlinie; am Kopf sind versehienlene Reihen von Hautporen angeblacht, welche vielleicht die Seitenlinien ersetzen ${ }^{* *}$ ). Näher änssepn sich Heckel mul Kner: "Dic Seitenlinie ist nicht sichthar, von Kopfeanälen gewaht man hingegen eine Reihe von Poren hinter mul iiber dlen Augen; fermer den bis gegen die Oberlippe sich fortsetzenden Suborbitalast und die quere Hinterlauptsanastomose"***).

Wieder anders sind lie Terhailtnisse bei der Seelamprete, $P$. marimus. Hiel sehe ich ansser rlen Kojfgruben, welehe in bestimmten lieihen sich verheiten, Poren nach oben vom Kiemenkorb; damn in ziemlicher Entfermmg rom Kiemenkorb, nahe an Riirken, eincn weitern Hiigel; ferner unterhalb der Kiemenlöcher finde irh

*) Untersuchungen iber Petromyzon Pluneri. Berichte ib. d. Versamml. d. naturf. Gesellsch. zu Freiburg i. Br. Band 1.

$\left.{ }^{* *}\right)$ Die Silsswasserfische in Mitteleuropa. Leipzig 1863.

***) Die Süsswasserfisehe der österreich. Monarehie, Leipzig 1858. 
ahermals S-_! solcher Hiigel in muregelmässiger Reihe stehend. Heckel und Kner seheinen au'h keine grössere Zahl gesehen zu haben; denu sie sagen, naehdem sie ..tas Srstem der Kopfeanïlec heschrieben haben, welches sehr dentlich sei, dass man ansserlem noch eine ziemlich regehnaissige leihe ïber den Kiemenlörhern und einige irregulär stehende an Vorderriicken und an den Seiten des Rumpfes gewahre, gegen das Sehwanzende aber fehlten sie gäinzlich.

Die histologisthe Untersuchung der Kopf- oder Epithelgruben der Neunaugen bleilst eine schwierige. trotz aller Hilfsmittel der jetzigen Methode.

Nachdem ich vor langer Zeit und nur voriibergehend die Gruben des $P$. Aluritutilis auf den feineren Ban geprift. hatte, ohne Frhebliehes finden zu kiinnen, hat Jahrzehute hernach M. Schultze*), denselben ein eingehenderes Studium gewidmet. Von Nenem ist dieses von Langerhans**) geschehen. weleher die anatomische Kenutniss der Organe bei $P$. Planeri wesentlich förderte.

An Exemplaren der Scelamprete, $P$. marinus, welche in Weingeist gelegen hatten. erinnerte mich das Anssehen der am Kopfe, vor und hinter den Angen stehenden Organe, in manchen Stiicken an die gleichen Gebilde bei Menopoma giganteum. Sie grenzten sich an der ganz unverletzten Hant als einzelne Hiigel ab und ihre Oeftumng hatte die Gestalt einer gleichbreiteu, rorn und hinten zugerundeten Längsspalte. Nach Entfernung der Epidermis zeigte sich die Lederhant ebenfalls in einen rundlichen Hïgel erhoben, mit einer Fintiefung an Gipfel, welche wieder die Form einer Längsrinne hatte. Sie giebt dhe Teranlassung zu der Längsspalte in der Epidermis $\left.{ }^{* * *}\right)$.

Ein solcher Hügel sammt umgebender Lederhant mikroskopisch geprïift, elweist sich als eine Erhöhnug, welche im histologischen Ban der Lederhaut vorgebildet ist und nieht etwa erst dureh das Liegen in Weingeist entstanden. Die Ziige des Bindegewebes nämlich, in der Ebene der Lederhant sich einfaeh krenzend, streben, die einen strahlig, die andern ringförmig zusammen, un den Hiigel zu erzengen und der Mittelpunkt dieser Ziige wird zum Gipfel des Höekers.

Schnitte durch die ganze Haut und den Simneshiigel gefiihrt, lehren, dass die Rimne des Hiigels ron einem Zellenwulste †) ausgekleitlet wird, der im Zusammen-

*) A. a. 0 .

**) A. a. O.

***) Fig. 12, b.

†) Fig. 10, d. 
hang mit den Elementen der Epidermis steht und sich dur h ein gewisses Inukleres Wesen vou der muliegrenden Epilermis abhebt.

Gerade anf diese Zellen laalse ich natiirlich las Angemmerk im Besonderen gerichtet, so gut als dies M. Schultze und Laugerhans thaten. Der ersterc nemt die \%ellen selu schwer isolirbar; sie seien feiner, langgestreckt. schmal: es kïmen wie zu ummittelbarer Verbindumg. Fasern aus der 'Tiefe heranf, wolche aller Wahıscheinlichkeit nach Nervenfasern seien. Der zweite Beobarhter findlet. dass fragliche Zellen eine lango'estreckte Rirnform haben und sich durch einen grösseren Kern ans-

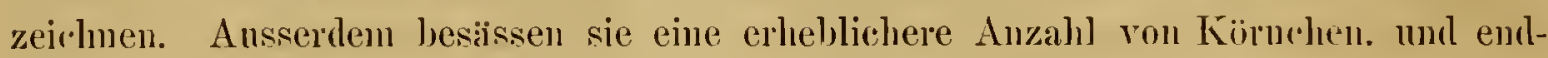
lich sässe dem alogestuzten Ende ihres peripherischen Fortsatzes ein fuines Haar anf.

Was nun die eigenen Wahmehmungen ambelangt, so scheinen an den Weingeistpraiparaten die Zellen wenig in iluer Natur sich von den gewiihnlichen Epidermiszellen der tioferen Lage zu entfernen. Ftwas mehr ist dies der Fall an Hantstiirken, auf welche dopluel'hromsanres Kali eingewirkt hat. Die Zellen, lang mul sclumal. sind kïniger und oftmals mit einer Vacuole oder Secretraum versehen; auch erhält man den Eindluck wie wenn sie weicher wären, als die gewöhnlichen Zellen der Epidermis. Mitmuter meine $i \cdot h$ ancl gesehen zu haben, dass ans dem freien Ende en versehieden langer: stumpfendigender Faden hervorstand. Doch muss ieh ansdricklich erwïhnen. dass in den meisten Fiallen aneh gar nichts ron einem solvhen Haar oder Faden zu erblicken war.

Noch gerade vor Abschluss gegenwaitiger Mittheilungen erhielt ich ein friselıes Exemplar von $P$. fluziatilis lind nahm abermals die Kopforuben rur, olne Anwendung von Reagentien. Anch jetzt zeigte sieh, dass die Zellen, welche die Furolı: des Simmeshiigrels ansfiillen, versehieden seien von den Zellen der limgebung und zwar insofern, als sie etwas könniges an sich haben und weicher sint. dahei anch sehr innig zusanmenlaingen. Damu glanbe ich noch bezigglieh der cigentlichen Gestalt derselben walıgenommen zu hahen, dass sie sieh marh vorno stahantign vor-

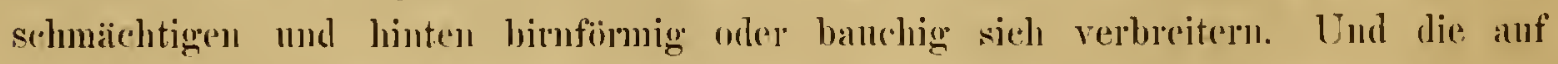
solvbe Weise eingeleitote Achnlichkeit mit dent Randzellen der Seitenorgane dor Knochenfisehe setzt sich anch noch dirrin fort, dass der verlaingerto unul verengate vordere Abschnitt der Zelle in soiner Substanz sich scheilet in eine lelle. wie lomogene Achse, wohl lichtiger gesagt, in einen mit linhter Substan\% erfiillten Hohlraum und in die unsehliessende. Wand. Unul als den Endtheil dieses Mbsehnittes ler Zello meine ich anch wierler eine zarte, diesmal spitz zulaufende Borste bemerkt zul habelı (Fig. 11). 
Dic Epridermis, indem sie gegen die Papille des Simesorgans heraufgeht und in lie Rimne oder Grube sich hineinzieht, verdiunt sich nicht bloss, sondern es bleiben anch in der Decke der eigentlichen Papille zwei charakteristische Elemente zuriick: die Kolben und die Kömehenzellen, wobei die ersteren noch etwas friiher :lufhören als die letzteren*).

Trotz der blassen, zarten Beschaffenheit wie sie den Nerven von Petromyzon iiberhanpt eigen ist, lisst sich doch mit Sicherheit ein verhältnissmässig dickes Nervenbiindel erkemnen, welches gerade anfsteigend, unterhalb der Mnlde oder Furche entlet. Fine eigentliche Verbindung der feinen letzten Ansläufer mit den „Simneszellen" kann man sich aber anch hier nicht zu ïberzengender Anschannng bringen.

\section{Bindegewebe.}

\section{Lederhaut der Neunaugen.}

Der senkrechte Schnitt durch die Lederhant**) zeigt zunächst die bei niederen Wirbelthieren weit verbreiteten bekannten Verhältnisse, indem die wagrechten Lagen des Bindegewebes von aufsteigenden, senkrechten Ziigen durchbrochen werden. Bevor sich an die Lederhaut der Fettkörper anschliesst, zieht in zusammenhängender Lage

*) Fig. 10 .

**) Es ist für mich, der ich seiner Zeit in Würzburg aus dem Main die Seelamprete Petromyzon marinus, nur als Seltenheit kennen gelernt hatte, und in Tübingen gar niemals zn Gesicht bekam, denn im Neckar steigt sie bloss bis Heilbronn auf, hier am Niederrhein eine nene nnd interessante Erscheinung, dass mir in den vicr Jabren meines bisherigen Aufenthaltes in Bonn jedesmal im Frülijalı cinige lebende Seelampreten von den Fischern zugetragen wurden. Dadurch ergab sich Gelegenheit, eine Kölperbeschaffenheit des geschlechtsreifen Männchens zu bestätigen, welche, wie es scheint, Panizza bisher einzig und allein beobachtet hat. Ans dem trefflichen Werke: v. Siebold, uber die Süsswasserfische vou Mitteleuropa, erfährt man nämlich, dass der genannte italienische Anatom, welcher im Laichen begriffene Seelampreten ans dem $\mathrm{P}_{0}$ und Ticino beschrieben hat, dem brïnstigem Nännchen eine gallertartige längs des Rückens verlaufende Hautfalte beilegt und die beiden Rüickenflossen dicht hintereinandel stehen lässt. Leider kanu ich die hier in Bonn fehlenden Memorie del Istituto Lombardo, welche die Ablandhung Panizza's bringen, nicht einsehen. Da aber ans den Worten v. Siebold's bemerklich ist, dass er sclber solche geschlechtsreife Individuen nicht vergleichen konnte, so mag gesagt sein, dass ich die Dinge allerdings so finde, wie sie Paniza darstellt. Bei dem einen Individuum z. B. ist der scbarf hervortretende Wulst, welcher in der Höhe des ersten Kiemenloches beginnt und sich nach der ganzen Länge des Rückens erstreckt, in senkrechten Schnitt $\tau \mathrm{mm}$. hoch; bei einem zweiten Stiuck $1 \frac{1}{2} \mathrm{~cm}$.; bei einem dritten Thier sogar $2 \mathrm{~cm}$. In dem 
das Pigment hin"). Es ist auffallend, dass die Hamptmasse des l'igmentes, sowohl das dunkle als anch das weisse, anstatt wie somst gewöbnlich nach oben, hier nach unten verlegt ist. Das weissglänzende Pigment besteht ans den irisirende Flitterchen, die hier von ziemlicher Grisse sind.

Betranthen wir die oberste Lage der Leslerhant, nach Entfermung der Ejpidermis, so lässt sich schon jetzt, besser im senkrechten Schnitt, bemerken, dass sic nicht rein eben, sondern wellig-höekerig ist. In den Vértiefungen stehen gern feine Oeffunngen, welche bei Ansicht von der Flïche unt muter gewisser Bulenchtung dnukehandig erscheinen kïmen. Dass es wirklich Oeffumgen orler Spuiltrhen sinrl, lässt sich ans den Licht- und Schattenverhailtnissen bestimmt erkennen. In vielen derselben hebt sich noch ein mitunter glänzendes Piinctehen ab, das nicht etwa anf ein kleines kernartiges Gebilde zn beziehen ist, somfem anf den Lurchschnitt oder das abgerissene Eude eines Fäserchens. Indem wir andere Erfahrungen wegen der Bedentung desselben zu Rathe ziehen, darf uns wahrscheinlich werden, dass es einerseits um ein nervöses Endfäscrehen sich handeh möge, andrerseits einfach nm einen feinen Auslïutere einer Protoplasma- oder "Häntehenzelle“.

Stellt man nänlich ein bischen tiefer unter die Oberfläche ein. so treten neben der bleibenten Gitterzeichnumg, welche von dem System der Spältchen herrihurt, grö̈sere rundlinhe Kerne mit je einem Kernkörperchen in Sicht $\left.{ }^{* *}\right)$. Bei ciniger Aufmerksamkeit gewahrt man bald, dass kein Kern frei daliegt, vielmehr alle ron einem feinkiinigen Protoplasma ungeben sind, das hiillenlos ist md in Fortsätze sich anszieht. Indem rlie letzteren sich mit gleirhen Auslïnfern nächstgelegener Balken oder Plättr.hen vom l'rotoplasma verbinlen, cntsteht ein Netz-oder 13 alkenwerk ron Zellsubstanz, in dessen Knotenpunten die Kerne liegen. Es ist das Bild, welrhes man seit Langem nnd zuerst aus einer Art anfgehellten Partic des Coriums, ants der Hornhaut, sich zolr Auselhaumug gebrarcht hat.

Ueber den Ort, wo in der Lederlant diese hiillenlosen P'rotoplasmaziige orler

ersten Falle bestand das Innere des Wulstes lediglich ans einer Whiebnug der Musculatur des Stanmes; bei den zwei anderen kam aber jenseits dieses Muskelstranges noch eine bindegewebige, 4 bis 8 mm. hohe Hantschwarte von weichem Bindegewebe hinz, ahnlich jenem, welches die Hautwucherungen der mämlichen Wassersalamander im Friblijalır erzengt. Es schien mir anch, als ob in dem Bindegewebe allsser den Blutgefässen noch einige grössere Lymplıginge zugegen wären. An den Thieren mit starker Entwicklung der Hantschwarte standen die zwei Rückentlossen unnttelbar hinter einander, so dass sie sich :n der Wurzel uahezu berihuten (vergl. Fig. 3i, Fig. :38, Fig. 39).

*) Vergl. Fig. 1.

**) Fig. 35. 
verästigten .Zellen" liegen, kinuen Sh-hnittränder der Lederhant, besser norh Zujfnripharate deutlichen Anfschluss geben. Es sind die grisseren und kleineren Spaltliicken der homogenen streifigen Biindel, welche die Zellen beherbergen mud ans denen sie anch bei gelegentlir.her Frweiterung des Spaltrammes heransfallen.

Zu den sogenannten Spiralfasern der Bünde\} hahen gedachte Zellen ebenfalls eine nithere Beziehung $\left.{ }^{*}\right)$. Un die letzteren, welche bekanntlich nur die reif-

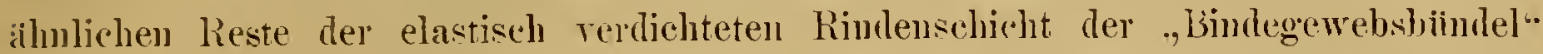
rorstellen. erstrecken sich die Ziige protoplasmatischer feinkiiniger Substanz mit den eingestreuten Kernen als Theile einer zarten hantartigen Schicht.

Die färbenten kïperlichen Elemcute der Pigmentzone liegen in gleichen Ausbreitungen ler kürnigen Zellsubstanz; loch lässt sich dies wegen Ueberfiillung nit Pigment reniger klar in der eigentlichen I'igmentschicht der Haut sehen, als in den einzelnen eingereprengten l'igmentzellen.

2. Matrixzellen des Bindegewebes und das Cuticulargewebe.

Iie híllenlosen Zellen, deren vorhin Erwähnung geschah und welche sowohl die streifig-homogenen Ziige des Bindegewebes durehsetzen als anch in jenen grö̈seren Liicken und Gängen, durch welche die Blutgefässe und Nerven anfsteigen, in ebenfalls dichterer Menge zugegen sint. miiss'm mis als die urspringlicheren mul wenn man will lebendigeren Elemente des Binlegewebes gelten. Ton ihnen stammen die homogen-streifigen Lagen her, anch wemn die Zellen durch ihr Protoplasma zu einer körnigen Substanz vou häntiger Ansbreitnng zusammengetlossen sind.

Desshalb halte ich es denn anch fiir passent. die Bezeichnumg Matrixzellen, welche ich für las, was Antle spöter die chitinogene Schiclit in der Hant der Arthropoden hiessen, gebranchte, anch fiir hesagte Zellen in der Lederhant der Wrirbelthiere in Anwendung zu bringen. Ja es hat sich dureh gegenwärtige Studien hei mir die Ueberzengung befestigt, dass an der Hant eines zarten Arthropoden, insofern sie ans der chitinogenen Zellenlage, d. l. Matrix, und der abgesonderten noels diinnen C'nti"ula besteht, gewissermassen das Schema vorliegt, nach welchem wir anch die zusammengesetztere Lederhaut eines Wirbelthieres, mi den Ban des Bintegewebes iiberhanpt, zu beurtheilen haben. Es wurlen diese Verhältnisse mud die einschlägigen

${ }^{*}$ ) Vergl. Fig. 1; Fig. 14; Fig. 36. 
Thatsachen schon anderwärts und in Weiteren ") von mir bespnochen, woranf ich mir zul relweisell gestatte.

Wer den Fragen nach dem Bau des Bindegewebes und der Terwandtschaft zum Cuticulargewebe gefolgt ist. Wird jetzt begreiflicher finden, wic es kommen konnte, dass die einen Benbachter mit Entsehiedenheit gewisse Zellenlagen .. Epithel" nannten. während sie Andre den Bindesubstanzzellen zurechneten. Und ferner. wie sich im Terfolge der Gugensatz anshilden komnte, dass die Finen die Cutienlarlagen dem Fpithel zuwieses, die Anderı deu Bindegewebe.

Die von mir vertretene Auffassung. wornach die Cuticularlag*en zum Bindegewebe gehiircu, grimdete sich wesenthroh daranf, dass die abscheidenden Zellen ohne Literbrechung mit erhten Binlesubstanzzellen zusemmenhängen. Diese Erkenntniss wurde vornehmlich gewomen durch Heranziehnug der Arthroponten in den Kreis der Untersuchung und Alles was später durch Andre nud mich ïber den greichen Geugenstand bei WVibelthieren bekamt wurde, liess sich durohaus als Bekriftigung einer solchen Betrachtmugsweise ansehen.

In Laufe gegenwärtiger Arbeit habe ich aber, ansicer den schon an Fischen gewomenen Beobachtungen noch Wahrnehmungen an den Larven von Pilobates fuscus g’emacht, welche mir die völlige Gleichheit dieser geweblichen Beziehungen zwischen Arthropoden nud Wirbelthieren darthum ${ }^{* *}$ ).

Man betrachte nämlich etwa den Saum der Selıwanzfosse der noch fusslosen

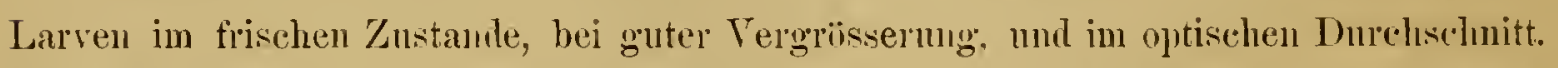
Es zeigt sich ein Bild, welches durchans anf dic Cuticularlagen und deren Matrixzellen bei Arthropoden passt. Die Lederhaut, wel-he den Gallertmantel begrenzt, ist noch sehr dimu und einfach längsstreifig, das heisst geschichtet: ron gleichem Aussehen, wie sirh eine ebenso dicke Cuticula eines Arthropoden darstellen wiirde. Unterhalb dieser Lederhant nun hebt sich eine Zellenlage ab, genan ron der Beschaffenheit, wie sie so oft an der Matrix del Cuticula bei Arthroporlen gesehen wird. Innerlalb eincr wie zusammenhängenden, feinkïnigen protoplasmatischen

*) Vom Ban d. thierischen Körpers, Tübingen 1864. z. B. S. $39 \mathrm{ft}$ - - Dic ron mir dort auch ausgesprocheue Ansicht, dass die Matrix oder Hypodermis der Haut der Gliederthiere, sowoht der epithelialen als auch der bindegewebigen Lage in der Haut der Wirbelthiere zusammen gteichansetzen sei, findet eine weitere Stitze in eine Thatsache, deren Kenntniss wir v. Mojsisovics verdanken. Nach diesem Forseher können bei Lumbricineu die Blutgefisse bis in die mittleren Partieen der Hypodermis gelangen (Sitzungsber. d. Akad. d. Wissensch. in Wien, 1s77. Kleine Beiträge z. Kenntniss der Anneliden).

**) Fig. 20. 
S.hicht stehen mämlich garosie rundliche Kerne in solchen Abstinden, dass man wie ich es vor Jahren that. ron ..Zellenterritorien" sprechen kam. Die Lage nimmt sieh ejithelartig ans und wiurien die Zellenleiber schärfer sich von einamler abgrenzen, so wirrde von einem wirklichen Elithel die Rede sein kömen* ${ }^{*}$.

Und gleiehwie ferner bei Arthropoden ron der Natrix der Cuticula weg die "Zellen" sieh einwärts erstrecken, als Balken und Blättchen, un in Zusammenlang zu treten z. B. mit den Zellen des Fettkïr'pers, so begeben sich auch hier bei der Larve de's Pilobates von der protoplasmatischen Schicht. welche unterhalb der Lederhaut hinzieht, rerästigte ..Zellen" in die Substanz des Gallertmantels hinein. Der Leib dieser feinkümigen Zellen ist so zart, dass er im frisehen Znstande fast unsichntbar ist, während der Kerıı leicht in die Angen fällt.

Immer an dem gleichen Object laisst sich anch erkemnen, dass die besagten Zellen es sind. welche die Wand der Bluteapillaren erzeugen. Den äusseren Contonr derselben nïmlieb. der die Kerne enthält nud von weirherem. feinkinnigem Aussehen ist; wähnend der imneren schärferen Linie die Bedeutung einer cuticnlaren Abscheidung zukommt. Somit mürlite ich es als nuzutreffend bezeichnen, wem man die Anlage der Blutcapillaren auf ein ..Epithelialrohı" zuriickfiilıren will; die bildenden Zellen gehüren vielmehr den Iiatrixzellen des Bindegewebes an.

Anch manche der fasrigen Züge des elastischen Gewebes in dem Gallertmantel mögen allem Anschein nach ebenfalls unter Betheiligung dieser Zellen entstehen, in Form von Abscheidnugen im Innern des Zellenleibes.

Fassen wir demnach das Ergebniss des bisher Vorgetragenen zusammen, so erscheinen uns die Zellen der Bindesubstanz als Ballen oder l'lättchen feinkiornigen Protoplasmas. ohne bäutige Abgrenzung, von blassem. zartem Wesen. Nahe zusammengerïrkt, in Hiächiger Ausbreitung, stellen sie feinkïrnige Schnichten das, mit Kernen, welche in Abstänten eingestreut sind. Nach Einwirkung von Härtungsmitteln kimmen sich Kern und Protoplasma unter dem Bilde des Ejithels abgrenzen. Dasselbe gesehieht auch schom in frisehen Zustande, nachdem bereits cuticulare $A b$ scheidungen rings um die Zelle erfolgt sind. Dahin gelı̈irt z. B. die zellige Lage,

* Die Larve von Pelobates fuscus zeigt, je nach der Belenchtungr über den ganzen Kürper hin, die Schwanzflosse mit inbegriffen, einen schönen bläulichen schiller. lch sehe, dass dieses Blan nach seiner Entstehung gleichznstellen ist dem blauen Schiller, welchen das Tapetum fibrosum im Ange der Wiederkäner, des Rindes etwa, erzengt. Das Blau rührt her von der Lederlıant, dessen lockig geschwungene und in feinste Fäserchen aussplitternde Elemente durch Interferenz den Schiller hervorrufen. Dieser wirkt alsdann durch die zarte, helle Epidermis ebenso hindurch, wie am Tapetum fibrosum dureh die pigmentfreie Epithellage der Lamina pigmentosa die Glanzfarbe dringt. 
welche zu oberst in der Lederhaut der Fische und Amphibien vom Aussehen mud der Art (cines Epithels angetrotten wird *).

Einen epithelialen Charaktur nehmen diese Matrixzellen anch dort an, wo sie unter einer hellen homngenen Seheiıle, sei es ler Nerven mud Ganglienkugeln oler jener der Mnskehı liegen. Schon anderwärts habe irh ansgefiihrt, dass unterhalb des Neurilemms und Saronlemus der Wirbelthiere eine Lage rorlanden sei. wel-he mit der Matrix der C'utirula an der iusseren Hant eines Arthopoden iibereinstimmt. Ientlich grehïrt anch hierher z. 13. dic protoplasmatische Srohicht sammt Fermen unter den einzehnen Schalen orler Kajseln der einfacheren und zusamuengesetztren Nervenendkolben (P'acini'srhe Kïrperchen). Anch in den Tymphrämmen kiinnen narh lieagentien die "Zellen“ die Zeichnng eines Epithels geben. So ist mir jetzt auch

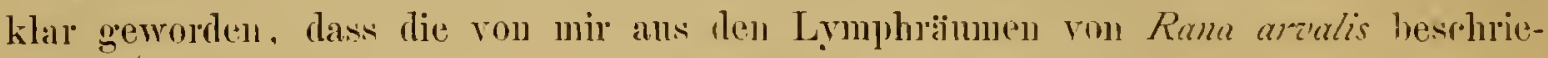
benen und abgebildeten Elemente**), welche zmm 'Thoil inmerhalb iler hindegewehigen Substanz, zum Theil frei auf der Oberfläche lagen. den greichen protoplasmatischen Zellen einzureilien siml.

Jene protoplasmatischen Zellen, welche sirh in die Tiefo des Bindegewebes, z. B. der Lederhant erstreckesı, wiirte aurh, indem wil die ahgeschierlenen lomogenstreifigen Lagen, ms wrgilenken, als ein zusammenlaingendes Hantchen- orler l3alkenwerk erscheinen. In liumster Entfaltmo erzengen lie protoplasmatisehen Elemente ein Netz vou Stralılenzellen.

Sinn in Bindegewebe Fett, Schlem, l'igment oder ambre Stoffe in Folm von Kïpperchen, Kiigelehen oder krystallinischen Gebilden zugegen, so sint es immen die obigen liiilenlosen Zellen, welche diese Materien enthalten. Die mit fettartiger Substanz erfiilten Zellemhanfen, welche die zwisohen den Samenkanalchen liulaufenden Blutcapillaren im Horlen der Simgethiere und Reptilien besetzen. zählen nieht minder zu der Art der Zellen, wie sie hier bespurohen wurden.

Nachlem mir das Verhalten der protoplasmatiseluen Zellen in der Lenlerhant

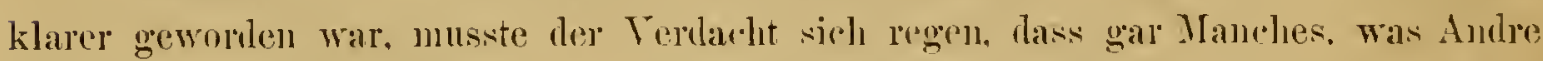
und irls selher friiher als eine einzige grössere \%elle angesehen haben, in Wirk-

*) Man verglejche z. B. die Mittheilungen und Figuren, welehe ich von dem Gewebe des Flossensaumes eines Triton gegeben habe. Arehiv f. mikrosk. Anat. Bd. XII (1876), Taf. XXI, Fig. 3.

**) Auure Batrachier d. deutschen Fauna, Boun 1877, S. 136, Taf. IX, Fig. 93. 
lichkeit nur 'Theil rines Fachwerkes war, an dessen Wand erst ein oder mehrere protoplasmatische Zellen gleich einer endotbelen Ansscheidung sieh finden.

Zunitchst sind es die grossen Fettzellen ans dem Bintegewebe der Fische, auf wolche sich die ausgesprochene Vermuthung lenkte. Bereits Schwan") hat solche Fettzellen aus der Schäilelhöhle einer jumgen Plïtze mit Absicht als Muster einer klaren Zelle abgebildet. Wenı ich aber jetzt die zusammenhäugende Fettschicht, welche bei Pitronyzon unter der Lederhat hinzieht, priffend ins Ange fasse, on lisst sich bemerken, dass die eigentliche Zelle aus dem Protoplasmahäuf(hen sammt Kern, beide nach aussen ron der Fettkugel gelegen, vorgestellt wird: wiihrend die „Membran" eine "apselartige Abgrenzung des Fachwerkes ist, welches als Zellenabscheidnng zu gelten lıt. Ist etwa an gehärteten Präparaten die Fettkugel herausgefallen, so ist das Terhalten der ,..Membran" als Grenze des Fachwerkes und demnach in unmittelbarem Znsammenhang mit cliesem ganz deutlich. Tritt gerade nur Ein Kern mit Protoplasma in Sicht, nach anssen die scharfe Abgrenzmig der Wabe, nach einwärts der grosse Fetttropfen, so kommt das täuschende Aussehen der „Fettzelle" zu Stande. Erimnern möchte ich hierbei noeh, dass ich vor vielen Jahren, als mir diese Gebilde noch als echte Fettzellen galten, doch sehon da mud dort .zwei Kelme" dentlich unterschied"*), eine Angabe die jetzt erst ihre Erklärung findet.

Anstatt des Fettes kann eine eiweissartige Substanz die Räume erfïllen, wie dies z. B. in der Haut des Phyllodacty/us europaz'us der Fall ist, woriiber ich naihere Wittheilungen gegeben habe $\left.{ }^{* * *}\right)$. Doch ist das Bild jetzt in bestimmterer Wreise so zu fassen, dass die blasigen, Kerne einsehliessenden Räume nicht selber und an sich die Zellen sint, sondern viehmehr ein Schwammwerk, das an seiner Innenseite die Kerne mit den protoplasmatisehen Auskleidungen besitzt. Und diese sind wieder das Vorall.gehende; das festere, .faserige" Geriiste ist das Nachfolgende.

Treiterhin musste ich an ein anderes Gewebe in diesem Sinne denken, an die Substanz der Chorda dorsalis von Fischen. Ich hatte vor Jahren den Gallertkïrper der Riickensaite z. 13. des Stiin's an. grossen runden Zellen bestehen lassen. Ohne selber mnterdessen zn einer Nachlprifung gekommen zu sein, hat juingst Gütte

*) Mikrosk. Untersuchungen iib. d. Uebereinstimmung in d. Structur u. d. Wachsthum d. Thiere u. Pflauzen, 1839, Tal'. IlI, Fig. 10.

**) Haut d. Siisswasserfische, Zeitsclur. f. wiss. Zool. 1850, S. 5, Anmerk.

***) Leber d. allgemeinen Bedeckungen der Amphibien, Bonn 1876. S. 104; Hautsinnesorgane d. Urodeleu, Morphol. Jahrb. Bd. II, Tif. XXXI, Fig. 30.

†) Archiv f. mikrosk. Anat. 1878 . 
in Wort und Bild eine Darstellung des Banes gegeben, wie sie genau mit der mir jet\%t vorschwebenden Vermuthung stimmt. Was ich friiher, dem Anschein folgend, Zellen nannte, sind, wie Götte hervorhebt, nicht Zellen, sondem Begrenzmngen eines "Fachwerkes", zu welchem aber eine "l'rotoplasmaschicht mit eingestrenten Kernen" geliört.

Ferner glanbe ich uiber das Schwellgewebe der Muschelthiere, des:en Ba!l sehr versehieden beurtheilt wird, einige Aufklïrmg geben zu kömen.

Vor Jahren wurde von mir") berichtet, dass im Körper der Najaden (-tnodontir \%. B.) an den vou Muskeln freien Gegenden ein grossmasehiges Gallertgewebe vorherrschend sei; und so veransehaulichte**) ich dem anch ein Fachwerk, in dessen Knotenpuncten die Kerne liegen. Im frischen Zustande zeigt das Gewebe anch ein Ansselien, als ob es aus hellen Blasen zusammengesetzt wïre. Flemming ${ }^{* *}$ ) hat sich mu, fussend auf ausgebreiteten genauen Studien, mit Bestimmtheit dahin ansgesprochen, dass diese blasigen Abgrenzungen Zellen seien. Kollmann $\dagger$ ) lingegen, nicht minder grïndlich und ebenso mit allen Hilfsmitteh der Untersuchmo die Bindesubstanz der Acephalen zergliedemd, lisst die Rämme nicht als "Zellen" gelten, sondern erklärt sie für Querschnitte von Lacunen. Noch ele ich die Sache selbst von Neuem angesehen, vermuthete ich bereits, dass es mit diesen "Schleimzellen" im Körper der Muscheh wohl eine öhnliche Bewandtniss haben werde, wie mit den Gallertzellen der Chorda dorsalis.

Zur Nachuntersuchung standen mir bloss in Weingeist auf bewalnrte Anodonten zи Gebote, aber schom der erste Schnitt dureh den Yantel liess keinen Zweifel iibrig, dass die Dinge nielit anders sind, als wie in Gallertgewebe der Ruickensaite $\dagger$ ). Man hat es mit einem Farhwerk zu thm, dessen "blasige" Hohluäume an der W"and protoplasmatische Iläutehen mit Kornen tragen. Flemming liess friilor die Kerne einfach imerhalb der blasigen Hohbriume liegen; spöter schiencu sie bhm so

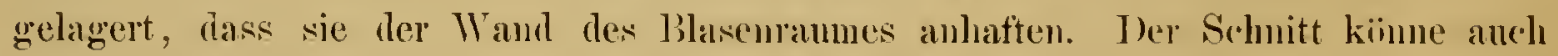
derart fallen, dass der Kern von der Blasenwand abgedriingt werde und num nitten in Inlalt der Blase zu sterken seheine. 1)as den Kern momgebende Protoplasma hat Flemming keineswegs ibersehen: el gedenkt desschben als einer feinen, blassen,

*) Lehrbuch d. llistologie 1857 , S. 102 .

**) A. :.. U. S. 109, Fig. 55.

***) Ueber Bindesubstanzen u. Gefinsswandung bei Mollusken. Habilitationsselnift 1871; Bintesubstanz und Gefïsswandung in Scluwellgewebe d. Muschehn, Arehiv f. mikıosk. Anat. Bt. 13.

t) Die Bindesubstauz d. Acephalen. Archiv f. mikrosk. Auat. Bi. 13.

胡 Fig. 45. 
melulecht begrenzten Substanz. Alle diese Augaben, sowie die begleitenden Ablildungen sind durchaus maturwahr wud doch kann ich der Dentung nicht vollständig heistimmen. Denn die , "zelle" sehe ieh nur in jener Protoplasmaschicht, welche den Kern in sirli birgt. Ihe ,Zellenmembran" ist Theil des Fachwerkes, dem der Zellenlrib, läutig ansgebreitet, anliegt. Zu je einen Kerne gehört iibrigens cine ansehnliche. Flaiche von l'rotoplasmaschicht, worauf schon hindentet, dass die Kerne weit anseinander stehen. Das gewihnlichste ist auch, dass nu Ein Kern im Bereiche eines solchen Hohlraumes liegt und sonach wieder, ganz wie an der Fettzelle, das Bild :ivh anf vine Zelle mit Membran bezieheu lässt.

Ich möchte sonacll Kolluann in dem Puncte Recht geben, wem er rlen Maschenriumen die Betlutung vou Zellen abspricht; hing'egen muss ich Flemming* darin beistimmen, wenn er die Kelne nicht in die Substanz des Balkengewebes verlengt sehen will, sondern in die Rïune himein. Und nach meiner Auffassmug kleideu diese protoplasmatischen Zellen endothelartig die Wraben aus.

Noch erlaube ich mir ins Gedichtuiss zuriuckzurufen, dass ich bei Auneliden, Artluopoden, answer den Matrixzellen des Hantpanzers, anch an andern enticularen oled bindegewebigen Schichten die gleichen Tatrixlagen schon vor Längerem nachgewiesen habe. So z. B. am Gehiru, an den Baurhganglien, an den Nerven*). I)ort zicht sirly unter der glashellen Srhicht des Nenrilemms ein Stratum dicht feinköniger Substanz hiu, in welohem klare, rundliche Nuclei eingebettet erscheinen. In den meisten Fällen kommt es nirlut zu eig*ntlichen zelligen Abgrenzungen der granulälen Substanz um die Kerne herum; mitunter jedoeh nimmt die Lage ein nahezu epithelartiges Ausschen an. Ich habe schon danals erkanut mol mit Bestimmtheit ausgesprochen, dass gedachte Schichit nach Ban und physiologisehem Terhalten jener als Matrix des Hantuanzers unterschiedenen, entspreche.

Aueh bei Mollusken labe ich die Anwesenheit der gleiehen Matrix an bindegewebigen lagen vor Kurzem angezeigt. Unter ıler homogenen Hant z. B., welehe bei Narktschuerken die Leibeshoilıle und die Bluträune begrenzt, liegt eine Schicht. mit Keruen und Protoplasma, als deren Absrlieidungsproduct die homogenen Lageu angeschen werlen iliiffen ${ }^{* *}$ ).

Fig. 1 ; Fig. 9.

*) Vom Bau des thierisehen Körper's, 1864, S. 215; Tafeln zur vergl. Anntomie, Taf. IX,

*) Hantdecke u. Schale d. Gastropoden, Arehiv f. Naturgesch. 1876, z. B. Taf. X, b. 


\section{Lickensystem der Bindesubstanz.}

Die wiederholte Betrathtmo des spalt- mil Liickensystems. der frïhler sugenamten . Binlegewebskiingerchen“. veranlasste mich anch die Frage niiler ins Ange zu fassen, auf weldhem Wege dem eigentlich die nervïsen Elemente ans der I.erderhant in die Ejidermis gelangen. Geselieht dieses durd, Canaile und Oeffinugen eigener Art ofler etwa durdh Gïnge, die somst schom vorgetbildet sind? Lis liess sich an der Lerlerhant hieriber eine bestimmte Antwort erhalten, wie sie zmm 'Theil in obigen Tharlegungen bereits ansgedriickt ist.

Das von der Ephilermis entbliste, aber somst muverletzte Corium des Petromyzon zeigt anf iler wberen Flärdhe dieselben Liirken und Spalten, wie der senkinente Schnitt. Die Liicken sint groisser unt kleiner, krenzen sich nach rerschiedenen Lagen, und ïfinen sidh frej zu Tage*). Ton den feinen Fortsetzungen onler Gäingen der Liicken der Thiete gehen viele nach oben ebenfalls frej aus. Beildes sind dir Wege, durch welche die in Endfäserchen ansplitternden Nerren ans dem ('orim herans in dic Ejidermis dringen kimmen. Somards sind keine eigens zun Zwerk des: Durchlassens besimmte Oeffinmgen vorhanden, sondern das Spalt - mul Liickensystem. dessen Wïnden die protoplasmatischen Zellen anliegen und relches anch die ron letzteren erzengten Umhiilhungen der Nerven und Bhutgefisse enthält, kann zиm Durchlass der Tervenelenente dienen.

Das gleiche Sichöftinen der Syalträmme nach when liess sieh ferner an Larven von Salamandra maculosa wahnehmen, welche frisch in doppeldnromsanres Kali geworfen, dam in Iteingeist anfluewaht worlen waren. Am mugeshlagenen freien Rande der Lederhaut erseheinen in klarer Weise die Spälthben in Form ilichtstehender, an der freien Flïchic ansmiindenter Caniiile.

Es ist mir in hohem Grale waluwcheinlich geworlen, dass durch gedachte Oeftimugen himbureh noch andere Terbindungen statt haben. Man nimmt hisher an, dass die sich auffanzenden Enden der untersten Epidemiszellen einfach zwischen

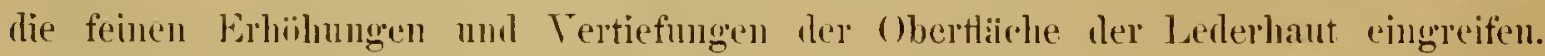
Ich halte, wie schon oben vorgebraldit wurde, jetzt dafiir, dass ein Theil der zarten

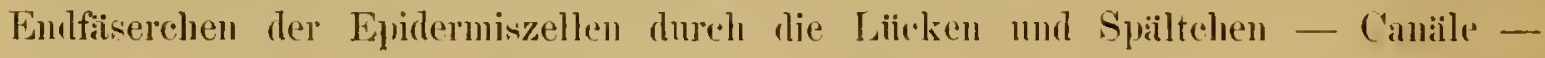
himdurch mit den ebenso zart gewordenen Ausfranzungen der motoplasmatischen Zellen der Lealerhant zusammenhaingen mingen. Sonach wibde sich die Tremnung 
zwischen ejuthclialem mo Bindegewebe mo durch die homogen-streifigen Lagen vollziehen, währond die Zellenleiber unter einander in Verbindung bleiben.

Was im Obigen iiber Oeftumngen an ter frejen Fläche tle verhältnissmaissig. wojchen Lederhaut angegeben wurde, stimmt mit ilem iibercin, was jeh vor langer Zeit am Knochengewebe beobachtet habe. An Knochen ter Amplibien mul Fische lässt sich im frischen Zustande die Ausmiuntung der Spältchen an der freien Fläche, wegen Starrheit des Gewebus, leieht wahmehmen, woriber irh z. l3. im Lehrbuch der Histologie berichtet labe*).

Derjenige. weleher lebende Amphibien hält und beobarhtet, gewinnt die Veber-

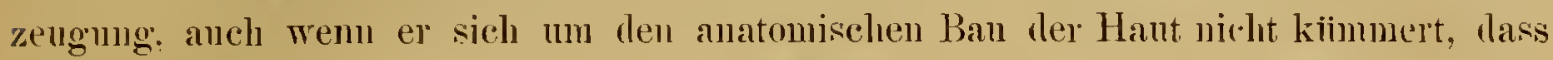
durch die Hautrlecke bei diesen Thieren Wasser von anssen in den Kïper anfgenommen werden miisse. Dureh die neuen Erfahrungen iiber ein System vun Inter-

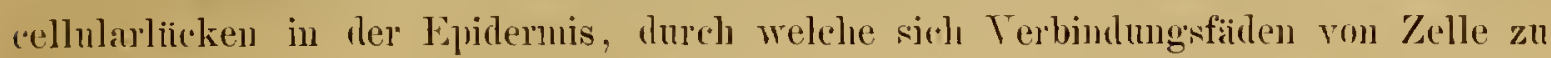
Zelle hinspannen, sowie durch den Nachweis, dass anch anf der Obertiärhe der Lederhant die Spaltrainme des Bindlegewebes sich offnen, kimmen wir in immer hestimmterer Weise fragen, welches dem die Wege seien für die Aufuahme des Wrassers mol dessen Weiterfiilnmm. Meine Torstellumg auf Gromd des anatomischen Banes der Hant ist die. dass Wasser von aussen in die Intercellulargainge der Fundermis gedrungen, sei es dur.h einfache, oder remu man will, molerulare Lurchtriuknng, sei es dureh schlon ebenfalls vorgebildete Oeffinugen, von da in die Spaltrimme des Bindegewebes, also in die Anfünge des Lymullugefïsssystemes weiter gefiilnt wird. Hielsei erlaube ich mir anch anf die Mittleilungen hinzuweisen, welche $i \cdot c_{1}$ an einem anderen Orte**) iiber die Lymphriaume unter der Haut der Batrachier und ihrer Bezielımng zur Wasseraufinahme vorgelegt habe ${ }^{* *}$ ).

*) S. 159 .

**) Die allgemeinen Bedeckungen d. Amphibien. Archiv t. mikrosk. Anat. 187f (Separatausg. S. 106). - Ueber Wasseranfnalıme in den Körper und Abgabe durch die Niere bei Mollusken habe ich ausführlicher gehandelt in dem Aufsatz: Znr Anatomie und Physiologie dej Lungenselmecken, Archiv f. mikrosk. Anat. Bd. 1.

***) Eben im Begriffe, gegenwärtige Blätter an die naturforschende Gesellschaft in nalle ahznliefern, erhalte ich die Schrift: Will. Pfitzuer, die Schleimzellen in der Epidermis der Larve vou Salamandra maculosa. Inauguralablıandlung, Kiel 1879, in welcher die im Titel genannten Elemente einer sehr eingehenden Priffung unterzogen werden nach Bau, Lebenserscheinungen nud Bedeutung. Hierbei wird denn auch der Verfasser aul die im Obigen angeregte Frage gefülnt nud beantwortet sie in einem andern, ja entgegengesetzten Sinne. als es von mir versucht wurde. Pfitzner, unter der Anleitung Flemming's arbeitend, kenut ebeufalls das "System communicirender Spalten" in der" Epidermis und nimmt an, dass die Schleimzellen ein Secret liefern für diese Intercellularriüme und 
Zum Schlusse dieses Abschnittes mörlite ich noch aussprechen, dass thie neu ermittelten 'Thatsachen keinen Anlass meben von rlen Darlegungen. wie inh sie beziiglich des Bindegewebes in der Schrift iiber den Ban des thierischen Körpers. Thibingen 1862, gegeben habe, alozureichen. vielmehr finde ich mich nuch mehr in jenen Auffassmigen bestiirkt, welche ich dazmmal, namentlich gestiitzt anf rergleirhent listologische Erfahrungen, gewommen hatte.

Und sie lassen sich kurz folgendermassen zusanmenfassen.

1) Ths Bindegewebe besteht ans den Matrixzelleu und den ron den Zellen abgesthiedenen homogenen Schichten und Balken. 1)ie Matrix- oder Bimlesubstanzzellen sind hiillenlose Ballen orler l'lättehen von feinkïrnigem Protoplasma, je einen Ker"u umschliessent; sie treten anch häufig anf unter ilem Bille stark rerzweigter Figuren; ferner können sie Hächenhaft znsammengetlossen sein und stellen ilann Häntchen von feinkïrniger protoplasmatiseller Substanz dar, mit eingestrenten Kernen. Solehe Lagen sind es, welche bald mit. bald olne Härtmug die Zeichnnmgr voun Epithelien und Zellenlaafen an sich haben kiimnen. Zus Tomgrenzung von Hiihlnngen. wie der Bhut- mol Lympheapillaren, oder ron Schlämehen. welche mit festerer sinbstanz erfillt sind, so z. B. Ner Nerven und Muskeln, ersiheinen sie in rolurartiger Anordnumg. - Tie Lỵmphräume der Bimdesubstanz nud die serösen Hühlen des Körpers stimmen im Ban durch Begrenzmog homngener Bindesubstanzlagen mol Anskleidung mit protoplasmatisehen Zellen - Embthel — so iiberein. dass man anch sagen kömute, alle Hohluämue des Binlegewebes, das ganze Spalten- mul Liirdensystem, sind .,seröser Natur".

2) Durrh die abscheidente Thätigkeit der Iatrixzellen entstehen jenc substanzlagen, welche man als homogene Hänte, Blätter nul Balken les Bindegewerbes zu bezeichnen pitlegt. Jas Schema ron dem Terhalten der Iatrixzellen zum ahogeschiedenen Stoff gibt die diinne Hant eines zarten Arthropolen. Die dort anftretemite C'nticularlage ist der Aufang dessen, was in dick'n Binlegewebschlichten sich nicht

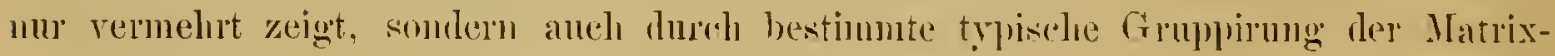

zwar zu dem Zweck, dass das Eindringen des Wassers wie dureh eine Art Einsalbung redhudert oder wenigstens beschriukt werle. Noeh fïgt der Verhsser aumerkungweise bei, dass er, was mit meinru Walurnchmungen stimmt, neine directe Communication der Intercelluluraiume mit spaltramen im Bincegewebe beim erwachsenen Thiere" glanbt beobachtet zu haben. Liesse sich vielleicht nicht vermuthen. dass das Sceret der Schleimzellen, in die Intercellulargainge gelaugt, dazn diene, durch Zumischung zu dem von aussen anfgenommenen Wasser, diesem solort den Charakter reinen Wassers zu nehmen und es der Lymphthiissigkeit anzuähulichen? 
zellen sich verdickt und rermanchfacht. Danach entsteht Bindegewebe in lamelliiver Form, oder in gefleclitartiger Anordnung. hier lockerer, dort fester zusammengefiiigt.

3) Die C'uticularschichten und die sogenamite Grundsubstanz des Bindegewebes gehiiren zusammen, sind eins und dasselbe.

t) Vielen der Matrixzellen kommt bei liöheren und niederen Thieren die Frihigkeit zu. sich zusammenzuziehen: sie besitzen Contractilität. Enthält ilır Protoplasma l'igment eingeschlossen, so tragen solche Zellen den herkimmlichen Namen Chromatophoren der lindesubstanz.

\section{Inhaltsverzeichniss.}

I. Epidermis.

1. Zellen wit fadigem Inlıalt

2. Netzartige Zeichnung der obersten Sehicht .

3. Porensaum

4. Driisenzellen gewöhnlicher Art

5. Driisencellen besonderer Art

6. Kiolben

i. Kürnchenzellen

5. Strablenzellen wit und ohne Pigment

II. Becherförmige Sinnesorgane.

1. Fische

2. Laven der anurea Batrachier

III. Seitenorgane.

1. linochenfische

2. Neunaugen

IV. Bindegewebe.

1. Lederhaut der Neunangen

2. Matrixzellen des Bindegewebes und Cnticulargewebe

3. Liickensystem der Bindesubstanz Erklärung der Abbildungen 


\section{Erklärmug der Abbildungen.}

\section{Taf. VII.}

Alle Figuren bei stärkerer Vergröisserung.

Fig. 1. Senkrechter Sclunitt durch die Hautdecke von l'etromyzon murinus.

" Eigentlı̈mliche Körperehen oben in des. Epidermis :

b Kolben;

c Körnchenzelle;

d Protoplasmazellen in der Lederlant;

$e$ Nerven;

$f$ Selicht der Fettzellen.

Fig. 2. Aus der Eipidermis von Petromyzon fluvialilis, im frischen Zustande.

a Gewöhnliche Epidermiszellen, durch Ausläufer untereinander verbunden;

$b$ eine Schlein- oder Beeherzelle mit Cutieularsaum.

Fig. 3. Writsenzellen ans der Haut von Petromyzon marinus.

a. Epidermiszellen mit Drïsenöffinungen und in denselben die eigenthiimliehen Körperehen der Fig. $1 a$.

$b$ die in der Tiefe liegenden Uriisenzellen.

Fig. 4. Beelierzellen der Karausehe, cyprimus carassius.
Fig. 5. Stückchen Oberhaut des Petromyzon marimus von innen angesehen.

a Gewöhnliche Epidermiszellen;

b Kolben, fein fadig sich ausziehend;

c Körnchenzellen.

Fig. 6. Körnelienzellen des Petromyzon marinus fiur sich dargestellt und in theilweiser Veränderung dureh Reagentien.

Fig. 7. Kolben ans der Epidermis eines Weingeistexemplars von Petromyzon fluviatilis. Es hebt sieh dentlich eine quergefaltete Hülle ab.

Fig. 8. Kolben aus der Epidermis eines frischen Petromyzon fluviutilis, auf dessen Hant eine Mischung von schwachem Weingeist und Essigsianre eingewirkt hat.

Fig. 9. Epidermis von aussen des Petromyzon marimus.

a Oberste Lage mit dem aus Driisenzellen gebildeten Höeker;

b etwas tiefere Schicht; man unterscheidet zwisehen deu gewöhnlichen Epidermiszellen die Kolben- und die Körnclienzelleu vou der Fläche.

\section{Taf. VIII.}

Fig. 10. Durehselnitt eines Sinneshiigets von I'etromyzon marinus, missig starke Vergrösscrung. Weingeistexemplar.

A Lederhaut:

"l anfsteigender Nirr;

B Oberhaut:

b Kolben:

c Köruchenzellen:

d simesepitlel.

Fig. 11. Finige del Sinneszellen aus den kopf- 
gruben des Petromyzon fluriatilis isolirt. Starke Vergösserung, Osmiumsäure.

Fig. 12. Liopfgrube von Petromyzon marimus, geringe Vergrösserung, Weingeistexemplar.

a Epidernis, gegen einwärts abgehobeu;

b Hügel der Lederlant mit der Eintiefung an Gipfel.

Fig. 13. Stuck des Vorderkörpers von Petromyzon marinus, watürliche Grösse.

a Alige;

$b$ Seitenorgane;

c Beperlung der Oberhaut (Bau der Höcker siehe Fig. 9 anf Taf. VIl).

Fig. 14. Aus der Lederhaut vou Pelromyzon marimus.

a homogen-streifige Lagen:

$b$ die Protoplosmazellen dazwischen.

Fig. 15. Becherförmiges Organ des Cyprinus carassius, voin lebenden Thier genommen.

a auftretende Vacnolenbildung.

Fig. 16. Epidermis mit zwei Kolben von der Aalrutte, Lota vulgaris.

Fig. 17. Kolben aus der Epidermis von Lotu mugaris isolint und etwas gequollen.

a das Käppchen;

$b$ die Innensubstanz;

$c$ Fuss der Zelle.
Fig. 18. Eine Gruppe Schleimzellen desselben Fisches: sind durchweg von länglicher Gestalt.

Fig. 19. Käppclen und Innensubstanz eines Kolbe ns in andrer Ansicht, als es in Fig. 17 dargestellt erseheint.

Fig. 20. Sanm der Schwanzflosse der Larve des Pelobates fuscus; die Entstehung der Lederhaut versinnlichend.

a homogene Lagen der Lederhaut;

b) Matrixzellen;

$c$ Blatcapillargefäss.

Fig. 21. Ein grösseres der becherförmigen $\mathrm{Or}^{r}$ gane (nGeschmacksknospen") aus der Mundliölıle der Larve von Pelobates fuscus, von oben geselien; ist noch ganz iiberdeckt von der zusammenhängenden Epidernis.

Fig. 22. Dasselbe Organ von der Seite.

a Epidermiszellen (Deckzellen);

b Gruppe der birnförmigen Zellen.

Fig. 23. Ein kleineres solches Organ ans der gleichen stelle und von derselben Batrachierlarve.

$a, b$ wie in Fig. 22;

$c$ die Endstiftchen.

\section{Taf. IX.}

Fig. 24. Seitenorgane, freie, rom Rumpfe des Hechtes, Esox hucius: stärkere Vergrösserung.

" Epidermiszellen und Schleimzellen;

$b$ Pigmentzellen;

c Sinneshingel.

Fig. 25. Becherförmige Organe des Gaumens rom Hecht, Esox lucins, aus dem eben getödeten Thier genommen. Man nuterscheidet anf der Gipfelfläche des einen Mittelfeld und Randpartie.

Fig. 26. Ebensolches becherföruiges Organ, dessen Mittelfeld sich in bestimnter Weise zu sondern begiunt.

Fig. 27. Zwei der Mantelzellen eines becherfürmigen Organs, sehr stark vergrössert. a Fuss der Zelle;

$b$ bauchige Auftreibung mit Vacnole oder Secretraum;

$c$ stabförmig verengtel Theil;

$d$ zarte Endborste, ans dem Secretraum kommend.

Fig. 28. Beclierfömiges Organ des Gaumens von Acerina cermu, ans dem frischen Thier.

a Papille;

b Epidermis mit Schleimzellen im Profil.

$c$ das Organ an der Spitze trichterig eingezogen.

Fig. 29. Ein gleiches Organ, Gipfel ebenfalls eingezogen; die zusammenueigenden Encbor'sten sind sichtbar. 
Fig. 30. Zellen eines becherförmigen Organs von Cyprinus carassius durch doppelchromsaures Kali verändert.

Fig. 31. Epidermis von der Lippe einer jungen Karansche, Cyprinus Carassius.

a Zelle mit Härchenbesatz;

$b$ Schleimzellen, eine noch ohne, die zwei andern mit Oeffnung.
Fig. 32. Aus der Epidermis der Larve von Pelobutes fuscus.

a Zellen mit fadigem Inhalt;

$b$ Zellen mit Secretraum;

c Chromatophoren oder bewegliche Farbzellen.

Fig. 33. Zellen mit fadigem Inlalt aus der Epidermis der Larve von Hyla arborea.

\section{Taf. $\mathbf{X}$.}

Fig. 34. Stück Oberfläche der Lederhaut entblösst von der Epidermis, Petromyzon marimus.

a die freien Oefiuungen der Bindegewebslücken.

Fig. 35. Flächenansichl einer tieferen Schicht der Lederlaut, Petromyzon marinus.

a Protoplasmazellen.

Fig. 36. Spiralfasern des Bindegewebes von Petromyzon marinus.

$a$ die Protoplasma- oder Häutchenzellen.

Fig. 37. Hantwulst des geschlechtsreifen männlichen Thieres von Petromyzon murimes von oben.

Fig. 38. Derselbe Tlueil im Durchschnitt.

Fig. 39. Wieder der gleiche Theil von einem audern Individuum, im Durchschnitt. (Alle drei Figuren in natürlicher Grösse).

Fig. 40. Seitenorgan vom Rumpfe der Aalrutte. Lota vulgaris; Ansicht von oben. IIan sieht die Scheidnng des epithelialen Ueberznges in Mittelfeld und Randzone.

Fig. 41. Stuck eines Seitenolganes (Nervenknopf) aus den Kopfcanälen des Kaulbar'sches, Acerina cernua.

a Randzone; b Mittelfeld;

$c$ die Borsten.

Fig. 42. Zellen der epithelialen Lage der Seitenorgane, fiir sich dargestellt.

$a$ aus dem Nittelfeld, mit Borsten;

$b$ aus der Randzone (Acerina cerma);

$c$ ebenfalls aus der Randzone (Lota vulgaris).

Fig. 43 Stück eines Seitenorganes (Nelvenknopf) aus den Kopfeanälen von Acerina cerma, im optischen Schnitt nach dem frisclıen, kurze Zeit mit Osmiumsiture belıandelten Präparat.

a Nervenfaseru des "Kuopfes";

$b$ Blutgefässe;

$c$ ins Epithel aufsteigende, noch dunkelrandige Nervenfasern.

Fig. 44. Schnitt aus dem durch Osmiumsäure erlıärteten Nervenknopt vou Acerina cermua.

a Bindegewebige, die Nerven und Gefässe tragende Schicht; aus ihr erheben sich frei die abgerissenen Nervenfascru.

b Epitheliale Lage, hat sich grösstentheils abgrelöst.

Fig. 45. Alus dem Mantel von Anodonta;

( Bindegewebiges Fachwerk;

b Protoplasma- oder Häutchenzellen. 
Fiy $: 3$

Fig 1.3

Fig. 3.j
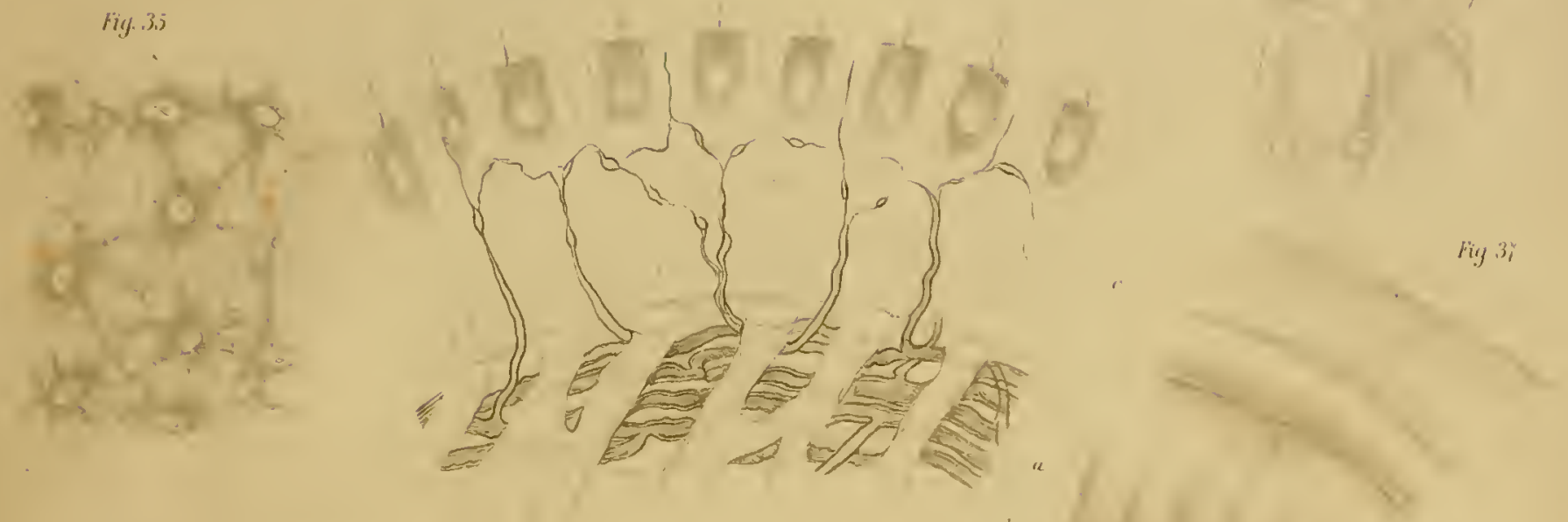

Fig. 41

Fiy. 4 ?

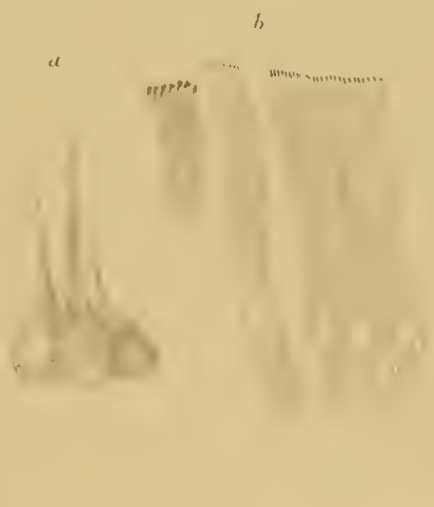

Fig. 39

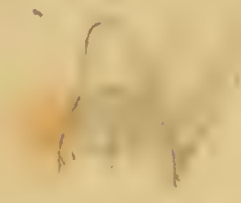

Fig 4

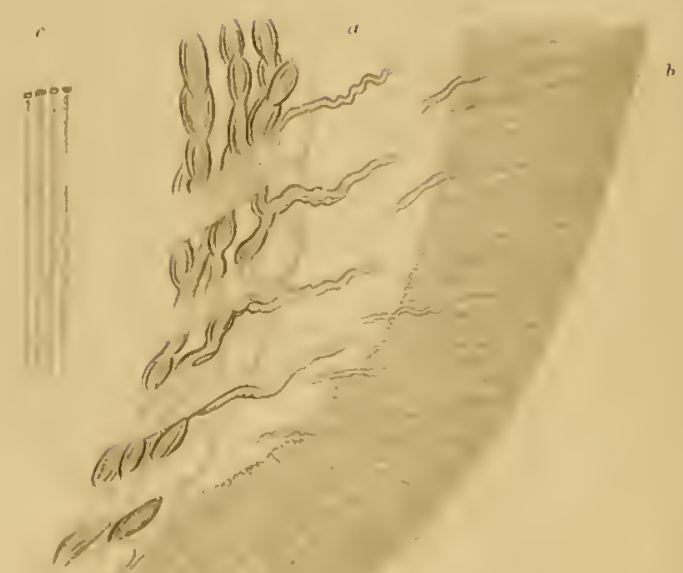

17

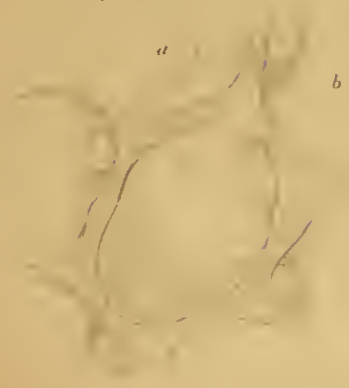

Fig. 39

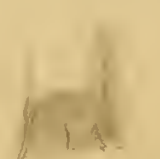



Fig. 1.

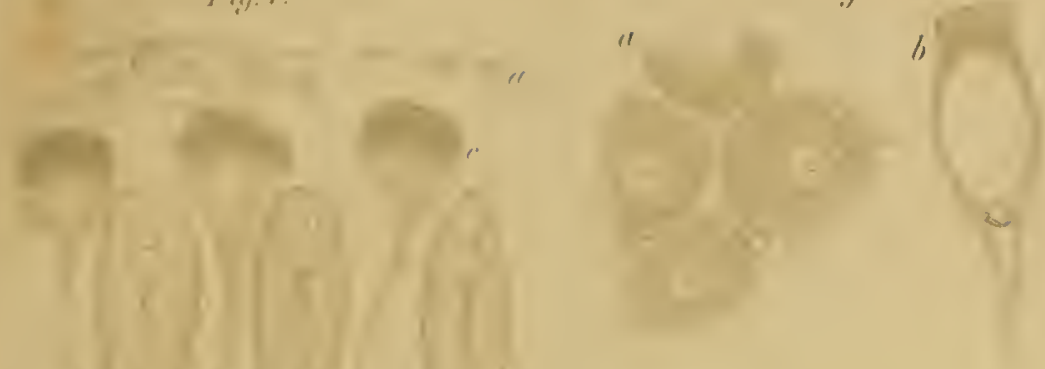

fig. . .
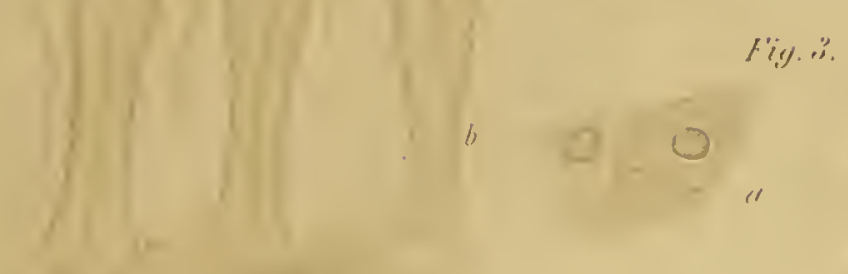
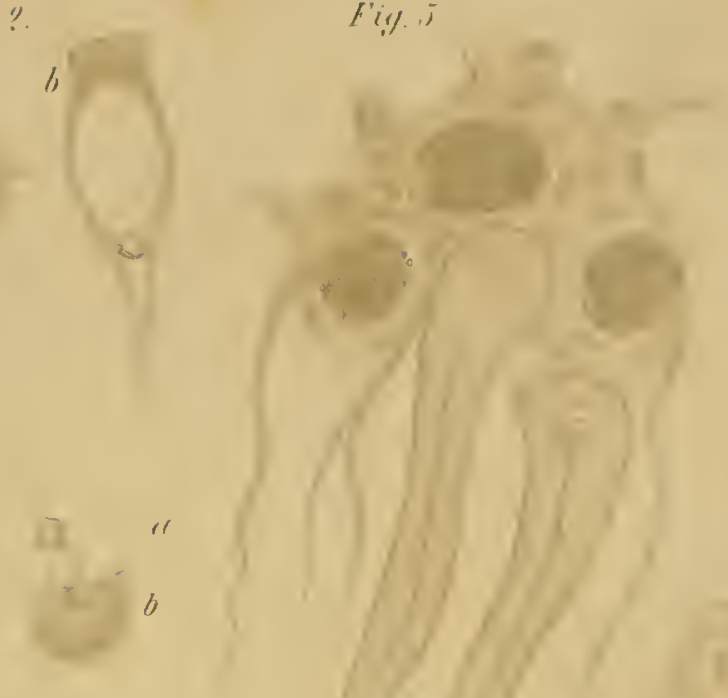

Fiy, i

Fig. :

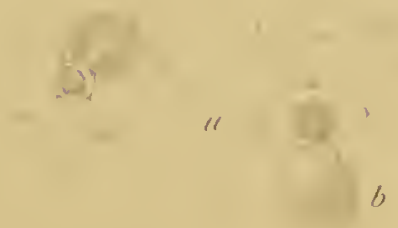

\section{Fig. 0 .}
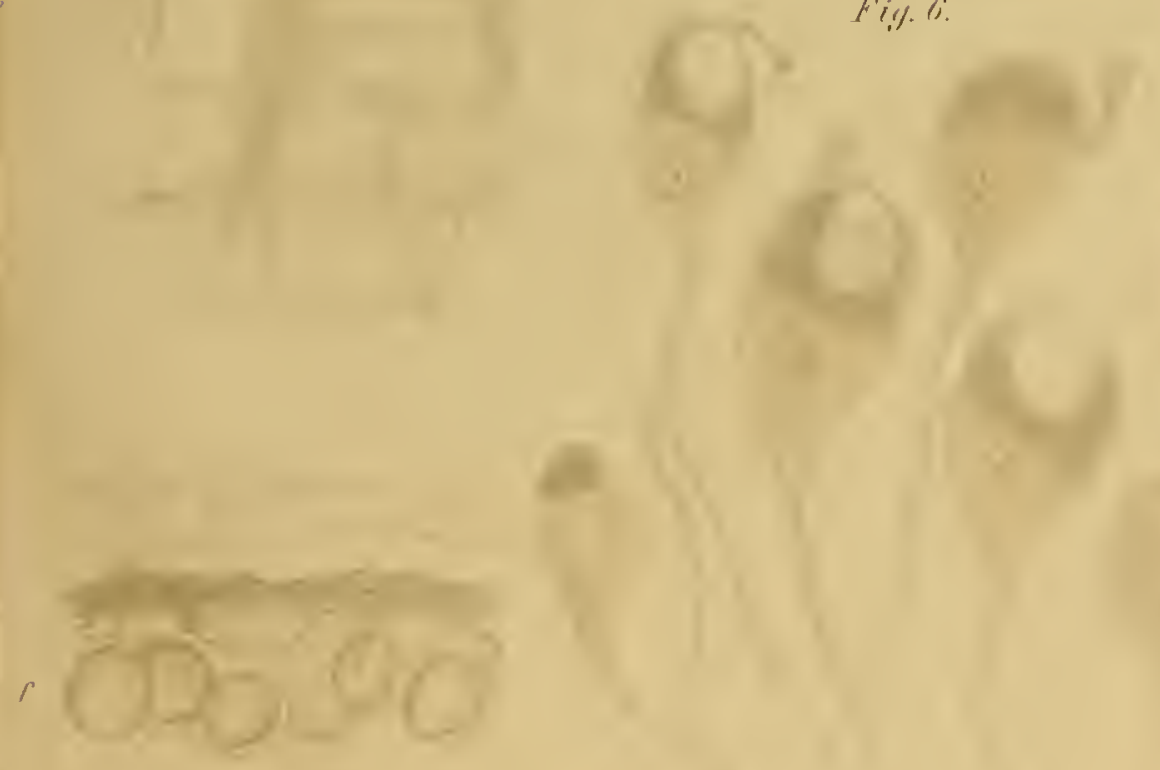

Fig. 4.

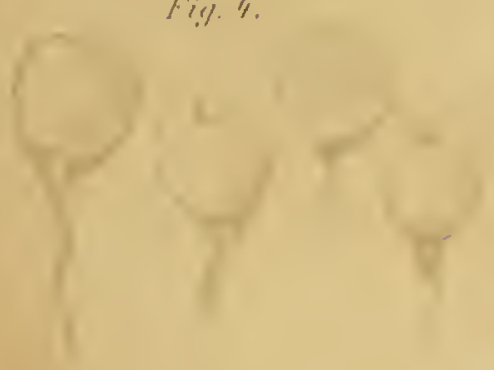

Figy.
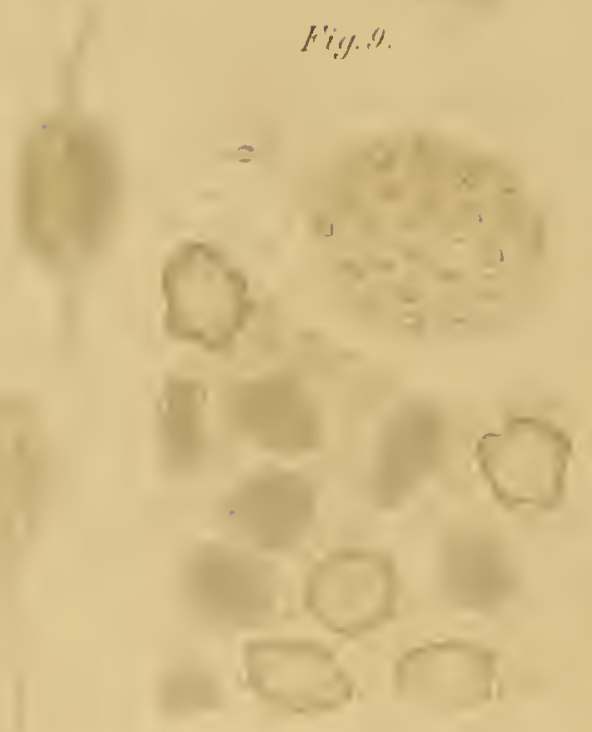

fig. s 
3 
tiy. $/ 1$

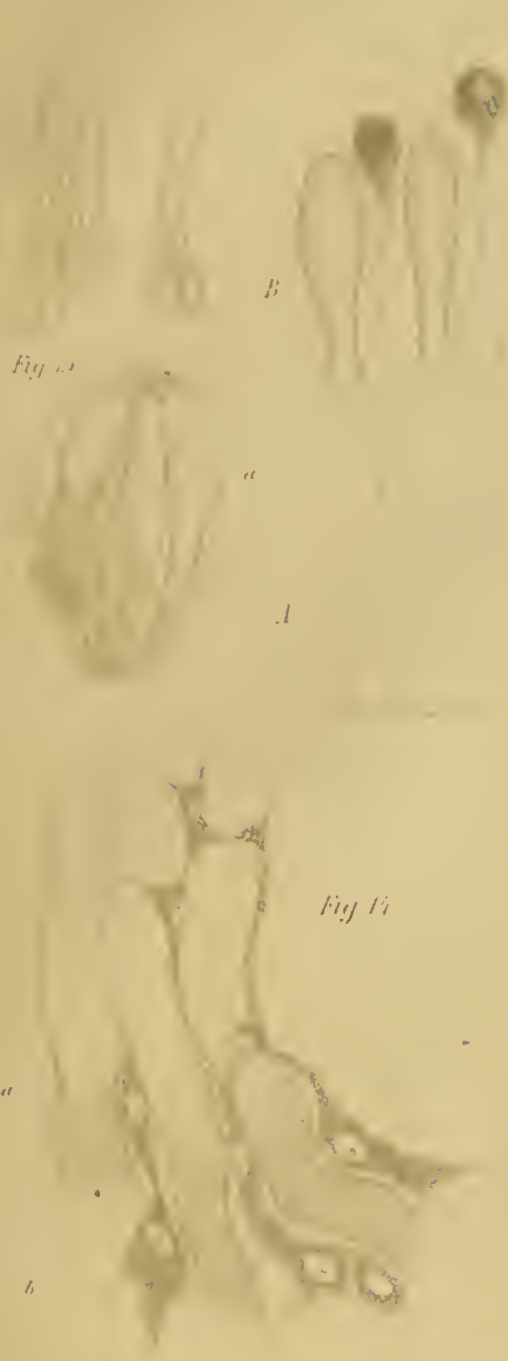

litg $9 ;$

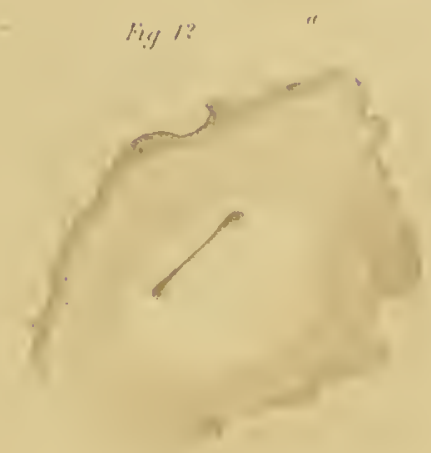

fig ".

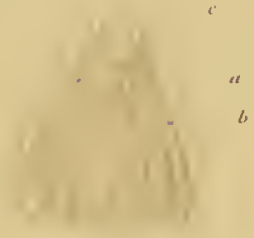

Vigf 1.3

fig. is

fig. I;

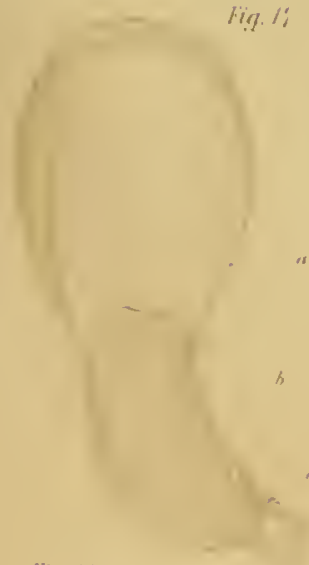

$x+2 x+1$

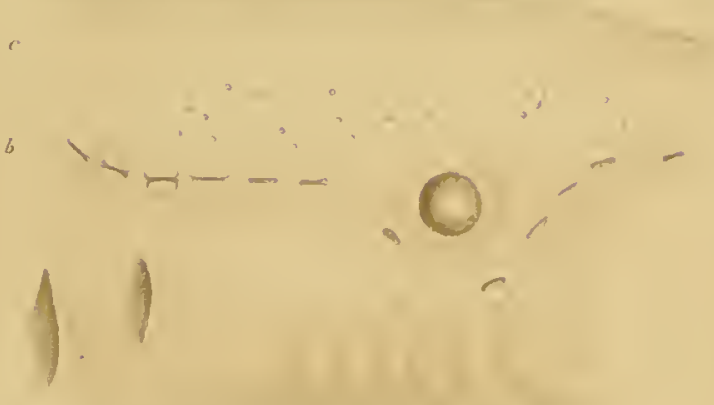

li, "II

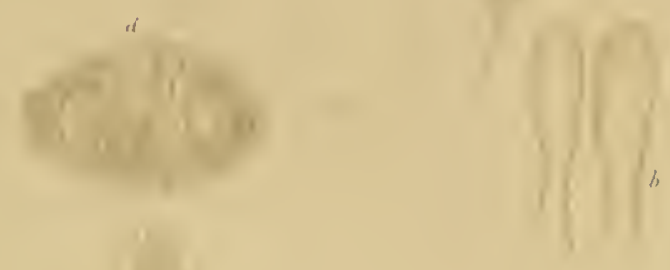

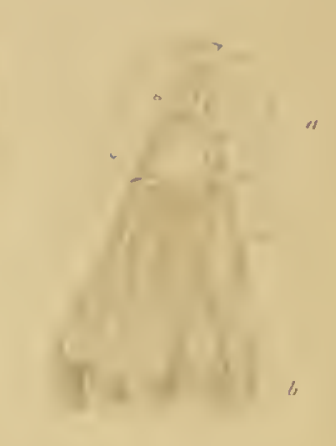

Fiy :!: if.

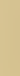

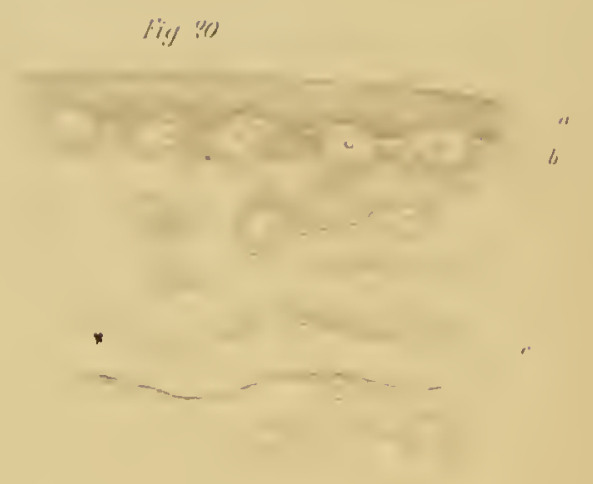

ligy II,
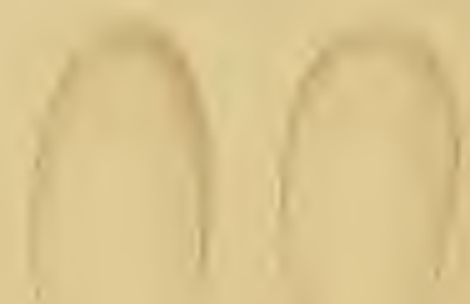

fi!) :y

Fin. 24

Fig 30

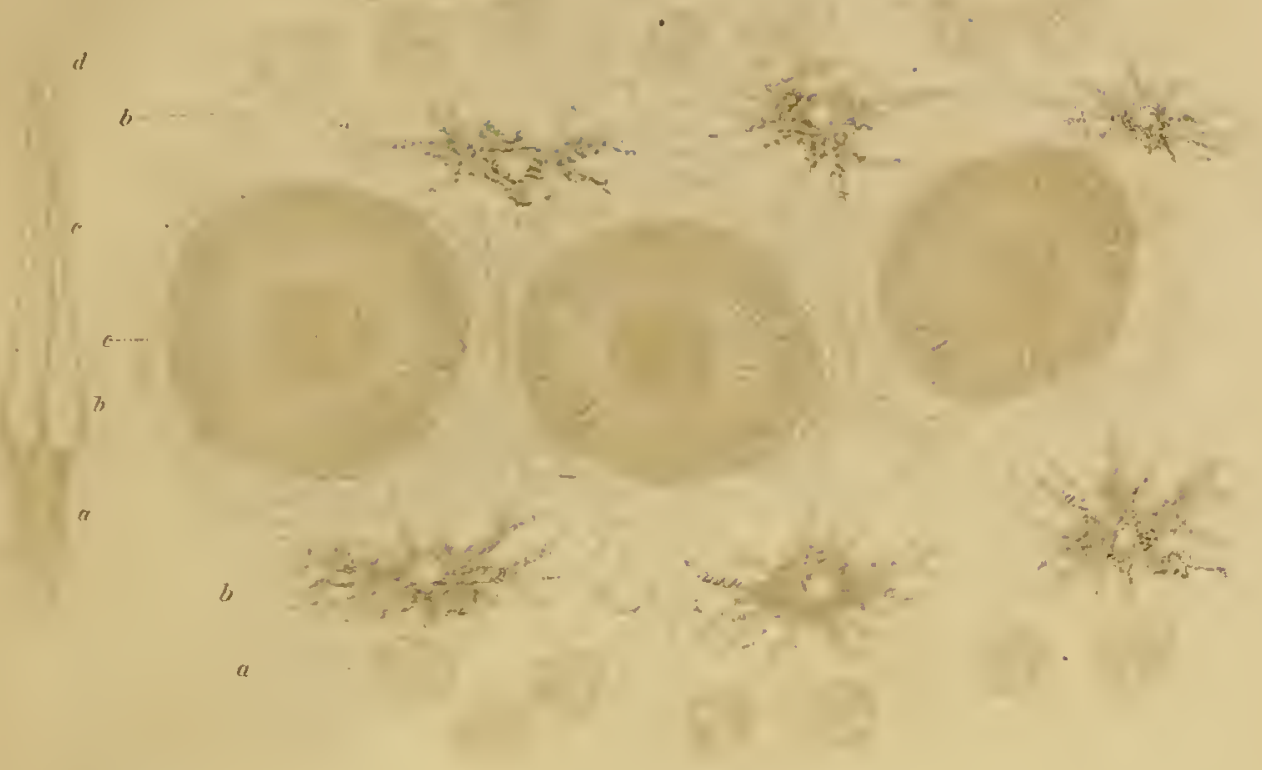

Fi. 26.

Fig. 25
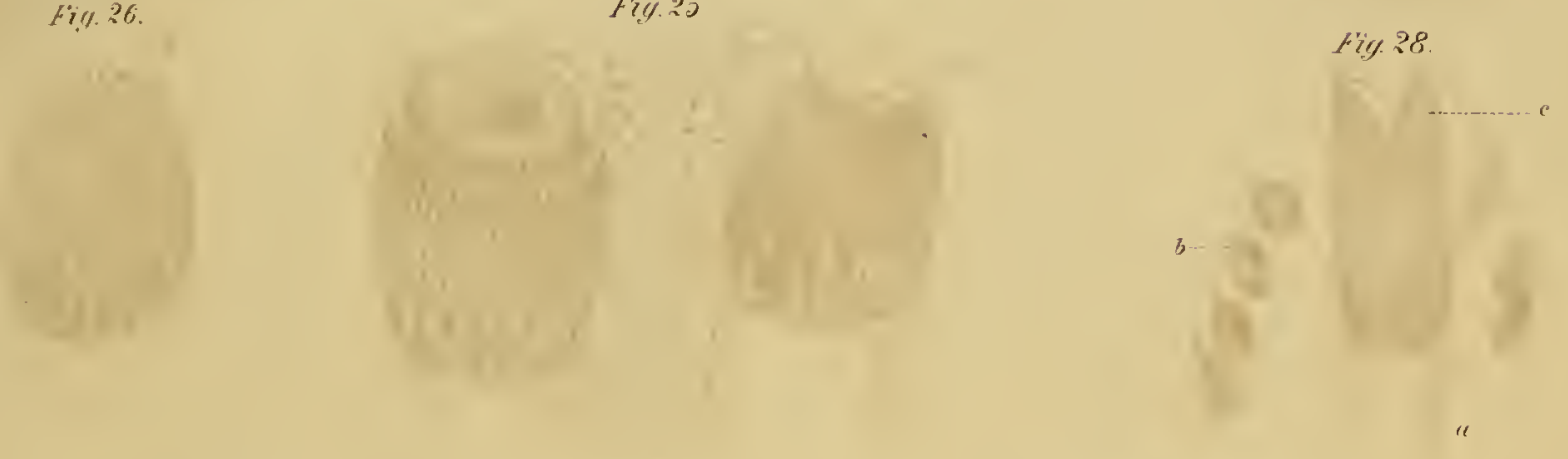

Fiy 31

Fin 39
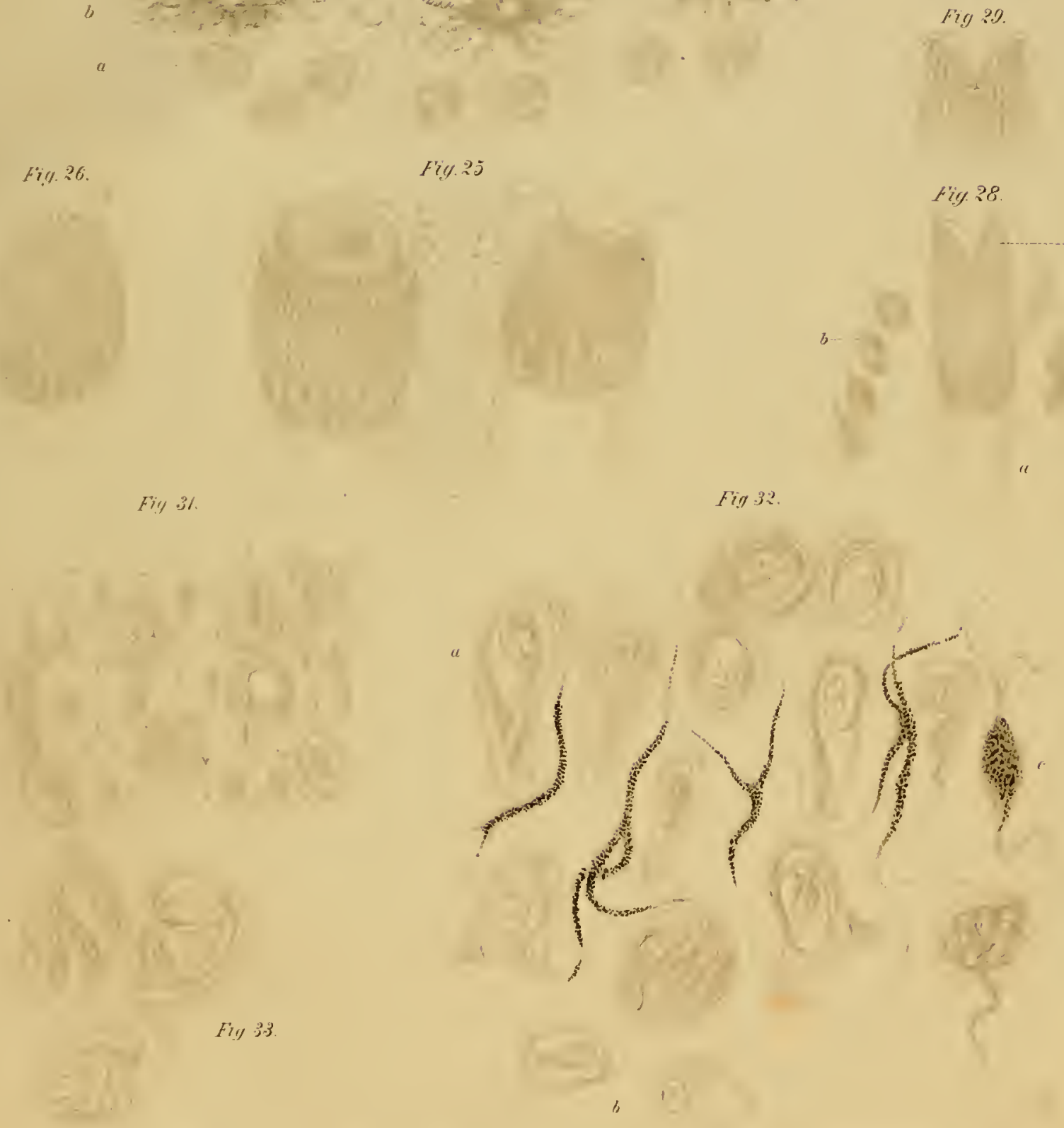


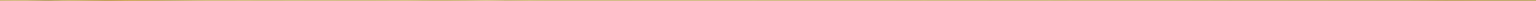









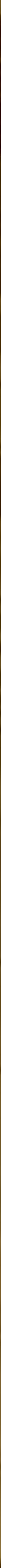

